\title{
Nanodimensional and Nanocrystalline Calcium Orthophosphates
}

\author{
Sergey V. Dorozhkin
}

Kudrinskaja sq. 1-155, Moscow 123242, Russia

\begin{abstract}
Nano-sized particles and crystals play an important role in the formation of calcified tissues of various animals. For example, nano-sized and nanocrystalline calcium orthophosphates in the form of apatites of biological origin represent the basic inorganic building blocks of bones and teeth of mammals. Namely, according the recent developments in biomineralization, tens to hundreds nanodimensional crystals of a biological apatite are self-assembled into these complex structures. This process occurs under a strict control by bioorganic matrixes. Furthermore, both a greater viability and a better proliferation of various types of cells have been detected on smaller crystals of calcium orthophosphates. Thus, the nano-sized and nanocrystalline forms of calcium orthophosphates have a great potential to revolutionize the hard tissue-engineering field, starting from bone repair and augmentation to controlled drug delivery systems. This review reports on current state of the art and recent developments on the subject, starting from synthesis and characterization to biomedical and clinical applications. Furthermore, the review also discusses possible directions for future research and development.
\end{abstract}

Keywords Calcium Orthophosphates, Hydroxyapatite, Nanodimensional, Nano-Sized, Nanocrystalline, Biomedical Applications, Bone Grafts, Tissue Engineering

\section{Introduction}

Living organisms can create the amazing ways to produce various high-performance materials and over 60 different inorganic minerals of biological origin have already been revealed[1]. Among them, calcium orthophosphates are of a special importance since they are the most important inorganic constituents of hard tissues in vertebrates[2, $3]$. In the form of a poor crystalline, non-stoichiometric, ion-substituted CDHA (commonly referred to as "biological apatite"), calcium orthophosphates are present in bones, teeth, deer antlers and tendons of mammals to give these organs stability, hardness and function[2, 4, 5]. Through we still do not exactly know why the highly intelligent animals use conformable calcium orthophosphates as their crucial biomineral for survival[6], current biomedical questions of persistent pathological and physiological mineralization in the body force people to focus on the processes, including the occurrence, formation and degradation of calcium orthophosphates in living organisms[7, 8, 9].

Biological mineralization (or biomineralization) is a process of in vivo formation of inorganic minerals[1, 2]. In the biomineralization processes, organized assemblies oforganic macromolecules regulate nucleation, growth,

* Corresponding author:

sedorozhkin@yandex.ru (Sergey V. Dorozhkin)

Published online at http://journal.sapub.org/ajbe

Copyright (C) 2012 Scientific \& Academic Publishing. All Rights Reserved morphology and assembly of inorganic crystals. Biologically formed calcium orthophosphates (biological apatite) are always nanodimensional and nanocrystalline, which have been formed in vivo under mild conditions. According to many reports, dimensions of biological apatite in the calcified tissues always possess a range of a few to hundreds of nanometers with the smallest building blocks on the nanometer size scale[2, 4, 5, 10, 11]. For example, tens to hundreds of nanometer-sized apatite crystals in a collagen matrix are combined into self-assembled structures during bone and teeth formation[2, 4, 5]. Recent advances suggest that this is a natural selection, since the nanostructured materials provide a better capability for the specific interactions with proteins[12].

Due to the aforementioned, nanodimensional and nanocrystalline forms of calcium orthophosphates are able to mimic both the composition and dimensions of constituent components of the calcified tissues. Thus, they can be utilized in biomineralization and as biomaterials due to the excellent biocompatibility[13, 14]. Further development of calcium orthophosphate-based biomaterials obviously will stand to benefit mostly from nanotechnology[15], which offers unique approaches to overcome shortcomings of many conventional materials. For example, nano-sized ceramics can exhibit significant ductility before failure contributed by the grain-boundary phase. Namely, already in 1987, Karch et al., reported that, with nanodimensional grains, a brittle ceramic could permit a large plastic strain 
up to $100 \%[16]$. In addition, nanostructured ceramics can be sintered at lower temperatures; thereby major problems associated with a high temperature sintering are also decreased. Thus, nanodimensional and nanocrystalline forms of bioceramics clearly represent a promising class of orthopedic and dental implant formulations with improved biological and biomechanical properties[17].

Many other advances have been made in biomaterial field due to a rapid growth of nanotechnology[18]. For example, a recent theory of "aggregation-based crystal growth"[19] and a new concept of "mesocrystals" [20, 21] highlighted the roles of nano-sized particles in biological crystal engineering. In this aspect, the study of calcium orthophosphates is a specific area in nanotechnology, because they might be applied readily to repair hard skeletal tissues of mammals[22-24].

Herein, an overview of nanodimensional and nanocrystalline apatites and other calcium orthophosphates in studies on biomineralization and biomaterials is given. The available calcium orthophosphates are listed in Table 1. To narrow the subject of this review, with a few important exceptions, undoped and un-substituted calcium orthophosphates are considered and discussed only. The readers interested in various nanodimensional and nanocrystalline ion-substituted calcium orthophosphates[25-63] are referred to the original publications. Furthermore, details on calcium orthophosphate-based nanodimensional biocomposites[64-85] or nanodimensional calcium orthophosphate-based biocomposites[86-104] are available in Refs.[105, 106].

This review is organized into several sections. After a brief introduction (current section), general information on "nano" is provided in the second section. The third section briefly compares the micron-sized and nanodimensional calcium orthophosphates. The forth section briefly discusses the presence of nano-sized and nanocrystalline calcium orthophosphates in normal calcified tissues of mammals. The structure of nano-sized and nanocrystalline apatites is described in the fifth section. Synthesis of nanodimensional and nanocrystalline calcium orthophosphates of various dimensions and shapes is reviewed in the sixth section, while the biomedical applications are examined in the seventh section. Finally, the summary and reasonable future perspectives in this active research area are given in the last section.

Table 1. Existing calcium orthophosphates and their major properties[204, 205].

\begin{tabular}{|c|c|c|c|c|c|}
\hline $\begin{array}{l}\mathrm{Ca} / \mathrm{P} \text { molar } \\
\text { ratio }\end{array}$ & Compound & Formula & $\begin{array}{c}\text { Solubility at } \\
25^{\circ} \mathrm{C},-\log \left(\mathrm{K}_{\mathrm{s}}\right)\end{array}$ & $\begin{array}{l}\text { Solubility at } \\
25^{\circ} \mathrm{C}, \mathrm{g} / \mathrm{L}\end{array}$ & $\begin{array}{l}\text { pH stability range in aque- } \\
\text { ous solutions at } 25^{\circ} \mathrm{C}\end{array}$ \\
\hline 0.5 & $\begin{array}{l}\text { Monocalcium phosphate } \\
\text { monohydrate (MCPM) }\end{array}$ & $\mathrm{Ca}\left(\mathrm{H}_{2} \mathrm{PO}_{4}\right)_{2} \cdot \mathrm{H}_{2} \mathrm{O}$ & 1.14 & $\sim 18$ & $0.0-2.0$ \\
\hline 0.5 & $\begin{array}{l}\text { Monocalcium phosphate an- } \\
\text { hydrous (MCPA or MCP) }\end{array}$ & $\mathrm{Ca}\left(\mathrm{H}_{2} \mathrm{PO}_{4}\right)_{2}$ & 1.14 & $\sim 17$ & [c] \\
\hline 1.0 & $\begin{array}{l}\text { Dicalcium phosphate dihydrate } \\
\text { (DCPD), mineral brushite }\end{array}$ & $\mathrm{CaHPO}_{4} \cdot 2 \mathrm{H}_{2} \mathrm{O}$ & 6.59 & $\sim 0.088$ & $2.0-6.0$ \\
\hline 1.0 & $\begin{array}{l}\text { Dicalcium phosphate anhy- } \\
\text { drous (DCPA or DCP), min- } \\
\text { eral monetite } \\
\end{array}$ & $\mathrm{CaHPO}_{4}$ & 6.90 & $\sim 0.048$ & {$[c]$} \\
\hline 1.33 & Octacalcium phosphate (OCP) & $\mathrm{Ca}_{8}\left(\mathrm{HPO}_{4}\right)_{2}\left(\mathrm{PO}_{4}\right)_{4} \cdot 5 \mathrm{H}_{2} \mathrm{O}$ & 96.6 & $\sim 0.0081$ & $5.5-7.0$ \\
\hline 1.5 & $\begin{array}{c}\alpha \text {-Tricalcium phosphate } \\
(\alpha-\text { TCP })\end{array}$ & $\alpha-\mathrm{Ca}_{3}\left(\mathrm{PO}_{4}\right)_{2}$ & 25.5 & $\sim 0.0025$ & [a] \\
\hline 1.5 & $\begin{array}{c}\beta \text {-Tricalcium phosphate } \\
(\beta-\mathrm{TCP})\end{array}$ & $\beta-\mathrm{Ca}_{3}\left(\mathrm{PO}_{4}\right)_{2}$ & 28.9 & $\sim 0.0005$ & [a] \\
\hline $1.2-2.2$ & $\begin{array}{c}\text { Amorphous calcium phos- } \\
\text { phates (ACP) }\end{array}$ & $\begin{array}{c}\mathrm{Ca}_{x} \mathrm{H}_{y}\left(\mathrm{PO}_{4}\right)_{z} \cdot n \mathrm{H}_{2} \mathrm{O}, n=3- \\
4.5 ; 15-20 \% \mathrm{H}_{2} \mathrm{O}\end{array}$ & [b] & [b] & $\sim 5-12^{[\mathrm{d}]}$ \\
\hline $1.5-1.67$ & $\begin{array}{l}\text { Calcium-deficient hydroxya- } \\
\text { patite (CDHA or Ca-def HA) }\end{array}$ & $\begin{array}{c}\mathrm{Ca}_{10-x}\left(\mathrm{HPO}_{4}\right)_{x}\left(\mathrm{PO}_{4}\right)_{6-x}(\mathrm{OH})_{2-x} \\
(0<x<1)\end{array}$ & $\sim 85$ & $\sim 0.0094$ & $6.5-9.5$ \\
\hline 1.67 & $\begin{array}{c}\text { Hydroxyapatite (HA, HAp or } \\
\text { OHAp) }\end{array}$ & $\mathrm{Ca}_{10}\left(\mathrm{PO}_{4}\right)_{6}(\mathrm{OH})_{2}$ & 116.8 & $\sim 0.0003$ & $9.5-12$ \\
\hline 1.67 & Fluorapatite (FA or FAp) & $\mathrm{Ca}_{10}\left(\mathrm{PO}_{4}\right)_{6} \mathrm{~F}_{2}$ & 120.0 & $\sim 0.0002$ & $7-12$ \\
\hline 1.67 & $\begin{array}{c}\text { Oxyapatite (OA, OAp or } \\
\text { OXA })^{[\mathrm{ff}}\end{array}$ & $\mathrm{Ca}_{10}\left(\mathrm{PO}_{4}\right)_{6} \mathrm{O}$ & $\sim 69$ & $\sim 0.087$ & [a] \\
\hline 2.0 & $\begin{array}{c}\text { Tetracalcium phosphate } \\
\text { (TTCP or TetCP), mineral } \\
\text { hilgenstockite }\end{array}$ & $\mathrm{Ca}_{4}\left(\mathrm{PO}_{4}\right)_{2} \mathrm{O}$ & $38-44$ & $\sim 0.0007$ & [a] \\
\hline
\end{tabular}

[a] These compounds cannot be precipitated from aqueous solutions.

[b] Cannot be measured precisely. However, the following values were found: $25.7 \pm 0.1(\mathrm{pH}=7.40), 29.9 \pm 0.1(\mathrm{pH}=6.00), 32.7 \pm 0.1(\mathrm{pH}=5.28)[269]$.

The comparative extent of dissolution in acidic buffer is: ACP $>>\alpha$-TCP $>>\beta$-TCP $>$ CDHA $>$ HA $>$ FA[126].

[c] Stable at temperatures above $100^{\circ} \mathrm{C}$

[d] Always metastable.

[e] Occasionally, it is called "precipitated HA (PHA)".

[f] Existence of OA remains questionable. 


\section{General Information on "Nano"}

The prefix "nano" specifically means a measure of $10^{-9}$ units. Although it is widely accepted that the prefix "nano" specifically refers to $10^{-9}$ units, in the context of nano-sized and nanocrystalline materials, the units should only be those of dimensions, rather than of any other unit of the scientific measurements. Besides, for practical purposes, it appears to be unrealistic to consider the prefix "nano" to solely and precisely refer to $10^{-9} \mathrm{~m}$, just as it is not considered that "micro" specifically and solely concerns something with a dimension of precisely $10^{-6} \mathrm{~m}[107]$. Currently, there is a general agreement that the subject of nanoscience and nanotechnology started after the famous talk: "There's plenty of room at the bottom" given by the Nobel Prize winner in physics Prof. Richard P. Feynman on December 26, 1959 at the annual meeting of the American Physical Society held at California Institute of Technology. This well-known talk has been widely published in various media (e.g., [108]).

In a recent extensive discussion about a framework for definitions presented to the European Commission, the nano-scale has been defined as being of the order of $100 \mathrm{~nm}$ or less. Similarly, a nanomaterial has been defined as "any form of a material that is composed of discrete functional parts, many of which have one or more dimensions of the order of $100 \mathrm{~nm}$ or less"[109]. Other definitions logically follow this approach such as: a nanocrystalline material is "a material that is comprised of many crystals, the majority of which have one or more dimensions of the order of 100 $\mathrm{nm}$ or less" (normally, with presence of neither the micron-sized crystals nor an intergranular amorphous phase) and a nanocomposite is a "multi-phase material in which the majority of the dispersed phase components have one or more dimensions of the order of $100 \mathrm{~nm}$ or less"[107]. Similarly, nanostructured materials are defined as the materials containing structural elements (e.g., clusters, crystallites or molecules) with dimensions in the 1 to $100 \mathrm{~nm}$ range[110], nanocoatings represent individual layers or multilayer surface coatings of $1-100 \mathrm{~nm}$ thick, nanopowders are extremely fine powders with an average particle size in the range of $1-100 \mathrm{~nm}$ and nanofibers are the fibers with a diameter within $1-100 \mathrm{~nm}[111,112]$. It also has been proposed to extend the lower size limit to $0.1 \mathrm{~nm}[113]$, which would include all existing organic molecules, allowing chemists to rightly claim they have been working on nanotechnology for very many years[114].

Strictly speaking, there are serious doubts that the term "nanomaterial" has a reasonable meaning. For example, let me cite Prof. David F. Williams, the Editor-in-Chief of Biomaterials: “... some words which have no rational basis whatsoever become part of everyday language so rapidly, even if so illogically, that it is impossible to reverse the process and their common use has to be accepted, or perhaps, accommodated. Nanomaterial is one such word, where I have argued that it should not exist, but accept that it does through common usage and have to recognise its existence[107]. The discussion about nanomaterial provides a hint of the analysis of a biomaterial that follows, since a prefix, which is an indicator of scale, cannot specify the integer that follows (in this case a material) unless that integer can be qualified by that scale. In other words, it is very clear what a nanometre is because nano - means $10^{-9}$ and a metre is a measure of length. In the case of nanomaterial, what is it about the material that is $10^{-9}$. Is it the dimension of a crystal within the material, or of a grain boundary, a domain, or a molecule, or is it a parameter of a surface feature of the sample, or perhaps of the resistivity or thermal conductivity of the material. Clearly this is nonsense, but one has to accept that nanomaterials are here to stay, with even some journal titles containing the word." $[115, \mathrm{p}$. 5898, left column]. Following this logic, such terms as "nanocomposite", "nanocoatings", "nanopowders", "nanofibers" and "nanocrystals" are senseless either and should be replaced, for example, by "composites with nano-sized (or nanodimensional) dispersed phase(s)", "coatings of nano-sized (or nanodimensional) thickness", "nano-sized (or nanodimensional) powders", "fibers of nano-sized (or nanodimensional) thickness" and "nano-sized (or nanodimensional) crystals", respectively. At least, this has been done in this review.

According to their geometry, all nanodimensional materials can be divided into three major categories: equiaxed, one dimensional (or fibrous) and two dimensional (or lamellar) forms. Selected examples and typical applications of each category of nanodimensional materials and their use in biomedical applications are available in literature[116]. It is important to note, that in literature on calcium orthophosphates there are cases, when the prefix "nano" has been applied for the structures, with the minimum dimensions exceeding $100 \mathrm{~nm}[44,83,117-133]$.

As a rule, nanodimensional materials can be manufactured from nearly any substance. Of crucial importance, there are two major characteristics conferring the special properties of any nanodimensional material. These are the quantum effects associated with the very small dimensions (currently, this is not applicable to the biomaterials field) and a large surface-to-volume ratio that is encountered at these dimensions. For instance, specific surface areas for submicron-sized particles are typically $60-80 \mathrm{~m}^{2} / \mathrm{g}$, while decreasing particle diameter to tens of nanometers increases the specific surface area up to 5 times more - an amazing amount of surface area per mass! Furthermore, all nanophase materials have the unique surface properties, such as an increased number of grain boundaries and defects on the surface, huge surface area and altered electronic structure, if compared to the micron-sized materials[107, 134]. While less than $\sim 1 \%$ of a micron-sized particle's atoms occupy the surface positions, over a tenth of the atoms in a $10-\mathrm{nm}$ diameter particle reside on its surface and $\sim 60 \%$ in a $2-\mathrm{nm}$ particle[135]. This very high surface-to-volume ratio of nanodimensional materials provides a tremendous driving 
force for diffusion, especially at elevated temperatures, as well as causes a self-aggregation into larger particles. Besides, solubility of many substances increases with particle size decreasing[136, 137]. What's more, nanophase materials could have surface features (e.g., a higher amount of nano-scale pores) to influence the type and amount of adsorption of selective proteins that could enhance specific osteoblast adhesion[138]. Finally and yet importantly, the nanodimensional and nanocrystalline materials have different mechanical, electrical, magnetic and optical properties if compared to the larger grained materials of the same chemical composition[139-142].

The nanostructured materials can take the form of powders, dispersions, coatings or bulk materials. In general, nanostructured materials contain a large volume fraction (greater than $50 \%$ ) of defects such as grain boundaries, interphase boundaries and dislocations, which strongly influences their chemical and physical properties. The great advantages of nanostructuring were first understood in electronic industry with the advent of thin film deposition processes. Other application areas have followed. For example, nanostructured bioceramics was found to improve friction and wear problems associated with joint replacement components because it was tougher and stronger than coarser-grained bioceramics[143]. Furthermore, nanostructuring has allowed chemical homogeneity and structural uniformity to an extent, which was once thought to impossible to achieve[110]. In calcium orthophosphate bioceramics, the major target of nanostructuring is to mimic the architecture of bones and teeth[144, 145].

\section{Micron- and Submicron-Sized Calcium Orthophosphates versus The Nanodimensional Ones}

The micron-sized calcium orthophosphate-based bioceramic powders suffer from poor sinterability, mainly due to a low surface area (typically $2-5 \mathrm{~m} 2 / \mathrm{g}$ ), while the specific surface area of nanodimensional calcium orthophosphates exceeds $100 \mathrm{~m} 2 / \mathrm{g}[146]$. In addition, the resorption process of synthetic micron-sized calcium orthophosphates was found to be quite different from that of bone mineral[147].

Although the nanodimensional and nanocrystalline features of natural calcium orthophosphates of bones and teeth had been known earlier[2, 148-153], the history of the systematic investigations of this field has started only in 1994. Namely, a careful search in scientific databases using various combinations of keywords "nano" + "calcium phosphate", "nano" + "apatite", "nano" + "hydroxyapatite", etc. in the article title revealed 5 papers published in 1994[154-158]. No papers published before 1994 with the aforementioned keywords in the title have been found.

Nanodimensional (size $\sim 67 \mathrm{~nm}$ ) HA was found to have a higher surface roughness of $17 \mathrm{~nm}$ if compared to $10 \mathrm{~nm}$ for the submicron-sized $(\sim 180 \mathrm{~nm}) \mathrm{HA}$, while the contact angles (a quantitative measure of the wetting of a solid by a liquid) were significantly lower for nano-sized HA (6.1) if compared to the submicron-sized HA (11.51). Additionally, the diameter of individual pores in nanodimensional HA compacts is several times smaller (pore diameter $\sim 6.6 \AA$ ) than that in the submicron grain-sized HA compacts (pore diameter within $19.8-31.0 \AA$ )[159]. A surface roughness is known to enhance the osteoblast functions while a porous structure improves the osteoinduction compared with smooth surfaces and nonporpous structure, respectively[138]. Furthermore, nanophase HA appeared to have $11 \%$ more proteins of fetal bovine serum adsorbed per 1 $\mathrm{cm} 2$ than submicron-sized HA[160]. Interfacial interactions between calcined HA nano-sized crystals and various substrates were studied and a bonding strength appeared to be influenced not only by the nature of functional groups on the substrate but also by matching of surface roughness between the nano-sized crystals and the substrate[161]. More to the point, incorporating of nanodimensional particles of HA into polyacrylonitrile fibers were found to result in their crystallinity degree rising by about $5 \%[162]$. In a comparative study on the influence of incorporated micron-sized and nano-sized HA particles into poly-L-lactide matrixes, addition of nano-sized HA was found to influence both thermal and dynamic mechanical properties in greater extents[163].

In general, nanostructured biomaterials[164] offer much improved performances than their larger particle sized counterparts due to their huge surface-to-volume ratio and unusual chemical synergistic effects. Such nanostructured systems constitute a bridge between single molecules and bulk material systems[165]. For instance, powders of nanocrystalline apatites[166-172] and $\beta$-TCP [173] were found to exhibit an improved sinterability and enhanced densification due to a greater surface area. This is explained by the fact that the distances of material transport during the sintering becomes shorter for ultrafine powders with a high specific surface area, resulting in a densification at a low temperature. Therefore, due to low grain growth rates, a low-temperature sintering appears to be effective to produce fine-grained apatite bioceramics[174]. Furthermore, the mechanical properties (namely, hardness and toughness) of HA bioceramics appeared to increase as the grain size decreased from sub-micrometers to nanometers[175].

More to the point, nano-sized HA is also expected to have a better bioactivity than coarser crystals[176-178]. Namely, Kim et al., found that osteoblasts (bone-forming cells) attached to the nano-sized HA/gelatin biocomposites to a significantly higher degree than to micrometer size analog did[179]. An increased osteoblast and decreased fibroblast (fibrous tissue-forming cells) adhesion on nanophase ceramics[180-184], as well as on nanocrystalline HA coatings on titanium, if compared to traditionally used plasma-sprayed HA coatings, was also discovered by other researchers[185-187]. Scientists also observed enhanced osteoclast (bone-resorbing cells) functions to show healthy remodeling of bone at the simulated implant surface[177]. Besides, the proliferation and osteogenic differentiation of periodontal ligament cells were found to be promoted when 
a nanophase HA was used, if compared to dense HA bioceramics[188]. Thus, the underlying material property, responsible for this enhanced osteoblast function, is the surface roughness of the nanostructured surface[18]. Interestingly, but an increased osteoblast adhesion was discovered on nano-sized calcium orthophosphate powders with higher $\mathrm{Ca} / \mathrm{P}$ ratios[189], which points out to some advantages of apatites over other calcium orthophosphates. Furthermore, a histological analysis revealed a superior biocompatibility and osteointegration of bone graft substitutes when nano-sized HA was employed in biocomposites[190-192]. However, data are available that nano-sized HA could inhibit growth of osteoblasts in a dose-dependent manner[193]. Furthermore, a cellular activity appeared to be affected by the shape and dimensions of nano-sized HA. Namely, the cellular activity of L929 mouse fibroblasts on nano-sized fibers with a diameter within $50-100 \mathrm{~nm}$ was significantly enhanced relative to that on a flat HA surface, while nanodimensional HA needles and sheets with a diameter/thickness of less than $30 \mathrm{~nm}$ inhibited cellular adhesion and/or subsequent activity because cells could not form focal adhesions of sufficient size[194].

Obviously, the volume fraction of grain boundaries in nanodimensional calcium orthophosphates is increased significantly leading to improved osteoblast adhesion, proliferation and mineralization. Therefore, a composition of these biomaterials at the nano-scale emulates the bone's hierarchic organization, to initiate the growth of an apatite layer and to allow for the cellular and tissue response of bone remodeling. These examples emphasize that nanophase materials deserve more attention in improving orthopedic implant failure rates. However, to reduce surface energy, all nano-sized materials tend to agglomerate and, to avoid self-aggregation of calcium orthophosphate nano-sized particles[195-198], special precautions might be necessary[54, 60, 120, 199-202].

Finally yet importantly, nano-sized crystals of CDHA obtained by precipitation methods in aqueous solutions were shown to exhibit physico-chemical characteristics rather similar to those of bone apatite[203]. In particular, their chemical composition departs from stoichiometry by calcium and hydroxide ions deficiency, leading to an increased solubility, and in turn bioresorption rate in vivo[148, 204-206]. The nano-sized crystals of CDHA have also a property to evolve in solution (maturation) like bone crystals. Namely, freshly precipitated CDHA has been shown to be analogous to embryonic bone mineral crystals whereas aged precipitates resemble bone crystals of old vertebrates[203].

\section{Nanodimensional and Nanocrystalline Calcium Orthophosphates in Calcified Tissues of Mammals}

\subsection{Bones}

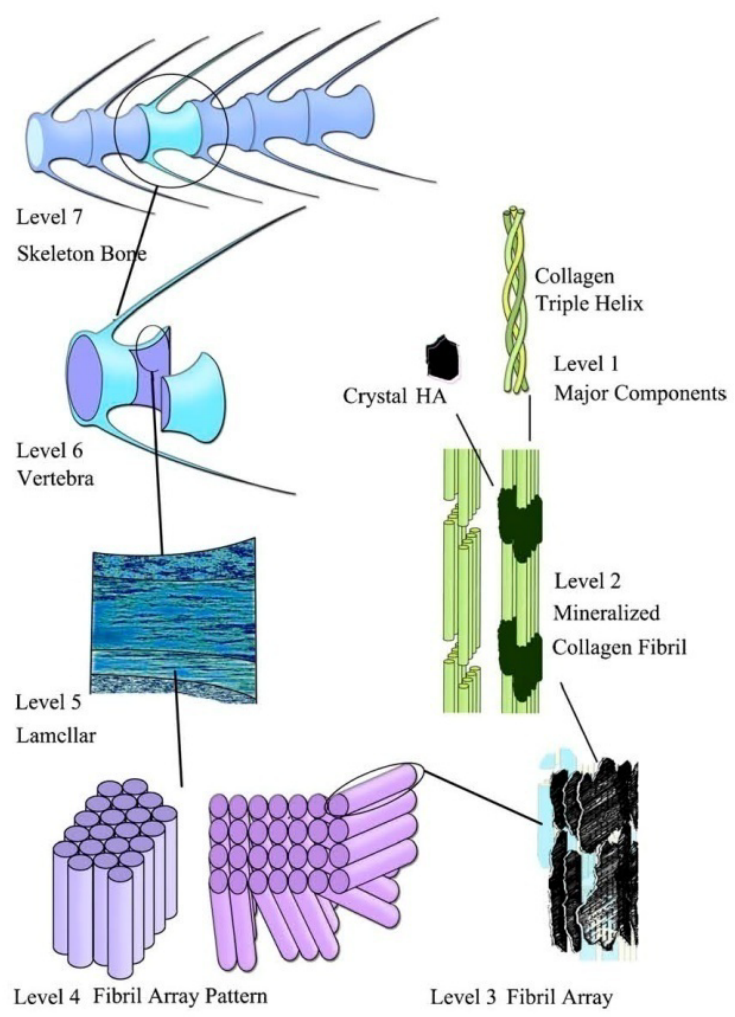

Figure 1. The seven hierarchical levels of organization of the zebrafish skeleton bone. Level 1: Isolated crystals and part of a collagen fibril with the triple helix structure. Level 2: Mineralized collagen fibrils. Level 3: The array of mineralized collagen fibrils with a cross-striation periodicity of nearly $60-70 \mathrm{~nm}$. Level 4: Two fibril array patterns of organization as found in the zebrafish skeleton bone. Level 5: The lamellar structure in one vertebra. Level 6: A vertebra. Level 7: Skeleton bone. Reprinted from Ref.[208] with permission

Bone is the most typical calcified tissue of mammals and it comes in all sorts of shapes and sizes in order to achieve various functions of protection and mechanical support for the body. The major inorganic component of bone mineral is a biological apatite, which might be defined as a poorly crystalline, non-stoichiometric and ion substituted CDHA[2-5, 204-207]. From the material point of view, bone can be considered as an assembly of distinct levels of seven hierarchical structural units from macro- to micro- and to nano-scale (Fig. 1) to meet numerous functions[2, 5, 134, 208-210]. Furthermore, all these levels of bones permanently interact with cells and biological macromolecules. At the nanostructural level, tiny plate-like crystals of biological apatite in bone occur within the discrete spaces within the collagen fibrils and grow with specific crystalline orientation along the $c$-axes, which are roughly parallel to the long axes of the collagen fibrils[211]. Type I collagen molecules are self-assembled into fibrils with a periodicity of $\sim 67 \mathrm{~nm}$ and $\sim 40 \mathrm{~nm}$ gaps between the ends of their molecules, into which the apatite nano-sized crystals are placed. A biocomposite of these two constituents forms mineralized fibers. The fibers also may be cross-linked, which provides a highly dynamic system capable of modification through the selec- 
tion of different amino acids to allow for different mechanical properties for different biomaterial applications[212]. This is why bone is usually termed a fiber-reinforced composite of a biological origin, in which nanometer-sized hard inclusions are embedded into a soft protein matrix[213]. Though dimensions of biological apatite crystals reported in the literature vary due to different treatment methods and analytical techniques, it is generally around the nanometric level with values in the ranges of $30-$ $50 \mathrm{~nm}$ (length), $15-30 \mathrm{~nm}$ (width) and $2-10 \mathrm{~nm}$ (thickness)[214]. Some details on the stability reasons of nanodimensional apatites in bones are available in literature[215, 216].

Why does the nanometer scale appear to be so important to bones? It was recently demonstrated that natural biocomposites exhibit a generic mechanical structure in which the nanometer sizes of mineral particles are used to ensure the optimum strength and maximum tolerance of flaws[217, 218]. Furthermore, nanodimensional apatite has another crucial function for organisms. It is a huge reservoir of calcium and orthophosphate ions necessary for a wide variety of metabolic functions, which offer or consume calcium and orthophosphate ions through a so-called "remodeling" process because of a continuous resorption and formation of nanodimensional apatite by osteoclasts and osteoblasts, respectively, in a delicate equilibrium[2, 5]. Additional details on the structure, properties and composition of bones might be found in special literature [5, 207, 219].

\subsection{Teeth}

Teeth are another normal calcium orthophosphate-based calcified tissue of vertebrates. Unlike bone, teeth consist of at least two different biominerals: enamel (a crown, the part above the gum line) and dentin (root, the part below the gum line)[220]. Dental enamel contains up to $98 \%$ of biological apatite, $\sim 1 \%$ of bioorganic compounds and up to $2 \%$ of water. Typical rods in enamel are composed of rod-like apatite crystals measuring $25-100 \mathrm{~nm}$ and an undetermined length of $100 \mathrm{~nm}$ to $100 \mu \mathrm{m}$ or longer along the $c$-axis[221-223]. However, the apatite crystals in enamel were found to exhibit regular sub-domains or subunits with distinct chemical properties[224]. This subunit structure reflects an assembly mechanism for such biological crystals[225, 226]. Like that for bones (Fig. 1), seven levels of structural hierarchy have been also discovered in human enamel; moreover, the analysis of the enamel and bone hierarchical structures suggests similarities of the scale distribution at each level[227]. In enamel, nano-sized crystals of biological apatite at first form mineral nanodimensional fibrils; the latter always align lengthways, aggregating into fibrils and afterwards into thicker fibers; further, prism/interprism continua are formed from the fibers. At the micro-scale, prisms are assembled into prism bands, which present different arrangements across the thickness of the enamel layer. These compositional and structural characteristics endow enamel special properties such as anisotropic elastic modulus, effective viscoelastic properties, much higher fracture toughness and stress-strain relationships more similar to metals than ceramics[228].

Dentin contains $\sim 50 \%$ of biological apatite, $\sim 30 \%$ of bioorganic compounds and $\sim 20 \%$ of water. In dentin, the nanodimensional building blocks $(\sim 25 \mathrm{~nm}$ width, $\sim 4 \mathrm{~nm}$ thickness and $\sim 35 \mathrm{~nm}$ length) of biological apatite are smaller than those of enamel. Dentin is analogous to bone in many aspects, for example, it has a similar composition and a hierarchical structure up to the level of the bone lamellae[204, 205]. Additional details on the structure, properties and composition of teeth might be found in special literature[229].

\section{The structure of the Nanodimensional and Nanocrystalline Apatites}

Due to the apatitic structure on natural calcified tissues, apatites appear to be the best investigated compounds among the available calcium orthophosphates (Table 1). Thus, nanodimensional and nanocrystalline apatites have been extensively studied by various physico-chemical techniques and chemical analysis methods[197, 230-242] with a special attention to the "nano" effect (i.e., an enhanced contribution of the surface against the volume). Unfortunately, no publications on the structure of other nanodimensional and/or nanocrystalline calcium orthophosphates were found in the available literature.

Due to a nanocrystalline nature, various diffraction techniques have not yet given much information on the fine structural details related to apatite nano-sized crystals (assemblies of nano-sized particles give only broad diffraction patterns, similar to ones from an amorphous material)[230, 231]. Nevertheless, the diffraction studies with electron microprobes of $35 \pm 10 \mathrm{~nm}$ in diameter clearly indicated a crystalline character of the nano-sized particles in these assemblies. Furthermore, high-resolution transmission electron microscopy results revealed that nano-sized particles of HA behaved a fine monocrystalline grain structure[197, 230].

Therefore, a recent progress on the structure of nanodimensional and nanocrystalline apatites has relied mainly on diverse spectroscopic methods, which are sensitive to disturbances of the closest environments of various ions. Namely, the structure analysis revealed an existence of structural disorder at the particle surface, which was explained by chemical interactions between the orthophosphate groups and either adsorbed water molecules or hydroxyl groups located at the surface of nano-sized apatites[232]. More to the point, infrared (FTIR) spectra of nanocrystalline apatites, in the $v_{4} \mathrm{PO}_{4}$ domain, revealed the existence of additional bands of orthophosphate ions which could not be assigned to an apatitic environment and which were not present in well-crystallized apatites (Fig. 2). These bands were assigned to non-apatitic environments of $\mathrm{PO}_{4}{ }^{3-}$ and $\mathrm{HPO}_{4}{ }^{2-}$ ions of the nano-sized crystals. Thus, FTIR 
spectra can be used to provide a sufficiently accurate evaluation of the amounts of such environments. Furthermore, the non-apatitic environments were found to correspond to hydrated domains of the nano-sized crystals, which were distinct from the apatite domains[234]. Hence, precipitated crystals of nano-sized apatite appeared to have a hydrated surface layer containing labile ionic species, which easily and rapidly could be exchanged by ions and/or macromolecules from the surrounding fluids[233, 232, 241]. For the as-precipitated apatites, such a layer appears to constitute mainly by water molecules coordinated to surface $\mathrm{Ca}^{2+}$ ions, approximately in the $1: 1$ ratio, while the $\mathrm{OH}$ groups account only for $\sim 20 \%$ of the surface hydration species. The FTIR data indicated that water molecules, located on the surface of nanodimensional apatites, are coordinated to surface cations and experience hydrogen bonding significantly stronger than that in liquid water[240]. The surface hydrated layer is very delicate and becomes progressively transformed into a more stable apatitic lattice upon ageing in aqueous media. Furthermore, it irreversibly altered upon drying[234]. Outgassing at increasing temperatures up to $\sim 300{ }^{\circ} \mathrm{C}$ resulted in a complete surface dehydration, accompanied by a decrease of the capability to re-adsorb water. Combination of these data with rehydration tests suggested that a significant part of the surface $\mathrm{Ca}^{2+}$ ions, once dehydrated, could undergo a relaxation inward the surface, more irreversibly as the outgassing temperature increased[239].

In another study, elongated nano-sized crystals of CDHA of $\sim 10 \mathrm{~nm}$ thick and of $\sim 30-50 \mathrm{~nm}$ length were synthesized followed by investigations with X-ray diffraction and nuclear magnetic resonance techniques. The nano-sized crystals of CDHA were shown to consist of a crystalline core with the composition close to the stoichiometric HA and a disordered (amorphous) surface layer of $1-2 \mathrm{~nm}$ thick[238, 239] with the composition close to DCPD[237]. Based on the total $\mathrm{Ca} / \mathrm{P}$ ratio, on the one hand, and the crystal shape, on another hand, a thickness of the DCPD surface layer along the main crystal axis was estimated to be $\sim 1 \mathrm{~nm}$ [237], which is close to dimensions of the unit-cells (Table 2). A similar structure of a crystalline core with the composition of the stoichiometric HA and a disordered (amorphous) surface layer was found by other researchers[243]; however, in yet another study devoted to nanodimensional carbonateapatites[244], the model of a crystalline core and an outer amorphous layer was not confirmed. Perhaps, this discrepancy could be explained by the presence of carbonates. A lack of hydroxide in nanodimensional apatites was detected; an extreme nanocrystallinity was found to place an upper bound on $\mathrm{OH}^{-}$possible in apatites[245].

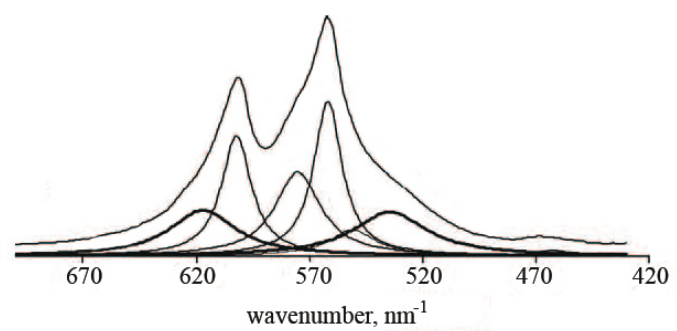

Figure 2. FTIR spectra of poorly crystalline apatites showing the non-apatitic environments of the orthophosphate ions (bold lines with peaks at 617 and $534 \mathrm{~cm}^{-1}$ ) and the apatitic $\mathrm{PO}_{4}{ }^{3-}$ (thin lines with peaks at 600,575 and $560 \mathrm{~cm}^{-1}$ ) and $\mathrm{HPO}_{4}{ }^{2-}$ (thin line with peak at $550 \mathrm{~cm}^{-1}$ ) in the $v_{4} \mathrm{PO}_{4}$ domain. Reprinted from Ref.[234] with permission

Table 2. Crystallographic data of calcium orthophosphates[206].

\begin{tabular}{|c|c|c|c|c|}
\hline Compound & Space group & Unit cell parameters & $Z^{[a]}$ & $\begin{array}{l}\text { Density, } \\
\mathrm{g} / \mathrm{cm}^{3}\end{array}$ \\
\hline MCPM & triclinic $P \overline{1}$ & $\begin{array}{l}a=5.6261(5), b=11.889(2), c=6.4731(8) \AA \\
\alpha=98.633(6)^{\circ}, \beta=118.262(6)^{\circ}, \gamma=83.344(6)^{\circ}\end{array}$ & 2 & 2.23 \\
\hline MCPA & triclinic $P \overline{1}$ & $\begin{array}{c}a=7.5577(5), b=8.2531(6), c=5.5504(3) \AA \\
\alpha=109.87(1)^{\circ}, \beta=93.68(1)^{\circ}, \gamma=109.15(1)^{\circ}\end{array}$ & 2 & 2.58 \\
\hline DCPD & monoclinic Ia & $a=5.812(2), b=15.180(3), c=6.239(2) \AA, \beta=116.42(3)^{\circ}$ & 4 & 2.32 \\
\hline DCPA & triclinic $P \overline{1}$ & $\begin{aligned} a & =6.910(1), b=6.627(2), c=6.998(2) \AA \\
\alpha & =96.34(2)^{\circ}, \beta=103.82(2)^{\circ}, \gamma=88.33(2)^{\circ}\end{aligned}$ & 4 & 2.89 \\
\hline $\mathrm{OCP}$ & triclinic $P \overline{1}$ & $\begin{aligned} a=19.692(4), b= & 9.523(2), c=6.835(2) \AA, \alpha=90.15(2)^{\circ}, \beta= \\
& 92.54(2)^{\circ}, \gamma=108.65(1)^{\mathrm{o}}\end{aligned}$ & 1 & 2.61 \\
\hline$\alpha-\mathrm{TCP}$ & monoclinic $P 2_{1} / \mathrm{a}$ & $a=12.887(2), b=27.280(4), c=15.219(2) \AA, \beta=126.20(1)^{\circ}$ & 24 & 2.86 \\
\hline$\beta$-ТCP & $\begin{array}{c}\text { rhombohedral } \\
R 3 \mathrm{cH} \\
\end{array}$ & $a=b=10.4183(5), c=37.3464(23) \AA, \gamma=120^{\circ}$ & $21^{[b]}$ & 3.08 \\
\hline HA & $\begin{array}{c}\text { monoclinic } P 2_{1} / \mathrm{b} \\
\text { or hexagonal } P 6_{3} / \mathrm{m}\end{array}$ & $\begin{array}{c}a=9.84214(8), b=2 a, c=6.8814(7) \AA, \gamma=120^{\circ} \text { (monoclinic) } \\
a=b=9.4302(5), c=6.8911(2) \AA, \gamma=120^{\circ} \text { (hexagonal) }\end{array}$ & $\begin{array}{l}4 \\
2 \\
\end{array}$ & 3.16 \\
\hline FA & hexagonal $P 6_{3} / \mathrm{m}$ & $a=b=9.367, c=6.884 \AA, \gamma=120^{\circ}$ & 2 & 3.20 \\
\hline $\mathrm{OA}$ & hexagonal $P \overline{6}$ & $a=b=9.432, c=6.881 \AA, \alpha=90.3^{\circ}, \beta=90.0^{\circ}, \gamma=119.9^{\circ}$ & 1 & $\sim 3.2$ \\
\hline TTCP & monoclinic $P 2_{1}$ & $a=7.023(1), b=11.986(4), c=9.473(2) \AA, \beta=90.90(1)^{\circ}$ & 4 & 3.05 \\
\hline
\end{tabular}

${ }^{[a]}$ Number of formula units per unit cell.

${ }^{[b]}$ Per the hexagonal unit cell. 
However, it is possible to address the structure of surface terminations of HA nano-sized particles to be amorphous or crystalline by properly selecting the preparation parameters and, in particular, the temperature; thus, nanodimensional HA without the amorphous layer on the surface has been prepared[246]. The two types of surfaces (amorphous or crystalline) of nanodimensional HA appeared to be quite similar in terms of their first hydration layer, as well as Lewis acid strength of exposed $\mathrm{Ca}^{2+}$ ions. Both features have a strong dependence on the local structure of surface sites (well probed by small molecules, such as $\mathrm{H}_{2} \mathrm{O}$ and $\mathrm{CO}$ ) that appeared essentially unaffected by the organization at a longer range. Interestingly, but once treated at $573 \mathrm{~K}$, the crystalline surfaces of nanodimensional HA was found to adsorb multilayers of water in a larger extent than the amorphous ones[246].

Nevertheless, after summarizing the available data, the following statements on the structure of nano-sized crystals of apatites have been made:

(1) they involve non-apatitic anionic and cationic chemical environments (in another study, the researchers mentioned on "ordered and disordered HA"[238]),

(2) at least part of these environments are located on the surface of the nano-sized crystals and are in strong interaction with hydrated domains,

(3) immature samples show FTIR band fine substructure that is altered upon drying without leading to long-range order (LRO) modifications,

(4) this fine substructure shows striking similarities with the FTIR spectrum of OCP[235].

All these elements favor a model in which nano-sized crystals of apatites are covered with a rather fragile but structured surface hydrated layer containing relatively mobile ions (mainly, bivalent anions and cations: $\mathrm{Ca}^{2+}, \mathrm{HPO}_{4}{ }^{2-}$, $\mathrm{CO}_{3}{ }^{2-}$ ) in "non-apatitic" sites (Fig. 3), which is supposed to be of either OCP or DCPD structure. Unfortunately, both the exact structure and the chemical composition of this hydrated layer are still uncertain (regrettably, as the hydrated layer cannot be isolated, it is not possible to standardize the methods for detailed studies)[235, 237-239]. Nevertheless, it is known that the surface layer might adsorb considerable amounts of foreign compounds (molecules and ions) in the percent mass range[247]. Strictly speaking, all the aforementioned apply to both biological apatite of calcified tissues[248] and micron-sized apatites as well[249]; nonetheless, in nano-sized crystals, the composition of the hydrated surface layer contributes to the global composition for a non-negligible proportion. The results of electron states spectroscopy of nanostructural HA bioceramics are available elsewhere[250, 251].

The hydrated surface layer confers unexpected properties to nano-sized apatite, is responsible for most of the properties of apatites, and, for example, can help to explain the regulation by biological apatites of the concentration in mineral ions in body fluids (homeostasis). These properties are important for living organisms; therefore, they need to be used in both material science and biotechnology[234].
The consideration of this type of surface state can help understanding and explaining the behavior of biological apatites in participating in homeostasis due to a very high specific surface area of bone crystals and in constituting an important ion reservoir with an availability that depends on the maturation state. The important consequences are that the surface of nanodimensional apatites has nothing in common with the bulk composition and that the chemistry of such materials (e.g., binding of protein molecules) must be reconsidered[235, 237]. Interestingly, but, in response to an electrical potential, the surface of nano-sized HA bioceramics was found to exhibit dynamic changes in interfacial properties, such as wettability. The wettability modification enabled both a sharp switching from hydrophilic to hydrophobic states and a microscopic wettability patterning of the HA surface, which may be used for fabrication of spatially arrayed HA for biological cells immobilization or gene transfer[252].
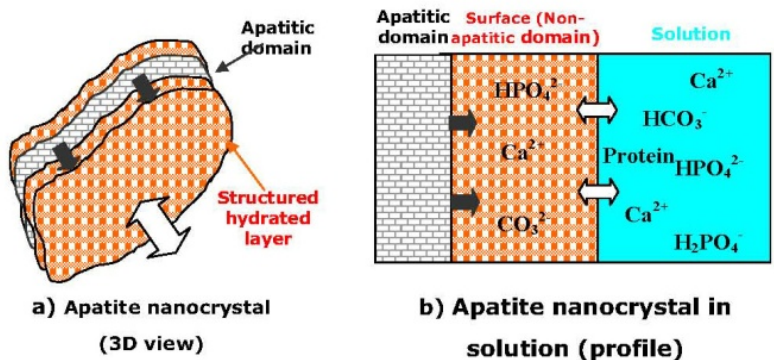

b) Apatite nanocrystal in solution (profile)

Figure 3. A schematic representation of the "surface hydrated layer model" for poorly crystalline apatite nanocrystals. Reprinted from Ref.[235] with permission

Furthermore, dry powders of nanodimensional HA were found to contain an X-ray amorphous portion with an unspecified location[253]. After mixing of an initial nano-sized HA powder with a physiological solution (aqueous isotonic $0.9 \% \mathrm{NaCl}$ solution for injections), this amorphous portion was fully converted into the crystalline phase of HA. The initial crystallite average size $(\sim 35 \mathrm{~nm})$ was enlarged by a factor of about 4 within the first $100 \mathrm{~min}$ after mixing the powder with the physiological solution and no more structural changes were detected during the following period[253]. In the light of the aforementioned studies, presumably, the discovered X-ray amorphous component of the initial powder was located on the surface of nanodimensional HA.

\section{Synthesis of the Nanodimensional and Nanocrystalline Calcium Orthophosphates}

\subsection{General Nanotechnological Approaches}

The synthesis of nano-scale materials has received considerable attention and their novel properties can find numerous applications, for example, in the biomedical field. This has encouraged the invention of chemical, physical and biomimetic methods by which such nano-sized materials can 
be obtained[134]. Generally, all approaches for preparation of nanodimensional and nanocrystalline materials can be categorized as "bottom-up" and "top-down" ones[142, 254]. The bottom-up approach refers to the build up of a material from the bottom, i.e., atom by atom, molecule by molecule or cluster by cluster and then assembles them into the final nanostructured material. An example is production of a nano-sized powder and its compaction into the final product (e.g., hot-pressed or sintered nanostructured ceramics). The top-down approach starts from a bulk material and then, via different dimension decreasing techniques, such as milling, slicing or successive cutting, leads to the formation of nanodimensional materials[134]. Using this approach, a novel 2-dimensional carbon material graphene of just 1 atom thick has been prepared from bulk graphite. Furthermore, environmentally friendly methodologies of nanostructure synthesis have been summarized into a special review[255].

Concerning calcium orthophosphates, presumably, all of them (see Table 1) might be manufactured in a nanodimensional and/or a nanocrystalline state; however, not all of them (especially those with low $\mathrm{Ca} / \mathrm{P}$ ionic ratios) have been prepared yet. The details on the available preparation techniques are given below.

\subsection{Nanodimensional and Nanocrystalline Apatites}

First of all, one should stress that the stoichiometric HA with well resolved X-ray diffraction patterns might be prepared mostly at temperatures exceeding $\sim 700{ }^{\circ} \mathrm{C}$ either by calcining of CDHA with the $\mathrm{Ca} / \mathrm{P}$ molar ratio very close to 1.67 or by solid-state reactions of other calcium orthophosphates with various chemicals (e.g., DCPA $+\mathrm{CaO}$ ). Thus, with the exception of a hydrothermal synthesis[256-258], in aqueous solutions only CDHA might be prepared[148, 204-206, 259-263]. As apatites (CDHA, HA and FA) belong to the sparingly soluble compounds (Table 1), simple mixing of calcium- and orthophosphate-containing aqueous solutions at $\mathrm{pH}>9$ results in formation of extremely supersaturated solutions and, therefore, a very fast precipitation of the tremendous amounts of very fine crystals[264], initially of $\mathrm{ACP}$, those afterwards are re-crystallized into apatites[204-206, 265-268]. The dimensions of the precipitated nano-sized crystals might be slightly increased by the Ostwald ripening approach (maturation), that is, by boiling and/or ambient aging in the mother liquid (Fig. 4)[156, 169, 203, 235, 257, 267-272]. Heat treatment of ACP might be applied as well[273]. Therefore, preparation of nanodimensional and/or nanocrystalline apatites is not a problem at all and has been known for many years[156, 157, 274-276]; however, prefix "nano" had not been used before 1994. On the contrary, with the exception of a thermally stable FA (thus, big crystals of FA might be produced by a melt-growth process[277, 278]), manufacturing of big crystals of both CDHA and HA still is a challenge.

Many different methodologies have been proposed to prepare nanodimensional and/or nanocrystalline structures[279-286]. Prior to describing them, it is important to stress that in the vast majority of the available literature on apatites, the authors do not tell the difference between CDHA and HA. Therefore, getting through scientific papers, an attentive reader often finds statements, as: "Because natural bone is composed of both organic components (mainly type I collagen) and inorganic components (HA), ..."[116, p. 357], "The HA nanorods are synthesized via a wet precipitation process ...”[167, p. 2364], “... (TTCP) has been shown previously to be an essential component of self-setting calcium phosphate cements that form hydroxyapatite (HA) as the only end-product. ..."[287, abstract], etc. The matter with distinguishing between CDHA and HA becomes even much more complicated, when researchers deal with nanodimensional and/or nanocrystalline apatites because the assemblies of nano-sized particles give only broad diffraction patterns, similar to ones from an amorphous material[230, 231]. While composing this review, I always tried to specify whether each cited study dealt with CDHA or HA; unfortunately, the necessary data were found in just a few papers. Therefore, in many cases, I was forced to mention just "apatites" without a further clarification. Thus, the readers are requested to be understandable on this uncertainty.

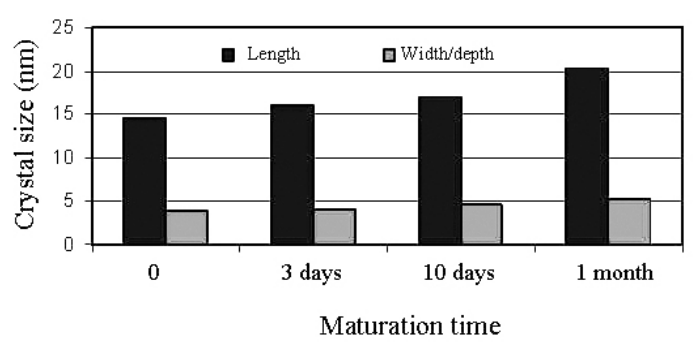

Figure 4. Variation of nanocrystalline apatite dimensions with maturation time. Reprinted from Ref.[235] with permission

The greater part of the published reports on synthesizing of nanodimensional and/or nanocrystalline apatites is focused on the bottom-up approach. Among the available preparation techniques, a wet chemical precipitation is the most popular one[74, 86, 88, 103, 119, 121, 167-169, 172, $178,201,203,265,274,288-332]$. Various authors discussed the effects of synthesis parameters, such as temperature[300-303, 322], time[301], calcium ion concentration[303], presents of surfactants[306-308], calcination[301] and the use of different reagents on the morphological properties of nanodimensional apatites. In general, the shape, stoichiometry, dimensions and specific surface area of nano-sized apatites appeared to be very sensitive to both the reaction temperature (Fig. 5) and the reactant addition rate[300, 315, 322]. Namely, particle sizes of nanodimensional apatites were observed to increase in a linear correlation with temperature[302,322], which is a good indication that sizes of nanodimensional apatites can possibly be tailored. Furthermore, the initial $\mathrm{pH}$ values and reaction temperatures both play important roles in the morphology of the precipitated apatites, as well as on the phase formation and 
degree of crystallinity[326]. For example, significant differences in the chemical composition, morphology and amorphous character of nano-sized CDHA produced through the reaction between aqueous solutions of $\mathrm{Ca}(\mathrm{NO} 3) 2$ and (NH4)2HPO4 can be induced, simply by changing the $\mathrm{pH}$ of the reactant hydrogen phosphate solution[327]. Thus, the solvent systems, dispersant species and drying methods appear to have effects on the particle size and dispersibility. However, some conflicting results have been obtained on how certain synthesis parameters can affect the morphological properties of these nano-sized particles. Nevertheless, it was commonly observed that nano-sized crystals of apatites synthesized through the chemical precipitation were often highly agglomerated; however, these agglomerates could be clusters of ultra-fine primary particles[304]. The prepared nanodimensional apatites might be consolidated to transparent bioceramics[330].
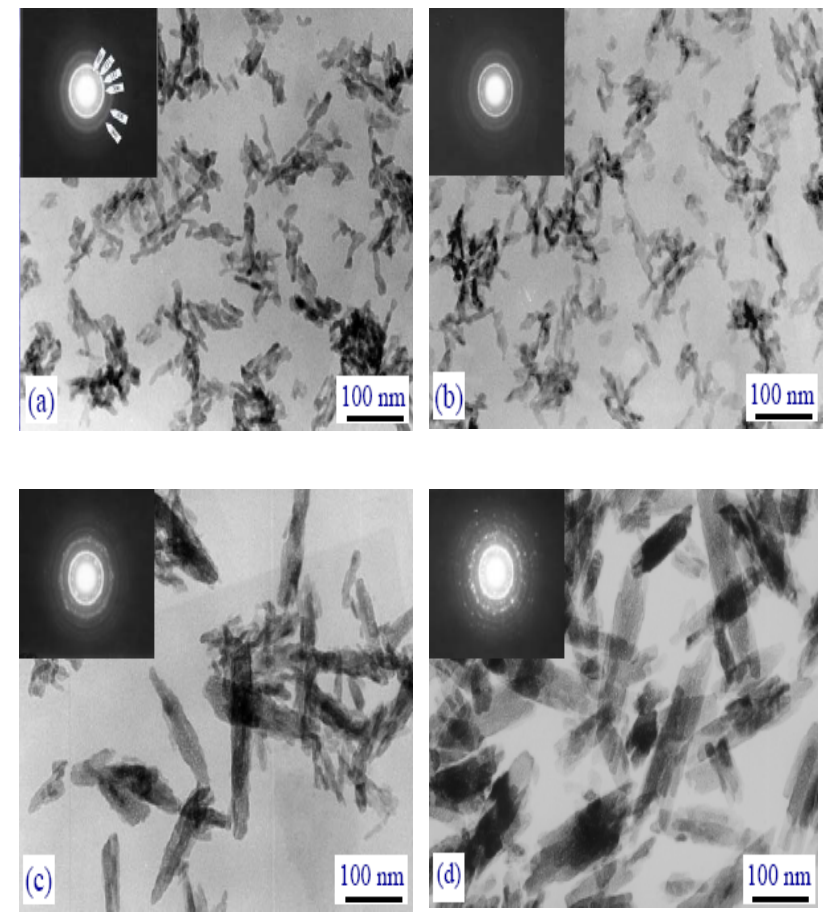

Figure 5. The influence of the reaction temperature on the crystal dimensions of precipitated CDHA: $\mathrm{a}-25^{\circ} \mathrm{C}, \mathrm{b}-37^{\circ} \mathrm{C}, \mathrm{c}-55^{\circ} \mathrm{C}, \mathrm{d}-75^{\circ} \mathrm{C}$

A hydrothermal synthesis $[69,72,156,157,257,258,288$, $322,323,333-357]$ seems to be the second most popular preparation technique of the nanodimensional and/or nanocrystalline apatites. The term "hydrothermal" refers to a chemical reaction of substances in a sealed heated solution above ambient temperature and pressure[358] and this process allows synthesis of highly pure fine-grained single crystals, with controlled morphology and narrow size distribution[333]. Extraneous additives, such as EDTA[351], surfactants[352, 359], anionic starburst dendrimer[353] etc., might be utilized to modify the morphology of nanodimensional and/or nanocrystalline apatites during the synthesis. Most of these techniques produced rod-like crystals or whiskers, while plate-like shapes were obtained in just a few studies[335, 345, 347].

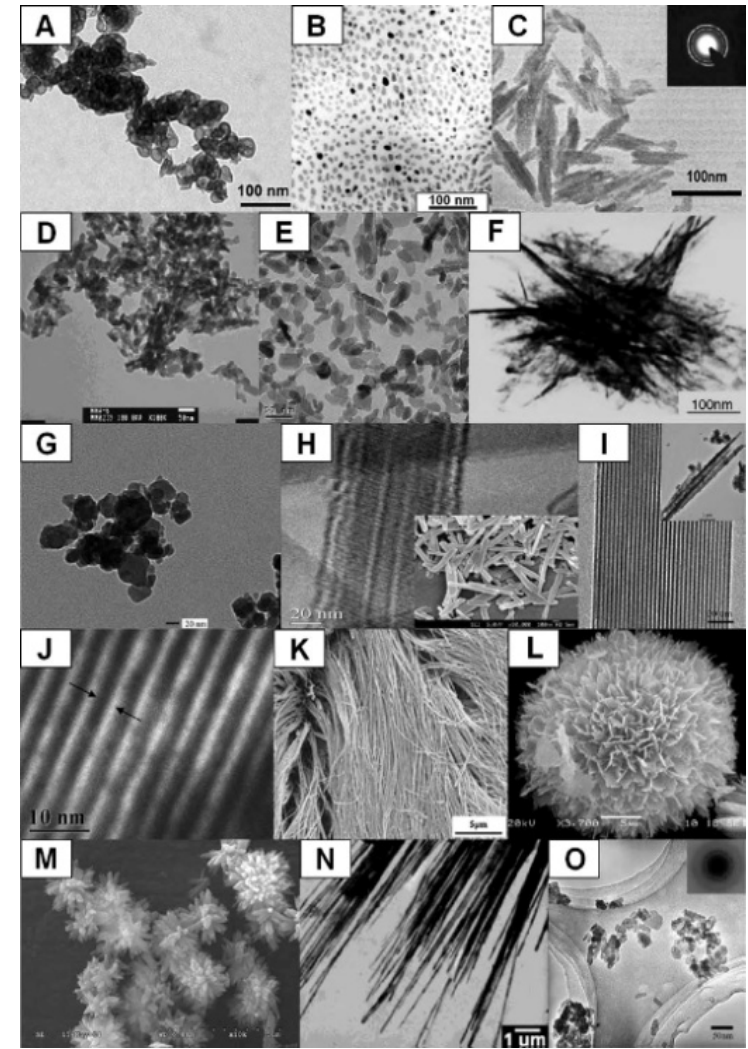

Figure 6. A variety of nano-scale calcium orthophosphates with different structures and morphologies synthesized by: (A and B) sol-gel processing, (C) co-precipitation, (D) emulsion technique, (E) hydrothermal process, (F) ultrasonic technique, $(\mathrm{G})$ mechano-chemical method, $(\mathrm{H}-\mathrm{L})$ template method, (M) microwave processing, $(\mathrm{N})$ emulsion-hydrothermal combination, (O) microwave-hydrothermal combination. Reprinted from Ref.[452] with permission

Other preparation methods of nanodimensional and/or nanocrystalline apatites of various states, shapes and sizes include sol-gel[30, 188, 231, 232, 270, 328, 360-376], co-precipitation[271, 333, 334, 377-380], mechanochemical approach[65, 250, 343, 348, 381-387], mechanical alloying[388, 389], ball milling[348, 383, 390-392], radio frequency induction plasma[393, 394], vibro-milling of bones[395], flame spray pyrolysis[396], liquid-solid-solution synthesis[397], electro-crystallization[158, 398, 399], electrochemical deposition[400], microwave processing[32, 69, 288, 333, 334, 342, 356, 401-415], hydrolysis of other calcium orthophosphates[416-418], double step stirring[419], emulsion-based[310, 349, 420-433], steam-assistant[434], sonochemical[435] and solvothermal[436] syntheses. However, still other preparation techniques are also known[31, 45, 147, 154, 275, 355, 437-457]. Continuous preparation procedures are also available[200, 458]. Application of both ultrasound[362, 459-461] and viscous systems [462] might be helpful. Furthermore, nanodimensional HA might be manufactured by a laser-induced fragmentation of HA targets in water[463-467] and in solvent-containing aqueous solutions[344, 371, 468], while dense nanocrystalline HA films might be produced by radio frequency magnetron sputtering[469, 470]. An interesting approach using sitting drop vapor diffusion technique should 
be mentioned as well[471]. A comparison between the sol-gel synthesis and wet chemical precipitation technique was performed and both methods appeared to be suitable for synthesis of nanodimensional apatite[328]. By means of these methods, a variety of nanodimensional calcium orthophosphate building blocks with various structures and morphologies have been synthesized, including needle-like, spherical, fibrous and mesoporous nano-sized crystals, as well as nano-sized rods, hollow spheres, layered structures and flowers as shown in Fig. 6[452].

Table 3 presents some data on the chronological development of synthesis of nanodimensional apatites for the period of 1995 - 2004[147]. Among the methods described, the thinnest crystals of apatite $(60 \mathrm{~nm} \times 15 \mathrm{~nm} \times 0.69$ or 0.84 $\mathrm{nm}$ ) have been prepared by Melikhov et al., they have been called "two dimensional crystalline HA"[296], while the smallest ones (size between 2.1 and $2.3 \mathrm{~nm}$, i.e. around two times the HA unit cell parameters) have been found by Biggemann et al.,[197]. Liu et al.,[477, 478] and Han et al.,[476] synthesized nano-sized HA via a template mediated and a non-template mediated sol-gel techniques, respectively. Both triethylphosphate[477, 478] and other alkylphosphates[122] might be used to produce nanocrystalline apatites. Besides, nanodimensional ion-substituted CDHA might be precipitated from both a synthetic[378] and a simulated[479] body fluids. A relatively simple sol-gel process using ethanol and/or water as a solvent has also been reported to obtain the stoichiometric, nanocrystalline single phase HA[371].

Nanocrystalline HA powder was synthesized at a low calcination temperature of $750{ }^{\circ} \mathrm{C}$ by the citric acid sol-gel combustion method[476]. The attractive features of this method were to synthesize materials with a high purity, a better homogeneity and a high surface area in a single step[476, 480]. An array of highly ordered HA nano-sized tubes of uniform length and diameter was synthesized by sol-gel auto-combustion method with porous anodic aluminum oxide template[370]. Varma et al., synthesized nano-sized HA by polymeric combustion method and self-propagating combustion synthesis by using novel body fluid solutions[481]. In another study, nanodimensional HA was synthesized by combustion in the aqueous system containing calcium nitrate + diammonium hydrogen orthophosphate with urea and glycine as fuels[482]. Furthermore, nano-sized particles of both FA and $\beta$-TCP might be synthesized by a simultaneous combustion of calcium carboxylate and tributylphosphate based precursors in a flame spray reactor[483]. Both a flame-based technique[484] and a spray drying approach $[125,485]$ might be applied as well. Furthermore, crystalline and phase pure nano-sized HA and CDHA were synthesized in a continuous hydrothermal flow system using supercritical water at $\mathrm{t}<400{ }^{\circ} \mathrm{C}$ and $24 \mathrm{MPa}$ pressure[338].

Table 3. Synthesis of nanodimensional apatites - a chronological development[147].

\begin{tabular}{|c|c|c|}
\hline Year & Process & Reference \\
\hline 1995 & $\begin{array}{l}\text { Synthesis of nanocrystalline HA (particle size } \sim 20 \mathrm{~nm} \text { ) for the first time using calcium nitrate and diammo- } \\
\text { nium hydrogen orthophosphate as precursors by solution spray dry method. }\end{array}$ & [472] \\
\hline 2000 & $\begin{array}{c}\text { Synthesis of biomimetic nanosized CDHA powders }(\sim 50 \mathrm{~nm}) \text { at } 37^{\circ} \mathrm{C} \text { and } \mathrm{pH} \text { of } 7.4 \text { from calcium nitrate } \\
\text { tetrahydrate and diammonium hydrogen orthophosphate salts in synthetic body fluid using a novel chemical } \\
\text { precipitation technique. }\end{array}$ & [378] \\
\hline 2002 & Preparation of nanosized HA particles and HA/chitosan nanocomposite. & [473] \\
\hline 2002 & Direct precipitation from dilute calcium chloride and sodium orthophosphate solutions. & [474] \\
\hline 2003 & $\begin{array}{l}\text { Radio frequency plasma spray process employing fine spray dried HA powders (average size } \sim 15 \mu \mathrm{m} \text { ) as a } \\
\text { feedstock. }\end{array}$ & [393] \\
\hline 2003 & $\begin{array}{l}\text { Sol-gel process using equimolar solutions of calcium nitrate and diammonium hydrogen orthophosphate dis- } \\
\text { solved in ethanol. }\end{array}$ & [371] \\
\hline 2003 & $\begin{array}{l}\text { Chemical precipitation through aqueous solutions of calcium chloride and ammonium hydrogen orthophos- } \\
\text { phate. }\end{array}$ & [301] \\
\hline 2003 & Mechanochemical synthesis of nanosized $\mathrm{HA}$ and $\beta-\mathrm{TCP}$ powders using DCPD and $\mathrm{CaO}$ as starting materials. & [384] \\
\hline 2003 & $\begin{array}{l}\text { Synthesis of nano-powders via sucrose-templated sol-gel method using calcium nitrate and diammonium hy- } \\
\text { drogen orthophosphate as precursor chemicals. }\end{array}$ & [475] \\
\hline 2004 & Hydrolysis method of DCPD and $\mathrm{CaCO}_{3}$ by $2.5 \mathrm{M} \mathrm{NaOH}(\mathrm{aq})$. & [416] \\
\hline 2004 & $\begin{array}{l}\text { Citric acid sol-gel combustion process using calcium nitrate tetrahydrate, diammonium hydrogen orthophos- } \\
\text { phate and citric acid. }\end{array}$ & [476] \\
\hline
\end{tabular}


Nanodimensional powders of the stoichiometric HA of $20 \mathrm{~nm}$ particle size were synthesized by hydrolysis of a mixture of DCPD and $\mathrm{CaCO} 3$ performed with $2.5 \mathrm{M}$ aqueous solution of $\mathrm{NaOH}$ at $75{ }^{\circ} \mathrm{C}$ for $1 \mathrm{~h}$. The only product synthesized was nanocrystalline HA and its crystallinity was improved with increasing annealing temperature[416]. Similar results were obtained in other studies[417, 418]. Furthermore, $\mathrm{Xu}$ et al., used radio frequency plasma spray process to synthesize nanodimensional HA powders with particle size in the range of $10-100 \mathrm{~nm}$ [393]. Kuriakose et al., synthesized nanocrystalline $\mathrm{HA}$ of size $\sim 1.3 \mathrm{~nm}$ that was thermally stable until $1200{ }^{\circ} \mathrm{C}[371]$. Nanocrystalline plate-shaped particles of HA were directly precipitated at ambient temperature and $\mathrm{pH} \sim 7.4$ from dilute aqueous solutions of calcium chloride and sodium orthophosphate. The direct precipitation of nano-sized HA was achieved by submitting the aqueous suspension to microwave irradiation immediately after mixing[474]. A simple and easy approach for synthesizing thermally stable nanostructured stoichiometric HA powder under invariant $\mathrm{pH}$ conditions of 7.5 , known as the NanoCaP process, was developed. Under these conditions, the synthesized HA not only remained in the nanostructured state but also did not exhibit any compositional fluctuations that were observed in conventional approaches for synthesizing $\mathrm{HA}[12]$. Other preparation techniques of nano-sized apatite might be found elsewhere[275]. Bulk bioceramics made of nanocrystalline HA with a grain size of no more than $50 \mathrm{~nm}$ and a near-theoretical density might be prepared by application of a high $(\sim 3.5 \mathrm{GPa})$ pressure in uniaxial compaction of nanodimensional powders with subsequent sintering at $640{ }^{\circ} \mathrm{C}[168]$. A similar approach was reported by another research group[406].

Mechanochemical processing is another compelling method to produce nanostructured apatites in the solid state[65, 238, 343, 381-386]. For example, Yeong et al., used the appropriate amounts of DCPA and calcium oxide. The initial stage of mechanical activation resulted in a significant refinement in crystallite and particle sizes, together with a degree of amorphization in the starting powder mixture. This was followed by steady formation and subsequent growth of HA crystallites with increasing degree of mechanical activation. Finally, a single-phase HA of an average particle size of $\sim 25 \mathrm{~nm}$, a specific surface area of $\sim 76 \mathrm{~m} 2 / \mathrm{g}$ and a high crystallinity was attained after $20 \mathrm{~h}$ of mechanical activation[382].

The use of macromolecules as templating agents to manipulate the growth of inorganic crystals has been realized in many biological systems. Namely, in the presence of biological macromolecules (such as collagen), nucleation and growth of nanocrystalline apatite to form highly organized bone minerals is one of the most fascinating processes in nature. These processes might be simulated. For example, layers of nanocrystalline apatite were formed in situ on the surface of various films at soaking them in aqueous solutions containing ions of calcium and orthophosphate. The in situ synthesized particles were found to be less agglomerated which was believed to be the result of nucleation of apatite crystallites on the regularly arranged side groups located on polymer chains[486, 487]. Another approach comprises precipitation of nanodimensional apatites from aqueous solutions in the presence of dissolved high molecular weight polyacrylic acid[488, 489] that acts as an inhibitor for the crystallization of apatite crystals[490, 491]. A similar inhibiting effect was found for dimethyl acetamide[492], polyvinyl alcohol[291] and several other (bio)polymers[493, 494]. This type of synthesis is expected to lead to formation of nanodimensional composites, which might be structurally more comparable to bones with closely related mechanical and biological properties. Furthermore, a control of particle size of aqueous colloids of apatite nano-sized particles was described involving a presence of amino acids[495, 496]. The amino acids ensured effective growth inhibition by a predominant adsorption onto the Ca-rich surfaces during the initial stages of crystallization. Thus, the nano-sized particles were formed by an oriented aggregation of primary crystallite domains along the c-axis direction. The size of the domains was shown to be governed by the interactions with the amino acid additives, which restricted a growth of the primary crystallites[495, 496]. Furthermore, nanodimensional apatites might be precipitated from aqueous solutions of gelatin[70, 497]. The development of nano-sized apatite in aqueous gelatin solutions was highly influenced by the concentration of gelatin: namely, a higher concentration of gelatin induced formation of tiny $(4 \mathrm{~nm} \times 9 \mathrm{~nm})$ nano-sized crystals, while a lower concentration of gelatin contributed to the development of bigger $(30 \mathrm{~nm} \times 70 \mathrm{~nm})$ nano-sized crystals. In this experiment, a higher concentration of gelatin supplied abundant reaction sites containing groups such as carboxyl, which could bind with calcium ions. This lead to formation of a very large number of nuclei and creation of a large number of tiny nano-sized crystals[70].

Although each of the reported approaches to produce nanodimensional apatites has both a scientific and a practical relevance, a little attention has been dedicated to the physicochemical details involved in the careful control of the particle size distribution and particle shape. Indeed, in the case of particle size distribution, most of the reported ways to synthesize nanodimensional apatites really produced a particle mixture with a wide size distribution from tens to hundreds of nanometers. Moreover, the control of particle shape is another problem for these methods, which commonly result in pin-like or irregular particles. It is well known that bone consists of homogeneous plate-like crystals of biological apatite of $15-30 \mathrm{~nm}$ wide and $30-50 \mathrm{~nm}$ long, while enamel consists of rod-like crystals of biological apatite of $25-100 \mathrm{~nm}$ thick and lengths of $100 \mathrm{~nm}$ to microns (Fig. 7)[2, 5, 207, 208, 210, 219, 227, 229]. The study of higher-level biomineralization and biomimetic assembly involves a search for advanced methods so that the synthesis of nano-sized apatite can be accurately controlled[498]. Namely, the size-controlled synthesis of materials can be achieved by using limited reaction spaces. For example, microemulsions have been shown to be one of the few 
techniques, which is able to produce particle sizes in the range of nanometers and with minimum agglomeration[499]. Thus, microemulsions[349, 423-433], micelles[500] and reverse (inverse) micelles[339, 501-504] have been successfully applied to synthesize nanodimensional apatites with minimal agglomeration. It was found that experimental conditions, such as aqueous/organic phase volume ratio, $\mathrm{pH}$, aging time, aging temperature and ion concentration in the aqueous phase can affect the crystalline phase, surface area, particle size and morphology of nanodimensional apatites.

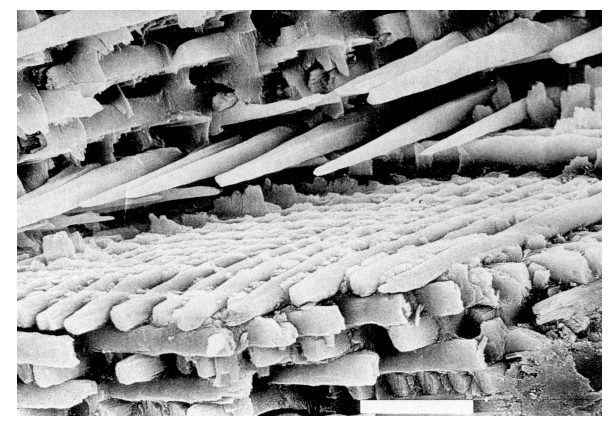

Figure 7. Scanning electron micrograph of the forming enamel of a continuously growing rat incisor showing ordered rods of calcium orthophosphates. Scale bar: $10 \mu \mathrm{m}$. Reprinted from Ref.[2] with permission

In some cases, special polymers can be used as spatial reaction vessels for fabrication of CDHA. For example, Shchukin et al., employed a poly(allylamine hydrochloride)/PO43- complex as a source of orthophosphate anions to capture calcium cations and make them react in the capsule volume[505]. Bose and Saha synthesized spherical-like nanocrystalline CDHA powder with particle diameters of 30 and $\sim 50 \mathrm{~nm}$ using the emulsion route[425]. Furthermore, nano-sized crystals of apatite might be aggregated into microspheres $[438,506]$. Hexadecyl (cetyl)trimethylammonium bromide (CTAB) was selected as an efficient agent to modulate the formation of CDHA nano-sized particles[501, 502]. The particle size can be regulated feasibly by changing the concentration of CTAB in the supersaturated by calcium orthophosphates solutions. For example, three different types of spherical particles of nano-sized CDHA with average diameters of $20 \pm 5,40 \pm 10$ and $80 \pm 12 \mathrm{~nm}$ were fabricated using a series of $\mathrm{CTAB}$ concentrations to control the particle size. The experimental results revealed that the dimensions of the prepared nano-sized CDHA were relatively uniform. In contrast, nano-sized CDHA grown in the absence of organic additives are typical, rod-like particles with lengths of hundreds of nanometers and width of tens of nanometers[507]. Colloidal formulations are known as well[54, $60,202]$. Interestingly, but nano-sized apatites might perform crystalline to amorphous phase transformation when powders were aged for 5 months in $30 \%$ relative humidity[508].

To conclude this part, the nano-sized particles of apatite might be functionalized and/or doped by various compounds (even by quantum dots $[509,510]$ ) to provide new important properties[495, 511-518], e.g., fluorescence[27-29, 515, 516] and luminescence[54, 60, 510, 517, 518]. Both fluorescence and luminescence can be used as a tracking property for the nano-sized particles to give an observable indication of agent delivery, while the particles are served to protect the agent in vivo until it has reached the destination.

\subsection{Nanodimensional and Nanocrystalline TCP}

Many researchers have formulated synthesis of nanodimensional $\beta$-TCP. For example, Bow et al., synthesized $\beta$-TCP powders of $\sim 50 \mathrm{~nm}$ particle diameter at room temperature in anhydrous methanol as a solvent[519]. With increase in aging time, the phase transformation was found to take place from initial DCPA, to intermediate ACP phases, then to final $\beta$-TCP. The authors observed that incorporation of carbonates helped in suppressing formation of ACP phases with apatitic structure and its transformation into poorly crystalline (almost amorphous) CDHA and favored the formation of $\beta$-TCP phase[519]. Nano-sized particles of both FA and $\beta$-TCP were synthesized by a simultaneous combustion of calcium carboxylate and tributylphosphate based precursors in a flame spray reactor[483]. The same technique was used to synthesize nano-sized particles of amorphous TCP of $25-60 \mathrm{~nm}$ size[520-523], those after calcinations transformed into $\alpha$-TCP or $\beta$-TCP. Nanodimensional $\beta$-TCP powders with an average grain size of $\sim$ $100 \mathrm{~nm}[173,524]$ and less[525] were prepared by wet precipitation methods, followed by calcining at elevated temperatures. Furthermore, a sol-gel technique[526], reverse micelle-mediated synthesis[527] and a polystyrene template method[528] are also applicable. In wet precipitation techniques, dialysis might be applied as a separation method[524]. When wet precipitation methods were used, initially nanodimensional $\mathrm{CDHA}$ with $\mathrm{Ca} / \mathrm{P}$ ratio of $\sim 1.50$ was precipitated, that was transformed into nano-sized $\beta$-TCP at calcination.

To synthesize nano-sized TCP, other techniques, such as milling[529, 530], a high temperature flame spray pyrolysis[531] and pulsed laser ablation[532], might be employed as well. Afterwards, the nanodimensional $\beta$-TCP powders can be compacted into 3D specimens, followed by sintering to achieve the appropriate mechanical strength[173]. The maximal values of the bending strength, elastic modulus, Vickers hardness and compressive strength of the samples fabricated from nano-sized $\beta$-TCP powders were more than two-times higher as compared to those of bioceramics obtained from micron-sized $\beta$-TCP powders. However, the degradability of bioceramics sintered from nanodimensional powders was just about one fourth of that sintered from micron-sized powders. Thus, the degradability of $\beta$-TCP bioceramics could be additionally regulated by the particle dimensions[173].

Nano-sized whiskers of several calcium orthophosphates (HA, $\beta$-TCP and biphasic calcium phosphate BCP (HA + $\beta$-TCP)) were produced by using a novel microwave-assisted "combustion synthesis (auto ignition)/molten salt synthesis" hybrid route. Aqueous solutions containing $\mathrm{NaNO}_{3}$, $\mathrm{Ca}\left(\mathrm{NO}_{3}\right)_{2}$ and $\mathrm{KH}_{2} \mathrm{PO}_{4}$ (with or without urea) were irradiated 
in a household microwave oven for $5 \mathrm{~min}$ at 600 watts of power. The as-synthesized precursors were then simply stirred in water at room temperature for $1 \mathrm{~h}$ to obtain the nano-sized whiskers of the desired calcium orthophosphate[533]. Furthermore, nanostructured biphasic (HA + $\beta$-TCP) bioceramics was successfully prepared by microwave synthesis $[534,535]$ and a polymer matrix mediated process[536] in other studies. Good cellular activities of the biphasic bioceramics have been reported.

Layrolle and Lebugle developed a synthesis route of nano-sized FA and other calcium orthophosphates, using calcium diethoxide $\left(\mathrm{Ca}(\mathrm{OEt})_{2}\right)$ and $\mathrm{H}_{3} \mathrm{PO}_{4}[154]\left(+\mathrm{NH}_{4} \mathrm{~F}\right.$ to prepare $\mathrm{FA}[537]$ ) as the initial reagents and anhydrous ethanol as a solvent. By a simple variance of the ratio of reagents, calcium orthophosphates of various chemical compositions were precipitated in ethanol. The precipitates were characterized and the results indicated that those calcium orthophosphates were amorphous and nanodimensional. Furthermore, they had large specific surface areas and possessed a high reactivity[154, 537].

\subsection{Other Nanodimensional and Nanocrystalline Calcium Orthophosphates}

Nano-sized particles of DCPD (with some amount of CDHA and ACP) of a relatively high monodispersity could be synthesized from aqueous solutions of calcium nitrate and H3PO4 in the presence of 2-carboxyethylphosphonic acid. They are produced in a discoid shape with a diameter of $30-$ $80 \mathrm{~nm}$ and a height of less than $\sim 5 \mathrm{~nm}$. They form stable colloidal solutions displaying minimal agglomeration[538]. Nano-sized rods and nanodimensional fibers of DCPD with average diameters of $25 \pm 5 \mathrm{~nm}$ (aspect ratio $\sim 6$ ) and $76 \pm 20$ $\mathrm{nm}$ (aspect ratio $\sim 40$ ), respectively, were synthesized by sucrose ester based reverse microemulsion technique[539]. A similar approach was used in another study[431]. Nanodimensional crystals of both DCPD and DCPA were prepared by EDTA-assisted hydrothermal method[351]. An interesting approach comprises precipitation of calcium orthophosphates inside nano-sized pores of another material. For example, nanodimensional clusters DCPD were immobilized into pores of an oxide network by immersion of this network into an acidic $(\mathrm{pH}=2.7)$ calcium orthophosphate solution at $50{ }^{\circ} \mathrm{C}[540]$. The acid-base reaction between the calcium orthophosphate solution and the hydroxyl groups of the oxide network resulted in formation of nanodimensional clusters of DCPD immobilized inside the oxide pores. Interestingly, but the immobilized nanodimensional clusters of DCPD were further converted into those of ACP and CDHA by supplementary treatment of the oxide network in alkaline solutions[540]. Hollow nano-sized shells of undisclosed calcium orthophosphates (presumably, of ACP) with a size distribution of $(120-185) \pm 50 \mathrm{~nm}$ and predictable mean shell thickness from 10 to $40 \mathrm{~nm}$ were prepared by crystallization onto the surface of nanodimensional liposomes[541, 542]. Both the suspension stability and shell thickness control were achieved through the introduction of carboxyethylphosphoric acid. Variation of shell thickness and stoichiometry may be a way of manipulating the dissolution kinetics of ACP coating to control the release of encapsulated materials, necessary for drug delivery purposes[541, 542]. Other types of calcium orthophosphate shells with $\mathrm{Ca} / \mathrm{P}$ ratios of 0.97 (DCPD or DCPD-like $\mathrm{ACP}$ ) and 1.45 (CDHA or ACP) were prepared using liposome templates[543]. Roughly spherical DCPA particles of approx. 50 $-100 \mathrm{~nm}$ in sizes were synthesized via a spray-drying technique[125, 544-546], while ribbon-like fibers of nano-sized DCPA might be prepared upon hydrolysis in urea[417]. Furthermore, nanodimensional calcium orthophosphate powders with DCPD as the major phase have been synthesized by an inverse microemulsion system using kerosene as the oil phase, a cationic surfactant and a non-ionic surfactant[547]. Microskeletal constructions might be synthesized as well[548].

When it comes to ACP, it is nanodimensional in the vast majority cases. Approximately spherical nano-sized particles of ACP with a diameter of about $50 \mathrm{~nm}$ can be prepared by rapid precipitation from water[549] and subsequent colloidal stabilization by coating with polymers[550]. Nano-sized clusters of ACP[551] or those comprising a spherical core of $355 \pm 20$ DCPD units with density of $2.31 \mathrm{~g} / \mathrm{cm} 3$ and radius of $2.30 \pm 0.05 \mathrm{~nm}$ surrounded by $49 \pm 4$ peptide chains with a partial specific volume of $0.7 \mathrm{~cm} 3 / \mathrm{g}$, forming a tightly packed shell with an outer radius of $4.04 \pm 0.15 \mathrm{~nm}$ were prepared by precipitation using $10 \mathrm{mg} / \mathrm{ml}$ of the 25-amino-acid N-terminal tryptic phosphopeptide of bovine $\beta$-casein as a stabilizing agent[552]. Nano-sized particles of ACP were prepared by mixing of solutions of $\mathrm{Ca}(\mathrm{NO} 3) 2 \cdot 4 \mathrm{H} 2 \mathrm{O} \quad(450 \mathrm{mmol} / \mathrm{L})$ in acetone and (NH4)2HPO4 (30 mmol/L) in deionized water at $\mathrm{pH}$ within 10.0 - 11.0[553]. Furthermore, nanodimensional particles of ACP might be prepared by electrostatic spray pyrolysis[554, 555], pulsed laser ablation[532], spray drying[125], as well as by flame spray synthesis[457]. By means of the latter technique, one can produce nanodimensional ACPs with a broad $\mathrm{Ca} / \mathrm{P}$ ratio within $0.5-1.5[457]$.

Self-assembled shell cross-linked poly(acrylic acid-b-isoprene) micelles and/or cross-linked poly(acrylic) acid nano-sized cages in aqueous solutions might be used as templates for preparation of polymer/calcium orthophosphate nanodimensional capsules of $50-70 \mathrm{~nm}$ in diameter, which consisted of spherical polymer nano-sized particles enclosed within a continuous $10-20 \mathrm{~nm}$ thick surface layer of ACP[556]. Synthesis of hollow spherical calcium orthophosphate nano-sized particles using polymeric templates has been also reported by other researchers[557]. Furthermore, bundles of surfactant-coated ACP nanodimensional filaments of $\sim 2 \mathrm{~nm}$ in width and $>300 \mu \mathrm{m}$ in length were synthesized in reverse micelles[558]. Bundles of the nanodimensional filaments were stable in the reverse micelle phase up to around 5 days, after which they transformed into $5 \mathrm{~nm}$-wide surfactant-coated CDHA rods. Discrete filaments of $100-500 \times 10-15 \mathrm{~nm}$ in size and a linear superstructure based on the side-on stacking of surfactant-coated ACP nano-sized rods were also prepared[490]. A double re- 
verse-micelle strategy was realized to synthesize amine, carboxylate- and polyethylene glycol surface functionalized calcium orthophosphate nano-sized particles of an undisclosed nature[559]. Furthermore, the reverse micelle technique might be applied to prepare nanodimensional DCPA[501, 560].

Concerning OCP, an oriented growth of nanodimensional belts of OCP with a clean surface has been achieved by wet-chemical approach using cetyltrimethylammonium bromide[561]. Pulsed laser deposition technique was employed to obtain thin films of nanocrystalline OCP on pure Ti substrates[562]. The deposition was performed by a pulsed UV laser source in a flux of hot water vapors. High-resolution electron microscopy and X-ray diffraction at grazing incidence investigations indicated that the coatings were made of nanocrystalline OCP (unfortunately, the dimensions were not indicated). In vitro tests proved that both fibroblasts and osteoblasts adhered, reached a normal morphology, proliferated and remained viable when cultured on the nanocrystalline OCP coatings, supporting a good biocompatibility and absence of any toxicity[562].

Nanodimensional powders of BCP (both HA + $\beta-\mathrm{TCP}[563-565]$ and HA $+\alpha-\mathrm{TCP}[566])$ have been fabricated as well. To get the details, the interested readers are referred to the original publications.

Similar to that for apatites (see above), nano-sized particles of TCP, ACP and other calcium orthophosphates might be functionalized and/or doped by various compounds to provide new important properties[200, 559, 566-572], such as fluorescence[569, 570], luminescence[572] or a good disperseability in organic solvents[566]. Furthermore, nano-sized calcium orthophosphates might be used as templates to manufacture nanodimensional capsules[573].

\subsection{Biomimetic construction using nanodimensional particles}

Morphological control of bioinorganic materials is another interested issue in biomineralization, by which inorganic materials with complex morphologies can be produced. Complex forms or patterns with a hierarchical structure over several length scales are important features of biomineralization. Pattern formation in biomineralization is a process in which self-assembled organic templates are transformed by a material's replication into organized inorganic structures. Needless to mention, that researchers try to reproduce these processes in laboratories. For example, Chen et al., reported a way to create enamel-like structures by modifying synthetic nano-sized rods of apatite with a surfactant, bis(2-ethylhexyl)sulfosuccinate salt, that allowed the nano-sized rods to self-assemble into prism-like structures at the water/air interface[225]. A nanometer-scale rod array of apatite having preferred orientation to the c-axis was successfully prepared simply by soaking calcium-containing silicate glass substrates in $\mathrm{Na} 2 \mathrm{HPO} 4$ aqueous solution at $80{ }^{\circ} \mathrm{C}$ for various periods[574]. A biomimetic bottom-up route to obtain the first hierarchical level of bone was re- ported[212]. A pH-induced self-assembly of peptide-amphiphile to make a nanostructured fibrous scaffold reminiscent of extracellular bone matrix was obtained. After the cross-linking of the scaffold, the fibers were able to direct mineralization of CDHA to form a biocomposite, in which the crystallographic c-axes of the nano-sized crystals of CDHA were aligned with the long axes of the fibers. This alignment was similar to that observed between collagen fibrils and crystals of biological apatite in bones[212]. Other attempts to fabricate artificial materials having bone-like both nanostructure and chemical composition were performed and several significant achievements were obtained[575, 576].

The classical model of biomineralization considers mineral formation as an amplification process in which individual atoms or molecules are added to existing nuclei or templates[1, 2, 577]. This process occurs in the presence of various bioorganic molecules, which deterministically modify nucleation, growth and facet stability. A model involving aggregation-based growth[578] recently challenged this conventional concept for the crystal growth. Inorganic nano-sized crystals were found to aggregate into ordered solid phases via oriented attachment to control the reactivity of nanophase materials in nature[19, 579]. A model of "bricks and mortar" was suggested to explain the biological aggregation of nano-sized apatite[580]. In this model, ACP acts as "mortar" to cement the crystallized "bricks" of nano-sized HA. Meanwhile, biological molecules control the construction process. By using nanodimensional spheres of HA as the building blocks, highly ordered enamel-like and bone-like apatites were hierarchically constructed in the presence of glycine and glutamate, respectively. It is interesting that, during the evolution of biological apatite, the amorphous "mortar" can be eventually turned into the "brick" by phase-to-phase transformation to ensure the integrity of biominerals[580].
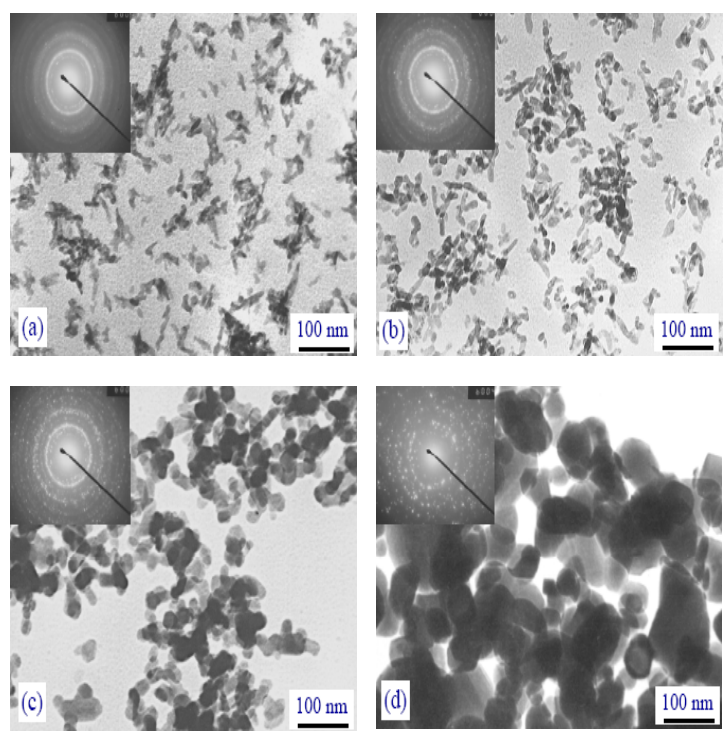

Figure 8. Particle sizes and crystallinity of HA powders after a heat treatment at various temperatures: $\mathrm{a}-300{ }^{\circ} \mathrm{C}, \mathrm{b}-500{ }^{\circ} \mathrm{C}, \mathrm{c}-700{ }^{\circ} \mathrm{C}, \mathrm{d}-900$ ${ }^{\circ} \mathrm{C}$ 


\section{Biomedical Applications of the Nanodimensional and Nanocrystalline Calcium Orthophosphates}

\subsection{Bone Repair}

Due to advances in surgical practice and a fast aging of the population, there is a permanently increasing demand for bone grafts[581]. Modern grafts should not only replace the missing bones, but also should be intrinsically osteoinductive by acting as scaffolds for guided bone growth. Furthermore, an ability to form a biologically active apatite layer to bond to living bone it is an essential requirement to modern biomaterials[582]. In addition, a good graft should provide a framework to support new blood vessels and soft tissues in forming a bridge to existing bones[581].

Calcium orthophosphate bioceramics of micron dimensions have been used in dentistry, orthopedics and surgery for over 30 years because of their chemical similarity to calcified tissues of mammals and, therefore, excellent biocompatibility[148, 204-206, 259, 260]. Due to a rapid development of nanotechnology, the potential of nanodimensional and nanocrystalline forms of calcium orthophosphates has received a considerable attention[18] because they produce favorable results in repair of bone defects[583, 584]. For example, due to an improved sinterability, an enhanced densification and a better bioactivity than coarser crystals, they might be chosen as the major components of self-setting bone cements[14, 25, 520, 521, 585-589]. However, there is a study in which an increase of particle and crystallite sizes of TCP did not prolong but shortened the induction time until the cement setting reaction started[523], which was against the common physical rules (generally, smaller particles or crystallites should enhance reactivity). Nevertheless, two general directions of the biomedical application of nanodimensional and nanocrystalline calcium orthophosphates can be outlined: (i) using them in powder form as filling materials to impart bioactivity to various biocomposites and hybrid biomaterials[64-104, 179, 590]; (ii) manufacturing of either dense compacts or porous scaffolds, possessing the sufficient mechanical properties[74, 96, 294, 295, 575, 576, 591, 592]. As the nanodimensional and nanocrystalline calcium orthophosphates tend to agglomerate at heating (Fig. 8)[313, 593-595], normally a low-temperature[169, 371] and/or a rapid consolidation[169, 258, 323, 596-602] techniques must be employed. The low-temperature approach comprises gel hardening $\left(\right.$ at $\left.4^{\circ} \mathrm{C}\right)[371]$ and uni-axial pressing at $150-200$ ${ }^{\circ} \mathrm{C}[169]$. The rapid consolidation techniques comprise spark plasma sintering[169, 258, 323, 596-599], pressure sintering[597] and microwave sintering over the temperature range $1000-1300{ }^{\circ} \mathrm{C}$, using a rapid sintering schedule[600-602].

Furthermore, nanodimensional crystals of calcined HA might be fabricated by calcination at $800^{\circ} \mathrm{C}$ for $1 \mathrm{~h}$ with an anti-sintering agent surrounding the original nano-sized CDHA particles and the agent is subsequently removed by washing after the calcination[603-605]. These consolidation approaches provided a limited alteration of the initial nano-sized crystals, while the final bioceramics possessed the mechanical properties similar to those reached with sintered stoichiometric HA.

Already in 1990-s, implants prepared from nanodimensional apatites, as well as biocomposites of nanodimensional apatite with organic compounds were tested in vivo[606-608]. Cylinders made of both pure nanodimensional apatite and organoapatite containing a synthetic peptide were analyzed 28 days after implantation into spongy bones of Chinchilla rabbits. Both implant types were well incorporated and interface events were found to be similar to those observed on human bone surfaces with regard to resorption by osteoclast-like cells and bone formation by osteoblasts. That study revealed a suitability of such materials for both bone replacement and drug release purposes[606]. Similar results were obtained in other studies[607, 608].

Among the available commercial formulations, NanOss ${ }^{\mathrm{TM}}$ bone void filler from Angstrom Medica, Inc.[609] is considered as the first nanotechnological medical device received the clearance by the US Food and Drug Administration (FDA) in 2005. It is prepared by precipitation of nano-sized calcium orthophosphates from aqueous solutions and the resulting white powder is then compressed and heated to form a dense, transparent and nanocrystalline material. NanOss ${ }^{\mathrm{TM}}$ mimics the microstructure, composition and performance of human bone, as well as it is mechanically strong and osteoconductive. It is remodeled over time into human bone with applications in the sports medicine, trauma, spine and general orthopedics markets[609].

Ostim ${ }^{\circledR}$ (Osartis GmbH \& Co. KG, Obernburg, Germany) is another popular commercial formulation. This ready-to-use injectable paste received CE (Conformite Europeenne) approval in 2002. Ostim ${ }^{\circledR}$ is a suspension of synthetic nanocrystalline HA (average crystal dimensions: $100 \times 20 \times 3 \mathrm{~nm} 3$ (a needle-like appearance); specific surface area $\sim 100 \mathrm{~m} 2 / \mathrm{g}$ ) in water, prepared by a wet chemical reaction[610]. After completion, the HA content in the paste is $\sim 35 \%$. Ostim ${ }^{\circledR}$ does not harden when mixed with blood or spongiosa, so it is highly suitable for increasing the volume of autologous or homologous material. Simultaneously, its viscosity enables its applications to form-fit in close contact with the bone. Ostim ${ }^{\circledR}$ can be used in metaphyseal fractures and cysts, alveolar ridge augmentation, acetabulum reconstruction and periprosthetic fractures during hip prosthesis exchange operations, osteotomies, filling cages in spinal column surgery, etc.[609-622]. It might be incorporated into bones and a new bone formation is visible after only three months[623]. For a number of clinical applications, Ostim ${ }^{\circledR}$ might be combined with other types of calcium orthophosphate bioceramics, e.g., with a HA bioceramic core (Cerabone $\left.{ }^{\circledR}\right)[610,624]$ or with biphasic $(\beta-\mathrm{TCP}+\mathrm{HA})$ granules (BoneSaves ${ }^{\circledR}$ )[625]. Application of such combinations of a nanocrystalline Ostim ${ }^{\circledR}$ with the microcrystalline calcium orthophosphate bioceramics appeared to be an effective method for treatment of both tibia head compression fractures[610] and metaphyseal osseous volume defects in the 
metaphyseal spongiosa[624]. Besides, such combinations might be used for acetabular bone impaction grafting procedures[625].

Cui et al., developed nano-sized HA/collagen biocomposites, which mimicked the nanostructure of bones[208, 626]. After implantation, such biocomposites can be incorporated into bone metabolism. Due to processing difficulties and poor mechanical properties of bulk calcium orthophosphates, their applications are currently confined to non-load-bearing implants and porous bodies/scaffolds. Porous 3D biocomposites of nanodimensional HA and collagen/polymer mimic bones in composition and microstructure and can be employed as a matrix for the tissue engineering of bone[89].
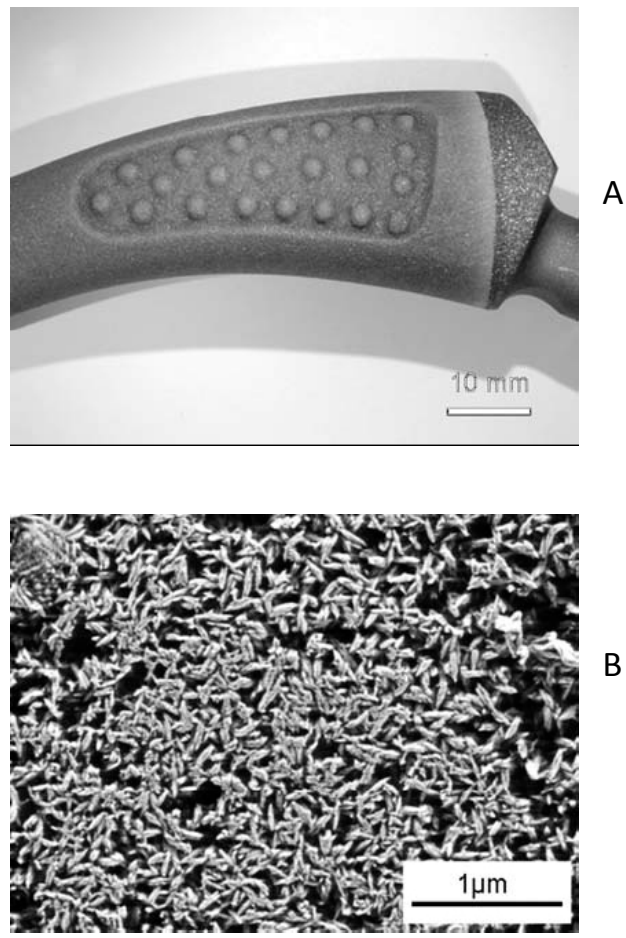

Figure 9. a - A photo of a titanium implant coated with electrochemically deposited HA at $37^{\circ} \mathrm{C}\left(\operatorname{Cenos}^{\circledR}\right.$ BoneMaster); b - A micrograph of a titanium implant surface coated with electrochemically deposited HA at 37 ${ }^{\circ} \mathrm{C}$. Reprinted from Ref.[650] with permission. Other micrographs of nano-CDHA coatings biomimetically deposited on $\mathrm{NaOH}$-treated Ti6Al4V surfaces might be found in Ref.[651]

Owing to their low mechanical properties, the use of calcium orthophosphates in load-bearing applications is rather limited: calcium orthophosphates are too stiff and brittle for such use. Today's solutions for weight-bearing applications rely mostly on biologically friendly metals, like cobalt-chromium alloys, titanium and its alloys, as well as stainless steel 316L, but problems with stress-shielding and long-term service can cause failures. All these metals, although nontoxic, are always bioinert and cannot bond to bone directly. In order to improve the biological properties of the metallic implants, nanostructured calcium orthophosphates (mainly, apatites) are generally used as a coating material to accelerate bone growth and enhance bone fixation[186, 187, 316, 439, 562, 627-648]. The coating techniques include thermal spraying, sputter coating, pulsed laser deposition, dynamic mixing method, dip coating, sol-gel method, electrophoretic deposition, biomimetic process, hot isostatic pressing and some other methods[649]. In the majority cases, the coatings are composed of uniform nanocrystalline apatites (Fig. 9). They are capable in performing bone formation and promoting direct osseointegration with juxtaposed bone[652-655]. For example, an enhanced new bone formation can be clearly seen on nanophase HA-coated tantalum compared to micro-scale HA-coated tantalum and non-coated tantalum (see Fig. 2 in Ref.[116]). Furthermore, nanostructured calcium orthophosphates might be used as a coating material to impart surface bioactivity to other materials, e.g., glasses[656] and polymers $[657,658]$. Finally but yet importantly, such coatings might be patterned, e.g., by laser direct writing[574] or electrohydrodynamic atomization spraying technique[659].

\subsection{Nanodimensional and Nanocrystalline Calcium Orthophosphates and Bone-Related Cells}

It is well accepted that bone-related cells (especially, osteoblasts and osteoclasts) play the key roles in the physiological formation of calcified tissues. Bone-related cells not only are speculated to take part in the formation of biominerals and macrostructure constructions of bones, but they also continuously modulate the density, regeneration and degradation of bones. Therefore, understanding the relationship between the bone-related cells and nano-sized calcium orthophosphates has been paid much attention in order to elucidate the formation mechanism of bones, to prevent and cure bone-related diseases and to design novel biomaterials. Better structural biomimicity and osteoconductivity can be achieved using nanodimensional and nanocrystalline calcium orthophosphates[178, 179, 185, 186, 660-663]. Biocompatibility of such biomaterials is the key question for their application possibility for clinical use. For example, adhesion, proliferation and differentiation of mesenchymal stem cells were studied on nano-sized HA/polyamide biocomposite scaffolds. The results indicated that such biocomposites exhibited a good biocompatibility and an extensive osteoconductivity with host bone in vitro and in vivo and proved that nano-sized HA/polyamide scaffolds had a potential to be used in orthopedic, reconstructive and maxillofacial surgery[664-666].

Most results demonstrate that nanostructured HA can improve cell attachment and mineralization in vivo, which suggests that nano-sized HA may be a better candidate for clinical use in terms of bioactivity[185, 186, 190, 667-669]. The size effects of nanodimensional HA on bone-related cells, as well as the influence of crystallinity of nano-sized HA were studied[507, 670]. Different nano-sized particles of HA, typically of $20 \pm 5,40 \pm 10$ and $80 \pm 12 \mathrm{~nm}$ in diameter, were prepared and their effects on the proliferation of two types of bone-related cells, bone marrow mesenchymal stem cells (MSCs) and osteosarcoma cells (U2OS and MG63) were studied. The cell culture experiments showed an improved cytophilicity of the nanophase HA if compared to the 
submicron-sized HA. A greater cell viability and proliferation of MSCs were measured for nano-sized HA, remarkably for $20 \mathrm{~nm}$-sized particles. However, the opposite phenomenon occurred for bone tumour cells when nano-sized HA were co-cultured with cells. Nano-sized HA can inhibit proliferation of U2OS and MG63 cells and the inhibited strengths were inversely proportion to the particle size, i.e. smaller particles possessed a greater ability to prevent cell proliferation. This suggests that nano-sized HA can exhibit favorable cell proliferation to optimize biological functionality, in which the particle dimensions are believed to play a key role. These in vitro findings are of a great significance for the understanding of cytophilicity and biological activity of nano-sized particles during biomineralization[507]. Furthermore, an early osteogenic signal expression of rat bone marrow stromal cells appeared to be influenced by nanodimensional HA content[671]. On the other hand, there is a study on early bone healing, in which an importance of nanometer thick coatings of nanodimensional HA on titanium implants appeared to be insignificant if compared to the control[672].

Studies confirmed that nano-sized ACP had an improved bioactivity if compared to nano-sized HA since a better adhesion and proliferation of osteogenic cells had been observed on the ACP substrates[673]. However, in order to understand the influence of crystallinity of the nano-sized calcium orthophosphates on the osteogenic cells correctly, it was critical to use nano-sized ACP and HA of the same size distribution[670]. Thus, ACP and HA particles of $\sim 20 \mathrm{~nm}$ size were synthesized and the effects of crystallinity were studied. The adhesion, proliferation and differentiation of MSC cells were measured on both ACP and HA films and compared at the same size scale. Surprisingly, more cells were adsorbed and proliferated on the films of the well crystallized nano-sized HA than those on the films of nano-sized ACP. Alkaline phosphatase activity assay and RT-PCR assay were also used to evaluate the differentiation of MSC cells. The results showed that the differentiation of MSC cells from osteoblasts was promoted significantly by nano-sized HA. These experimental phenomena clearly demonstrate that the crystallized phase of HA provides a better substrate for MSC cells than ACP, when the factor of size effect is removed. This new view on the relationship between the crystallinity of calcium orthophosphates and the responses of cells emphasized the importance of both size and phase control in the application of biomedical materials[670-673].

On the other hand, the chemical composition of the samples appears to be important. Interestingly, but in spite on the fact that the biological apatite of bones contains the substantial amount of carbonates, among investigated samples of nanocrystalline apatites, osteoclastic differentiation was found to be constrained on carbonate-rich samples, leading to smaller numbers of osteoclast-like cells and fewer resorption pits. Furthermore, the highest resorption rate was found for nanodimensional HA with a low carbonate content, which strongly stimulated the differentiation of osteo- clast-like cells on its surface[674].

Cells are sufficiently sensitive and nano-scale alterations in topography might elicit diverse cell behavior[675-677]. How cells can recognize the particle size and other very small differences in the properties of nano-sized HA in these experiments remains unclear. Actually, determining the mechanisms whereby nano-sized particles of calcium orthophosphates and their sizes exert effects on bone-related cells will require further systematic studies.

\subsection{Dental Applications}

Dental caries is a ubiquitous and worldwide oral disease. At the initial stage of caries lesions, bacteria cause damage of dental enamel, which is the exterior coating of teeth and possesses remarkable hardness and resistance. As the most highly mineralized structure in vertebrate bodies, enamel is composed of numerous needle-like apatite crystals of nanodimensional sizes, which are bundled in parallel ordered prisms to ensure unique mechanical strength and biological protection. As a non-living tissue, the main constituent $(\sim 97$ wt. \%) of mature enamel is inorganic nanodimensional apatite so that enamel is scarcely self-repaired by living organisms after substantial mineral loss. Filling with artificial materials is a conventional treatment to repair damaged enamel. However, secondary caries frequently arise at the interfaces between the tooth and foreign materials[678].

Nanodimensional HA and CDHA are often considered as model compounds of dental enamel due to the chemical and phase similarities[148, 204, 205]. Therefore, enamel remineralization by using nanodimensional apatite or other calcium orthophosphates is suggested in dental research[679]. For example, toothpastes containing nanodimensional apatite could promote a partial remineralization of demineralized enamel[680-684], as well as possess some whitening effect[685]. Furthermore, nano-sized HA might be added to methacrylate-based root canal sealers[686], as well as to a fluoride-containing mouth rinse[687]. A remineralization potential of sports drink, containing nano-sized HA, was also investigated[688,689]. A positive influence of addition of nanodimensional $\beta$-TCP against acid demineralization and promoted remineralization of enamel surface was detected as well[690]. Unfortunately, these chemically analogous compounds of enamel are not widely applied in clinical practices. The native structure of dental enamel is too complex to be remodeled and the synthesized apatite crystallites often have different dimensions, morphologies and orientations from the natural ones, which result in a poor adhesion and mechanical strength during dental restoration. Recent advances in biomineralization also indicate that features of smaller particles of nano-sized HA might approximate features of biological apatite more closely than features of the larger HA particles that are conventionally used[13]. For example, it has been demonstrated that nano-sized HA can be self-assembled to form enamel-like structures in the laboratory[225]. Therefore, a biomimetic technique is suggested as follows: the localized repair of the enamel surface can be improved by nano-sized HA (dimension of $\sim 20 \mathrm{~nm}$ ), 
analogues to the basic building blocks of enamel rods. Furthermore, it is found that nano-sized HA can adsorb onto the enamel surface strongly and can even be integrated into the natural enamel structure[691].

It is surprising but nano-sized HA of $\sim 20 \mathrm{~nm}$ can inhibit significantly a mineral loss from the enamel surface[228]. Without any treatment, the demineralization of the natural enamel surface was remarkable in acidic solution $(\mathrm{pH} \sim 4.5 \pm$ 0.1 , experimental period of 2 days) and damaged sites were observed. The mass loss rate was about $0.12 \pm 0.04 \mathrm{mg} / \mathrm{mm}^{2}$ per day. In contrast, a layer of nano-sized HA on the treated enamel surface was almost unchanged in acidic solution. The rate of mass loss of enamel coated by nano-sized HA approached zero $\left(<0.02 \mathrm{mg} / \mathrm{mm}^{2}\right.$ per day), which was beyond the sensitivity of the detection methods. Since the coating by nano-sized HA appeared to be insensitive to dissolution, the underlying enamel surface was well protected under slightly acidic conditions. Furthermore, the enamel surface coated by $\sim 20 \mathrm{~nm}$-sized HA had a hardness of $4.6 \pm 0.4 \mathrm{GPa}$ and an elastic modulus of $95.6 \pm 8.4 \mathrm{GPa}$. These data appeared to be very similar to those of natural enamel samples, which are $4.2 \pm 0.2$ and $94.1 \pm 5.4 \mathrm{GPa}$, respectively[228].

The similarity between $\sim 20 \mathrm{~nm}$-sized HA and building blocks of dental enamel results in a good fixation of artificial biomaterials to natural tissues. Moreover, the enamel structure appears to be reinforced by nano-sized HA since secondary caries formation is suppressed and hardness is retained[678, 692, 693]. This strategy may have prospective applications in dentistry as it offers an easy but effective method to reconstruct tooth enamel that is suffering from mineral losses. Generally, these studies also suggest that analogues of nanodimensional building blocks of biominerals should be highlighted in the entire subject of biomineralization.

In the case of nanodimensional DCPA, decreasing of DCPA particle dimensions were found to increase the $\mathrm{Ca}$ and $\mathrm{PO}_{4}$-ions releases from DCPA-based biocomposites. Therefore, biocomposites based on nano-sized DCPA, possessing both a high strength and good release of $\mathrm{Ca}-$ and $\mathrm{PO}_{4}$-ions, may provide the needed and unique combination of stress-bearing and caries-inhibiting capabilities suitable for dental applications[546].

\subsection{Other Applications}

Several other applications of nanodimensional and nanostructured calcium orthophosphates are in progress, some of which are described here. For example, there is a report on a successful preparation of a multi-modal contrast agent based on nano-sized crystals of HA, which was engineered to show simultaneous contrast enhancement for three major molecular imaging techniques such as magnetic resonance imaging, X-ray imaging and near-infrared fluorescence imaging[694]. Furthermore, various compositions based on nanodimensional calcium orthophosphates have been already tested for cancer treatment[48, 60, 199, 354, 570, 695-697]. Besides, nanodimensional HA was found to be effective for proliferation inhibition of highly malignant melanoma cells[698] and human chronic myeloid leukemia K562 cells[699].

Surface modification of nanodimensional calcium orthophosphates was performed in order to modulate their colloid stability, prevent dissolution in the case of low $\mathrm{pH}$, avoid inflammation, serve as an intermediate layer to allow strong bond formation between HA/polymer matrices and potentially enhance its bioactivity or improves its conjugation ability with special functional groups[12, 700-706]. Such surface modified nano-sized particles might be applied for oral insulin delivery[707].

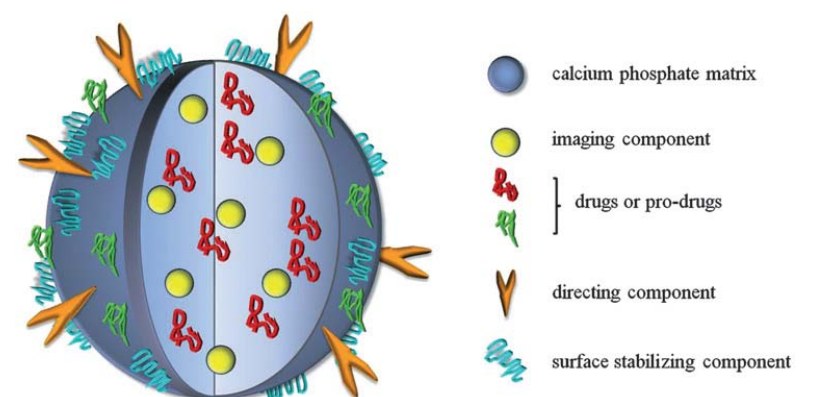

Figure 10. A generalized schematic setup of a nanodimensional particle of a calcium orthophosphate suitable for both imaging and drug delivery purposes. Reprinted from Ref.[756] with permission

In another aspect, many strategies have been employed to load various agents, i.e. therapeutic, bio imaging, etc., to nanodimensional calcium orthophosphates (mainly, apatites)[708]. In summary, these strategies can be broadly categorized into two main approaches. One approach is to load these agents during the synthesis - so called in situ loading. This is done by adding the desired agent(s) to the reaction mixture before the formation of a nanodimensional calcium orthophosphate is completed. The second approach is to load the agent(s) only after a nanodimensional calcium orthophosphate has been fully synthesized or, in other words, after the synthesis process - so called ex situ loading. This is mainly done through surface adsorption where the agents are adsorbed onto the surfaces of pre-synthesized nanodimensional particles[709]. Therefore, due to established biocompatibility, ease of handling and notorious adsorption affinity, nano-sized calcium orthophosphates have been applied as non-viral carriers for drug delivery and gene therapy[133, 203, 289, 318, 325, 511, 542, 559, 600d, 695, 710-721]. After loading with genes or drugs, nanodimensional calcium orthophosphates provide a protective environment that shields them from degradation while providing a convenient pathway for cell membrane penetration and controlled release of the genes or drugs[512]. The experimental results proved that nanodimensional calcium orthophosphates possessed a higher penetration rate into cell membranes and their transfection efficiency could be 25 -fold higher than that of the micron-sized particles. Furthermore, due to the larger specific surface areas, nanodimensional calcium orthophosphates can hold larger load amounts of drugs than coarser particles. These results indicate the po- 
tential of nano-sized calcium orthophosphates in gene delivery and as drug carriers[512, 722-725]. Since a charge of the particles influences their ability to pass through the cellular membrane and a positive charge is beneficial, positively charged nano-sized particles of calcium orthophosphate/polymer biocomposites were successfully applied for photodynamic therapy[726]. Furthermore, nanodimensional calcium orthophosphates can be stably loaded with radioisotopes[318, 727].

A transfer of functional foreign nucleic acids (DNA or RNA) into nuclei of living cells (transfection) with the aim of repairing missing cell function and to provide means to enhance or silence gene expression is currently used extensively in the laboratory and is fast becoming a therapeutic reality. As nucleic acids alone are unable to penetrate the cell wall, efficient carriers are required[728, 729]. Nanodimensional calcium orthophosphates can be represented as a unique class of the non-viral vectors, which can serve as efficient and alternative DNA carriers for targeted delivery of genes[289, 696, 697, 708, 714, 730-742] and cells[567, 743-749]. The standard transfection method using calcium orthophosphates, first introduced by Graham and van der Eb in 1973[748], is still used in biochemistry. It involves a straightforward in situ precipitation of calcium orthophosphate/DNA aggregates. A similar experimental approach is used to load calcium orthophosphates by drugs[719]. Interestingly, but the transfection efficiency of nanodimensional calcium orthophosphates were found to depend on $\mathrm{Ca} / \mathrm{P}$ ionic ratio: namely, calcium orthophosphates with $\mathrm{Ca} / \mathrm{P}=$ 1.30 ratio exhibited a fourfold increase in the transfection efficiency over the ones with $\mathrm{Ca} / \mathrm{P}=1.65$ ratio composition[289]. This data emphasizes the importance of understanding the interaction between calcium orthophosphates and DNA to optimize the DNA uptake and its channeling to the nucleus of the cell. Besides, it has been demonstrated that surface modified particles of nano-sized calcium orthophosphates can be used in vivo to target genes specifically to a liver[750]. Attachment of galactose moiety onto the particle surface has increased the targetability of the nano-sized particles. Furthermore, this surface modification makes it possible for site-specific gene delivery[750, 751]. Assemblies of block-copolymer/nano-sized calcium orthophosphate were prepared and used for cell transfection; a high biocompatibility of this system was emphasized[752]. Structures that are even more complex are known as well[753-755]. A schematic drawing of a functionalized nano-sized particle suitable for both imaging and drug delivery purposes is shown in Fig. 10[756]. Furthermore, vaccination to protect against human infectious diseases may be enhanced by using adjuvants that can selectively stimulate immuno-regulatory responses and nano-sized particles of calcium orthophosphates were found to be suitable for such purposes[757, 758].

In all these new applications of nano-sized calcium orthophosphates, knowledge of the exact internalization pathway into the cells represents the first necessary step towards the detailed investigation and optimization of the functional mechanism. The main groups of pathways into the cell are diffusion, passive and active transport, as well as a number of endocytic mechanisms[695]. Bigger particles of far above $10 \mathrm{~nm}$ are internalized by eukaryotic cells through the endocytic pathways including phagocytosis, macropinocytosis, clathrin-mediated endocytosis and non-clathrin-mediated endocytosis such as internalization via caveolae. To date, the exact internalization pathway of nano-sized calcium orthophosphates into cells has not been determined and there are many questions that remain to be answered, particularly, concerning possible interactions of calcium orthophosphates with nucleic acids. Furthermore, the mechanisms of cellular uptake and transport to the cell nucleus of calcium orthophosphate/DNA nanodimensional complexes remain unclear either. Therefore, there is a need to conduct a focused study on the synthesis of various forms of nano-sized calcium orthophosphates that could elucidate the mechanisms of binding, transport and release of attached plasmid DNA for understanding the gene delivery method. Research is also warranted to understand the tracking of DNA intracellularly[745] to understand the release and transport of DNA into cellular nuclei.

Concerning the healing abilities of nano-sized calcium orthophosphates, an in vitro inhibiting effect and even apoptotic action of un-functionalized nano-sized HA of about $50 \mathrm{~nm}$ diameter on a hepatoma cell line in the concentration range of $50-200 \mathrm{mg} / 1$ was reported[759]. A similar inhibiting effect was discovered for discrete nano-sized particles of HA, which appeared to cause apoptosis of leukemia P388 cells[119] and rat macrophages[760]. This effect might be due to a harmful increase in the intracellular calcium concentration. However, the correlation between the particle dimensions and the apoptotic action of nano-sized calcium orthophosphates appears not to be straightforward. Namely, the apoptosis efficacy of nanodimensional particles of HA of various sizes was found to decrease in the order of $45 \mathrm{~nm}>26 \mathrm{~nm}>78 \mathrm{~nm}>175$ $\mathrm{nm}[761]$.

Hollow nano-sized spheres are extremely attractive constructions because they can greatly enhance the load quantity. Though these novel biomaterials can improve the total intake of drugs, they also bring new problems, e.g., uncontrolled release kinetics and unreasonable metabolism pathway of the carriers[762]. In order to solve these problems, calcium orthophosphates were selected as suitable biomaterials to construct nanodimensional spheres hollow inside[198, 541, $542,717,763,764]$. Such spheres with dimensions ranged from 110 to $180 \mathrm{~nm}$ were synthesized by an ultrasonic-assisted wet chemical reaction in the presence of a modifier[765]. In addition, they might be prepared through emulsions[766]. Transmission electron microscopy investigations revealed that the uniform nanodimensional spheres were formed and they were well dispersed in the solutions. Thickness of the shells was about $45 \mathrm{~nm}$; thus, they always had $\sim 60 \mathrm{~nm}$-sized internal cavities, which could be used to load drugs. The hollow spheres appeared to be stable in both air and aqueous solutions without ultrasonic application. 
However, when an ultrasonic treatment $(40 \mathrm{kHz}, 150 \mathrm{~W})$ was applied, the hollow structures deconstructed to form pin-like nano-sized crystals of calcium orthophosphates[765]. During this transformation, the encapsulated drugs and chemicals are released[559, 765]. Different from a free and slow diffusion of encapsulated drugs from the cavity through the shells[199], the release kinetics in this system was triggered and controlled by ultrasound. Furthermore, the power density of ultrasound can conveniently regulate the release dynamics. Besides, the formed pin-like nano-sized crystals of calcium orthophosphates had similar behavior to the biological apatite of bones. Thus, a combination of the hollow calcium orthophosphate nanospheres and ultrasonic treatment might provide a good system for drug delivery and release[765].

\section{Non-Biomedical Applications of the Nanodimensional and Nanocrystal- line Calcium Orthophosphates}

Just a few publications are available on non-biomedical applications of the nanodimensional and nanocrystalline calcium orthophosphates. For example, nano-sized particles of calcium orthophosphates with a mean size of $150 \pm 20$ $\mathrm{nm}$ filled with a solution containing luminol, haematin and fluorescein were found to improve the ease and accuracy of $\mathrm{H}_{2} \mathrm{O}_{2}$ sensing[767]. Besides, nanodimensional HA particles were tested as a component of a green slow-release fertilizer composition[768]. Also, addition of nanodimensional HA remarkably inhibits desorption of heavy metals from soils, which increases their geochemical stability in metal contaminated soils[769]. Furthermore, nanodimensional HA was found to hold a great potential to remove cationic heavy metal species from industrial wastewater[770-774]. Finally yet importantly, nanodimensional and nanocrystalline calcium orthophosphates occasionally might possess a catalytic activity[ $[775,776]$.

\section{Summary and Perspectives}

As the basic building blocks of calcified tissues of mammals, nano-sized calcium orthophosphates of the apatitic structure play an important role in the construction of these biominerals. Therefore, they appear to be almost the ideal biomaterials due to their good biocompatibility and bioresorbability. Even more enhanced applications are expected in drug delivery systems[777]. However, there is still an unanswered question concerning their structure: whether the majority of nanodimensional calcium orthophosphates appear to be almost amorphous (according to numerous results of X-ray diffraction studies) due to their nanoscopic dimensions of well-crystallized structures or due to a really amorphous (i.e., retaining only a short-range order at the scale of few atomic neighbors) matter? A good attempt to discuss this topic is available in literature[778], where the interested readers are referred to.

In future, an ability to functionalize surfaces with different molecules of varying nature and dimensions by means of their attachment to cells will enable them to act selectively on biological species such as proteins and peptides. The capability of synthesizing and processing of nanodimensional and nanocrystalline calcium orthophosphates with the controlled structures and topographies, in attempts to simulate the basic units of bones and teeth, will provide a possibility of designing novel proactive bioceramics necessary for enhanced repair efficacy. The various primary positive results on the biocompatibility and biomimicity of novel nanostructured bioceramics merit further confirmations. Namely, much work remains to be undertaken to address the following key challenges and critical issues of nanodimensional and nanocrystalline calcium orthophosphates[779]:

- Consistency of the processing technologies;

- Optimization the structure and properties mimicking bones;

- Matching the strength of nanodimensional and nanocrystalline constructs with those of bones in order to provide a uniform distribution of stresses (load sharing);

- Optimizing bioresorption without comprising the mechanical properties;

- Assessing the inflammatory response to validate their biosafety.

Furthermore, substantial research efforts are required in the analysis of cells and their different behaviors with regard to their interactions with nanodimensional and nanocrystalline calcium orthophosphates[779]. An important but still unsolved question is how the cells can recognize the particle dimensions and crystallinity of nano-sized calcium orthophosphates. What is the signal for nanodimensional biomaterials to promote cell proliferation and differentiation and how can the pathways be found out? According to the experiments results on transfection, nano-sized particles can enter into cells readily but many details of this process remain unclear. Namely, the pathways for the nano-sized particles to enter the cells through the membranes should be revealed[780]. A greater influence of the hydrated surface layer with labile ionic species of smaller particles and crystals (see section 5. The structure of the nanodimensional and nanocrystalline apatites for the details) might be another possible option, to be confirmed experimentally. Then, it is important to examine the metabolism process of nano-sized calcium orthophosphates inside cells, so the existing forms of these particles during the biological processes could be understood. Further, a critical step will be the investigation of possible changes of gene or protein expression in the absence and presence of various nano-sized calcium orthophosphates, which may directly be related to cell proliferation and differentiation[13].

Understanding of the interactions between nano-sized particles and living cells is still a great challenge[779]. 
Namely, elucidating mechanisms, by which cells internalize and process nanodimensional particles, is of great importance for understanding their potential toxicity and for improving the targeted delivery of nanodimensional particles for biomedical applications. Already, some data are available that clathrin-mediated endocytosis might be responsible for the uptake of nano-sized HA[695]. In another study, nanodimensional particles of HA were sequestered within a specialized membrane-bound surface-connected compartment, directly connected to the extracellular space[781]. Future studies will focus on (1) the detailed interfacial structure of nanodimensional calcium orthophosphates and the specific adsorption of proteins or other matrices; (2) an uptake processes of the nano-sized particles by cells; (3) metabolism of nano-sized calcium orthophosphates inside the cells and its possible interference with physiological reactions. Another important topic is a biological security of nano-sized particles in general[144, 145, 782, 783] and those of calcium orthophosphates particularly[178, 376, 784]. For example, toxicity of nano-sized HA was found to vary considerably, which was related to their physico-chemical properties. Furthermore, cell death correlate strongly with the load of nano-sized particles. Namely, the biological effects of rod-shaped apatite, $50-80 \mathrm{~nm}$ in length, were investigated on human monocyte-derived macrophages[178]. High concentrations of apatite (200 nano-sized particles per cell) were incubated for 24 hours with the macrophages in both serum and serum-free conditions. This induced high levels of lactate dehydrogenase release, which is an indicator of cellular damage. However, lower concentrations ( 20 and 2 nano-sized particles per cell) of the rod-shaped apatite did not affect the cell viability similarly to the control group that did not contain nano-sized apatite[178]. Similarly, intracellular dissolution of nano-sized HA as a function of time suggests that increased cytoplasmic calcium load is likely to be the cause of cell death[784]. Furthermore, nano-sized calcium orthophosphates were found to interfere with cell cycle of cultured human ovarian granulosa cells thus increasing cell apoptosis[785]. That pilot study suggested that effects of nano-sized particles on ovarian function should be extensively investigated. Additional examples of cytotoxicity experiments of nanodimensional calcium orthophosphates are well described in a recent review[709].

To finalize this topic, one should stress that, in vivo evaluation of nano-sized particles includes the particle's activity, biodistribution and pharmacokinetic properties[786]. Ultimately, all these properties are determined by dimensions, surface charge, morphology and surface chemistry. Furthermore, nano-sized particles penetrate and leave biological organisms more readily using a number of pathways. Namely, very small $(<10 \mathrm{~nm})$ particles are generally eliminated from the body via renal clearance, i.e. being filtered through the kidneys and eliminated through urine, while nano-sized particles of larger dimensions are phagocytized by tissue macrophages of the reticuloendothelial system in the liver and spleen[713]. For example, intrave- nously administered nanodimensional $(\sim 40 \mathrm{~nm}$ and $\sim 200$ $\mathrm{nm}$ ) rod-shaped crystals of apatite showed clearance from the bloodstream within two hours, with $\sim 90 \%$ of them being cleared in the first 10 minutes post injection; those nanodimensional crystals of apatite were observed primarily in the liver with a minority seen in the spleen[318]. These results indicate that bloodstream clearance occurs rapidly for a wide range of nanodimensional sizes. The accumulation of nanodimensional $(50-100 \mathrm{~nm}$ in size) apatite in the liver was also noted in another study[510].

Thus, understanding the biological influence of nano-sized and nanocrystalline calcium orthophosphates is essential for a future development of bionanotechnology[787]. This interdisciplinary approach is very complicated and the effective collaboration of scientists from different disciplines is the key[13].

\section{Conclusions}

With a high surface area, un-agglomerated nanodimensional and nanocrystalline bioceramic particles are of interest for many applications including injectable or controlled setting bone cements, high strength porous or non-porous synthetic bone grafts and the reinforcing phase in biocomposites that attempt to mimic both the complex structure and superior mechanical properties of bone. Therefore, nano-sized and nanocrystalline calcium orthophosphates have already gained much regard in the biomedical field due to their superior biocompatibility and biomechanical properties. This is easily seen from a permanent increasing of the amount of publications. At present, apatites (HA and CDHA) and $\beta$-TCP are the major calcium orthophosphates used in clinics. Currently, nanodimensional apatites are used primarily as bioactive coatings on bioinert materials like titanium and its alloys, in bone tissue repairs and implants, as well as for drug delivery purposes. The nano-sized $\beta$-TCP exhibits a significant biological affinity and activity and responds very well to the physiological environment. A lot of research is expected for much enhanced applications of the nanodimensional and nanocrystalline calcium orthophosphates for both drug delivery systems and as resorbable scaffolds that can be replaced by the endogenous hard tissues with the passage of time[147, 787].

Although the nanostructured biomaterials may have many potential advantages in the context of promoting bone cell responses [534-536, 677], it is important to remember that studies on nanophase materials have only just begun; there are still many other issues regarding human health that must be answered. Since particles of very low size have higher reactivity and effectiveness, a rapid technical development of nanometer-scaled particles in the biomedical field leads to concerns regarding the unknown risks of such materials[782, 783]. These nano-sized particles might induce inflammatory reactions, cytotoxicity, oxidative stresses or thrombogenesis when injected for drug delivery purposes. Namely, nano-sized particles may enter the human body through 
pores and may accumulate in the cells of the respiratory or other organ systems (when becoming dislodged through wear debris) and the health effects are yet to be largely known. This could happen during commercial-scale processing of the nano-sized particles as well as using these materials as implants[790]. Besides, nano-sized particles might be the objects whose existence has not been assumed by living body defense system[18, 144, 145]. Up to now, only a small number of short-term and small-scale health effects of single nanodimensional materials have been examined in toxicological studies, usually of the lungs[783]. Therefore, prior to clinical applications, any toxicity concerns of the nanophase materials[791-796] need to be overcome.

In summary, despite the challenges that lie ahead, significant evidences now exist elucidating that nanophase biomaterials represent an important growing area of research that may improve bonding between the implants and the surrounding tissues. It has proven to be a versatile approach that can increase bone cell functions on a wide range of orthopedic implant chemistries. Even if the nanodimensional and nanocrystalline calcium orthophosphates do not provide the ultimate answer for increasing bone cell responses (due to some potential problems as mentioned above), researchers have learned a tremendous amount of information concerning bone cell recognition with nanostructured surfaces that will most certainly aid in improving orthopedic implant efficacy[144, 145].

\section{Post-Conclusion Remarks}

According to Prof. D. F. Williams[115], the term "nanomaterial" should not exist because it is senseless (see section 2. General information on "nano"). Following this logic, the term "nanoapatite" is senseless as well. However, it is presented in the titles of several publications, namely Refs.[606, $629,653,667]$. In a slightly modified form, the term "nano-apatite" is presented in the titles of several other publications, namely Refs.[89, 100, 226, 511, 631, 735, 789]. Furthermore, similar terms "nano-HA" $[103,575,608,659$, 681, 692], "nano-hydroxyapatite" $[42,87,91,92,96,97,102$, $119,190,191,294,295,314,338,451,459,486,492,578$, $583,606,627,628,641,664,666,677,682,685,687,693$, $698,701,703,705,770,773]$, nano-fluorapatite[104, 684] and "nanohydroxyapatite" $[86,93,99,162,201,239,240$, $242,246,253,274,320,329,362,462,576,656,664,764]$ are presented in the titles of still other publications. Presumably, it is wiser not to use these terms anymore.

\section{REFERENCES}

[1] Mann, S., Biomineralization principles and concepts in bioinorganic materials chemistry. Oxford University Press: New York, USA, 2001; pp. 216.
[2] Lowenstam, H. A., and Weiner, S., On biomineralization. Oxford University Press: New York, USA, 1989; pp. 324.

[3] Vallet-Regí, M., and González-Calbet, J. M., Calcium phosphates as substitution of bone tissues. Prog. Solid State Chem. 2004, 32, 1-31.

[4] Weiner, S., and Addadi, L., Design strategies in mineralized biological materials. J. Mater. Chem. 1997, 7, 689-702.

[5] Weiner, S., and Wagner, H. D., The material bone: structure-mechanical function relations. Ann. Rev. Mater. Sci. 1998, 28, 271-298.

[6] Pasteris, J. D., Wopenka, B., and Valsami-Jones, E., Bone and tooth mineralization: why apatite? Elements 2008, 4, 97-104.

[7] Giachelli, C. M. Ectopic calcification: gathering hard facts about soft tissue mineralization. Am. J. Pathol. 1999, 154, 671-675.

[8] Kirsch, T. Determinants of pathological mineralization: crystal deposition diseases. Curr. Opin. Rheumatol. 2006, 18, 174-180.

[9] Christian, R. C., and Fitzpatrick, L. A., Vascular calcification. Curr. Opin. Nephrol. Hypertens. 1999, 8, 443-448.

[10] Boskey, A. Bone mineral crystal size. Osteoporosis Int. 2003, 14, Suppl. 5, S16-S20; discussion S20-S21.

[11] Alivisatos, A. P. Enhanced naturally aligned nanocrystals. Science 2000, 289, 736-737.

[12] Narayan, R. J., Kumta, P. N., Sfeir, C., Lee, D. H., Choi, D., and Olton, D., Nanostructured ceramics in medical devices: applications and prospects. JOM 2004, 56, 38-43.

[13] Cai, Y., and Tang, R., Calcium phosphate nanoparticles in biomineralization and biomaterials. J. Mater. Chem. 2008, $18,3775-3787$

[14] Ginebra, M. P., Driessens, F. C. M., and Planell, J. A., Effect of the particle size on the micro and nanostructural features of a calcium phosphate cement: a kinetic analysis. Biomaterials 2004, 25, 3453-3462.

[15] Nanotechnology is an application of science and engineering at the nanoscale.

[16] Karch, J., Birringer, R., and Gleiter, H., Ceramics ductile at low temperature. Nature 1987, 330, 556-558.

[17] Webster, T. J. Nanophase ceramics: the future of orthopedic and dental implant material. In: Nanostructured materials. Ying, J. Y. Ed., Academic Press, New York, USA, 2001; pp. 125-166.

[18] Tasker, L. H., Sparey-Taylor, G. J., and Nokes, L. D., Applications of nanotechnology in orthopaedics. Clin. Orthop. Relat. Res. 2007, 456, 243-249.

[19] Banfield, J. F., Welch, S. A., Zhang, H., Ebert, T. T., and Penn, R. L., Aggregation-based crystal growth and microstructure development in natural iron oxyhydroxide biomineralization products. Science 2000, 289, 751-754.

[20] Cölfen, H. Bio-inspired mineralization using hydrophilic polymers. Top. Curr. Chem. 2007, 271, 1-77.

[21] Oaki, Y., and Imai, H., Nanoengineering in echinoderms: the 
emergence of morphology from nanobricks. Small 2005, 2, 66-70.

[22] Lee, S. H., and Shin, H., Matrices and scaffolds for delivery of bioactive molecules in bone and cartilage tissue engineering. Adv. Drug Delivery Rev. 2007, 59, 339-359.

[23] Ben-Nissan, B. Nanoceramics in biomedical applications. MRS Bulletin 2004, 29, 28-32.

[24] Rehman, I. Nano bioceramics for biomedical and other applications. Mater. Technol. 2004, 19, 224-233.

[25] Driessens, F. C. M., Boltong, M. G., de Maeyer, E. A. P., Wenz, R., Nies, B., and Planell, J. A., The $\mathrm{Ca} / \mathrm{P}$ range of nanoapatitic calcium phosphate cements. Biomaterials 2002, 23, 4011-4017.

[26] Doat, A., Fanjul, M., Pellé, F. Hollande, E., and Lebugle, A., Europium-doped bioapatite: a new photostable biological probe, internalizable by human cells. Biomaterials 2003, 24, $3365-3371$.

[27] Doat, A., Pellé, F., Gardant, N., and Lebugle, A., Synthesis of luminescent bioapatite nanoparticles for utilization as a biological probe. J. Solid State Chem. 2004, 177, 1179-1187.

[28] Lebugle, A., Pellé, F., Charvillat, C., Rousselot, I., and Chane-Ching, J. Y., Colloidal and monocrystalline $\mathrm{Ln}^{3+}$ doped apatite calcium phosphate as biocompatible fluorescent probes. Chem. Commun. 2006, 606-608

[29] Mondejar, S. P., Kovtun, A., and Epple, M., Lanthanide-doped calcium phosphate nanoparticles with high internal crystallinity and with a shell of DNA as fluorescent probes in cell experiments. J. Mater. Chem. 2007, 17, 4153-4159.

[30] Kalita, S. J., and Bhatt, H. A., Nanocrystalline hydroxyapatite doped with magnesium and zinc: synthesis and characterization. Mater. Sci. Eng. C 2007, 27, 837-848.

[31] Huang, J., Jayasinghe, S. N., Best, S. M., Edirisinghe, M. J., Brooks, R. A., Rushton, N., and Bonfield, W., Novel deposition of nanosized silicon substituted hydroxyapatite by electrostatic spraying. J. Mater. Sci. Mater. Med. 2005, 16, $1137-1142$.

[32] Pon-On, W., Meejoo, S., and Tang, I. M., Incorporation of iron into nano hydroxyapatite particles synthesized by the microwave process. Int. J. Nanosci. 2007, 6, 9-16.

[33] Predoi, D., Barsan, M., Andronescu, E., Vatasescu-Balcan, R. A., and Costache, M., Hydroxyapatite - iron oxide bioceramic prepared using nano-size powders. J. Optoelectronics Adv. Mater. 2007, 9, 3609-3613.

[34] Bakunova, N. V., Fomin, A. S., Fadeeva, I. V., Barinov, S. M., and Shvorneva, L. I., Silicon-containing hydroxylapatite nanopowders. Russ. J. Inorg. Chem. 2007, 52, 1492-1497.

[35] Miao, S., Weng, W., Cheng, K., Du, P., Shen, G., and Han, G., Preparation of nano-sized strontium containing tricalcium phosphate particles. Key Eng. Mater. 2007, 330-332, 263-266.

[36] Liu, Y., Zhou, R., Mo, A., Chen, Z., and Wu, H., Synthesis and characterization of yttrium/hydroxyapatite nanoparticles. Key Eng. Mater. 2007, 330-332, 295-298.

[37] Wu, H. C., Wang, T. W., Sun, J. S., Wang, W. H., and Lin, F.
H., A novel biomagnetic nanoparticle based on hydroxyapatite. Nanotechnology 2007, 18, 165601 (9 pages).

[38] Rameshbabu, N., Kumar, T. S. S., Prabhakar, T. G., Sastry, V. S., Murty, K. V. G. K., and Rao, K. P., Antibacterial nanosized silver substituted hydroxyapatite: synthesis and characterization. J. Biomed. Mater. Res. A 2007, 80A, 581-591.

[39] Fujii, E., Ohkubo, M., Tsuru, K., Hayakawa, S., Osaka, A., Kawabata, K., Bonhomme, C., and Babonneau, F., Selective protein adsorption property and characterization of nano-crystalline zinc-containing hydroxyapatite. Acta Biomater. 2006, 2, 69-74.

[40] Chowdhury, E. H., and Akaike, T., Fibronectin-coated nano-precipitates of calcium-magnesium phosphate for integrin-targeted gene delivery. J. Control. Release 2006, 116, e68-e69.

[41] Low, H. R., Phonthammachai, N., Maignan, A., Stewart, G. A., Bastow, T. J., Ma, L. L., and White, T. J., The crystal chemistry of ferric oxyhydroxyapatite. Inorg. Chem. 2008, 47, 11774-11782.

[42] Zhang, S. M., Hu, W., Zhou, W., Li, J., Liu, Y. H., and Qiu, Z. Y., Dialysis preparation of zinc-substituted nano-hydroxyapatite and its characterization. Key Eng. Mater. 2007, 330-332, 219-222.

[43] Pon-On, W., Meejoo, S., and Tang, I. M., Substitution of manganese and iron into hydroxyapatite: core/shell nanoparticles. Mater. Res. Bull. 2008, 43, 2137-2144.

[44] Zou, C., Weng, W., Cheng, K., Du, P., Shen, G., and Han, G., Preparation of nanosized $\beta$-tricalcium phosphate particles with Zn substitution. J. Mater. Sci. Mater. Med. 2008, 19, 1133-1136.

[45] Hwang, K. S., Hwangbo, S., and Kim, J. T., Silver-doped calcium phosphate nanopowders prepared by electrostatic spraying. J. Nanoparticle Res. 2008, 10, 1337-1341.

[46] Lee, D., Sfeir, C., and Kumta, P. N., Novel in-situ synthesis and characterization of nanostructured magnesium substituted $\beta$-tricalcium phosphate ( $\beta$-TCMP). Mater. Sci. Eng. C 2009, 29, 69-77.

[47] Petchsang, N., Pon-On, W., Hodak, J. H., and Tang, I. M., Magnetic properties of Co-ferrite-doped hydroxyapatite nanoparticles having a core/shell structure. J. Magnetism Magnetic Mater. 2009, 321, 1990-1995.

[48] Hou, C. H., Hou, S. M., Hsueh, Y. S., Lin, J., Wu, H. C., and Lin, F. H., The in vivo performance of biomagnetic hydroxyapatite nanoparticles in cancer hyperthermia therapy. Biomaterials 2009, 30, 3956-3960.

[49] Chen, F., Huang, P., Zhu, Y. J., Wu, J., Zhang, C. L., and Cui, D. X., The photoluminescence, drug delivery and imaging properties of multifunctional $\mathrm{Eu}^{3+} / \mathrm{Gd}^{3+}$ dual-doped hydroxyapatite nanorods. Biomaterials 2011, 32, 9031-9039.

[50] Cacciotti, I., Bianco, A., Lombardi, M., and Montanaro, L., Mg-substituted hydroxyapatite nanopowders: synthesis, thermal stability and sintering behaviour. J. Eur. Ceram. Soc. 2009, 29, 2969-2978.

[51] Bianco, A., Cacciotti, I., Lombardi, M., and Montanaro, L., Si-substituted hydroxyapatite nanopowders: synthesis, thermal stability and sinterability. Mater. Res. Bull. 2009, 44, 345-354. 
[52] Capuccini, C., Torricelli, P., Boanini, E., Gazzano, M., Giardino, R., and Bigi, A., Interaction of Sr-doped hydroxyapatite nanocrystals with osteoclast and osteoblast-like cells. J. Biomed. Mater. Res. A 2009, 89A, 594-600.

[53] Jiang, H., Li, Y., Zuo, Y., Yang, W., Zhang, L., Li, J., Wang, L., Zou, Q., Cheng, L., and Li, J., Physical and chemical properties of superparamagnetic Fe-incorporated nano hydroxyapatite. J. Nanosci. Nanotechnol. 2009, 9, 6844-6850.

[54] Al-Kattan, A., Dufour, P., Dexpert-Ghys, J., and Drouet, C., Preparation and physicochemical characteristics of luminescent apatite-based colloids. J. Phys. Chem. C 2010, 114, 2918-2924

[55] Hou, C. H., Chen, C. W., Hou, S. M., Li, Y. T., and Lin, F. $\mathrm{H}$., The fabrication and characterization of dicalcium phosphate dihydrate-modified magnetic nanoparticles and their performance in hyperthermia processes in vitro. Biomaterials 2009, 30, 4700-4707.

[56] Hanifi, A., Fathi, M. H., Sadeghi, H. M. M., and Varshosaz, J., $\mathrm{Mg}^{2+}$ substituted calcium phosphate nano particles synthesis for non viral gene delivery application. J. Mater. Sci. Mater. Med. 2010, 21, 2393-2401.

[57] Stojanović, Z., Veselinović, L., Marković, S., Ignjatović, N., and Uskoković, D., Hydrothermal synthesis of nanosize pure and cobalt-exchanged hydroxyapatite. Mater. Manuf. Process 2009, 24, 1096-1103.

[58] Veselinović, L., Karanović, L., Stojanović, Z., Bračko, I., Marković, S., Ignjatović, N., and Uskoković, D., Crystal structure of cobalt-substituted calcium hydroxyapatite nanopowders prepared by hydrothermal processing. J. Appl. Crystallogr. 2010, 43, 320-327.

[59] Evis, Z., and Webster, T. J., Nanosize hydroxyapatite: doping with various ions. Adv. Appl. Ceram. 2011, 110, 311-320.

[60] Al-Kattan, A., Girod-Fullana, S., Charvillat, C., Ternet-Fontebasso, H., Dufour, P., Dexpert-Ghys, J., Santran, V., Bordère, J., Pipy, B., Bernad, J., and Drouet, C., Biomimetic nanocrystalline apatites: emerging perspectives in cancer diagnosis and treatment. Int. J. Pharm. 2012, 423, 26-36.

[61] Kaflak, A., and Kolodziejski, W., Complementary information on water and hydroxyl groups in nanocrystalline carbonated hydroxyapatites from TGA, NMR and IR measurements. J. Mol. Struct. 2011, 990, 263-270.

[62] Kaflak, A., Ślósarczyk, A., and Kolodziejski, W., A comparative study of carbonate bands from nanocrystalline carbonated hydroxyapatites using FT-IR spectroscopy in the transmission and photoacoustic modes. J. Mol. Struct. 2011, $997,7-14$

[63] Li, Y., Widodo, J., Lim, S., and Ooi, C. P., Synthesis and cytocompatibility of manganese (II) and iron (III) substituted hydroxyapatite nanoparticles. J. Mater. Sci. 2012, 47, 754-763.

[64] Li, W., and Gao, L., Fabrication of Hap- $\mathrm{ZrO}_{2}$ (3Y) nano-composite by SPS. Biomaterials 2003, 24, 937-940.

[65] Wang, L., Nemoto, R., and Senna, M., Microstructure and chemical states of hydroxyapatite/silk fibroin nanocomposites synthesized via a wet-mechanochemical route. J. Na- nopart. Res. 2002, 4, 535-540.

[66] Nemoto, R., Wang, L., Ikoma, T., Tanaka, J., and Senna, M., Preferential alignment of hydroxyapatite crystallites in nanocomposites with chemically disintegrated silk fibroin. J. Nanopart. Res. 2004, 6, 259-265.

[67] Fang, L. M., Leng, Y., and Gao, P., Processing and mechanical properties of HA/UHMWPE nanocomposites. Biomaterials 2006, 27, 3701-3707.

[68] [Sugawara, A., Yamane, S., and Akiyoshi, K., Nanogel-templated mineralization: polymer-calcium phosphate hybrid nanomaterials. Macromol. Rapid Commun. 2006, 27, 441-446.

[69] Pushpakanth, S., Srinivasan, B., Sreedhar, B., and Sastry, T. P., An in situ approach to prepare nanorods of titania - hydroxyapatite $\left(\mathrm{TiO}_{2}-\mathrm{HAp}\right)$ nanocomposite by microwave hydrothermal technique. Mater. Chem. Phys. 2008, 107, 492-498.

[70] Chang, M. C., Ko, C. C., and Douglas, W. H., Preparation of hydroxyapatite-gelatin nanocomposite. Biomaterials 2003, $24,2853-2862$

[71] Hao, J., Liu, Y., Zhou, S., Li, Z., and Deng, X., Investigation of nanocomposites based on semi-interpenetrating network

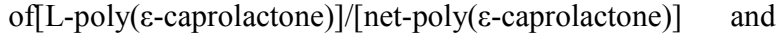
hydroxyapatite nanocrystals. Biomaterials 2003, 24, 1531-1539.

[72] Deng, X. M., Hao, J. Y., and Wang, C. S., Preparation and mechanical properties of nanocomposites of poly(D,L-lactide) with $\mathrm{Ca}$-deficient hydroxyapatite nanocrystals. Biomaterials 2001, 22, 2867-2873.

[73] Hong, Z., Zhang, P., He, C., Qiu, X., Liu, A., Chen, L., Chena, X., and Jing, X., Nanocomposite of poly(L-lactide) and surface grafted hydroxyapatite: mechanical properties and biocompatibility. Biomaterials 2005, 26, 6296-6304.

[74] Ramay, H. R. R., and Zhang, M., Biphasic calcium phosphate nanocomposite porous scaffolds for load-bearing bone tissue engineering. Biomaterials 2004, 25, 5171-5180.

[75] Cross, K. J., Huq, N. L., Palamara, J. E., Perich, J. W., and Reynolds, E. C., Physicochemical characterization of casein phosphopeptide - amorphous calcium phosphate nanocomplexes. J. Biol. Chem. 2005, 280, 15362-15369.

[76] Murugan, R., and Ramakrishna, S., Development of nanocomposites for bone grafting. Comp. Sci. Tech. 2005, 65, $2385-2406$

[77] Liou, S. C., Chen, S. Y., and Liu, D. M., Phase development and structural characterization of calcium phosphate ceramics - polyacrylic acid nanocomposites at room temperature in water-methanol mixtures. J. Mater. Sci. Mater. Med. 2004, $15,1261-1266$

[78] Sung, Y. M., Shin, Y. K., and Ryu, J. J., Preparation of hydroxyapatite/zirconia bioceramic nanocomposites for orthopaedic and dental prosthesis applications. Nanotechnology 2007, 18, 065602 (6 pages).

[79] Sreedhar, B., Aparna, Y., Sairam, M., and Hebalkar, N., Preparation and characterization of HAP / carboxymethyl chitosan nanocomposites. J. Appl. Polym. Sci. 2007, 105, 928-934. 
[80] Pramanik, N., Biswas, S. K., and Pramanik, P., Synthesis and characterization of hydroxyapatite/poly(vinyl alcohol phosphate) nanocomposite biomaterials. Int. J. Appl. Ceram. Technol. 2008, 5, 20-28.

[81] Jevtić, M., Radulović, A., Ignjatović, N., Mitrić, M., and Uskoković, D., Controlled assembly of poly(D,L-lactide-co-glycolide)/hydroxyapatite core-shell nanospheres under ultrasonic irradiation. Acta Biomater. 2009, 5, 208-218.

[82] Li, X., and Chang, J., Preparation of bone-like apatite - collagen nanocomposites by a biomimetic process with phosphorylated collagen. J. Biomed. Mater. Res. A 2008, 85A, 293-300.

[83] Ohsawa, H., Ito, A., Sogo, Y., Yamazaki, A., and Ohno, T., Synthesis of albumin/DCP nano-composite particles. Key Eng. Mater. 2007, 330-332, 239-242.

[84] Wilberforce, S. I., Finlayson, C. E., Best, S. M., and Cameron, R. E., The influence of the compounding process and testing conditions on the compressive mechanical properties of poly(D,L-lactide-co-glycolide)/ $\alpha$-tricalcium phosphate nanocomposites. J. Mech. Behav. Biomed. Mater. 2011, 4, 1081-1089.

[85] Wilberforce, S. I., Finlayson, C. E., Best, S. M., and Cameron, R. E., A comparative study of the thermal and dynamic mechanical behaviour of quenched and annealed bioresorbable poly-L-lactide/ $\alpha$-tricalcium phosphate nanocomposites. Acta Biomater. 2011, 7, 2176-2184.

[86] Degirmenbasi, N., Kalyon, D. M., and Birinci, E., Biocomposites of nanohydroxyapatite with collagen and poly(vinyl alcohol). Colloids Surf. B 2006, 48, 42-49.

[87] Zhang, X., Li, Y. B., Zuo, Y., Lv, G. Y; Mu, Y. H., and Li, H., Morphology, hydrogen-bonding and crystallinity of nano-hydroxyapatite/polyamide 66 biocomposites. Composites A 2007, 38, 843-848.

[88] Wei, J., Li, Y. B., and Lau, K. T., Preparation and characterization of a nano apatite/polyamide 6 bioactive composite. Composites B 2007, 38, 301-305.

[89] Wei, J., and Li, Y. B., Tissue engineering scaffold material of nano-apatite crystals and polyamide composite. Eur. Polym. J. 2004, 40, 509-515.

[90] Rauchmann, M. A., Wichelhaus, T. A., Stirnal, V., Dingeldein, E., Zichner, L., Schnettler, R., and Alt, V., Nanocrystalline hydroxyapatite and calcium sulphate as biodegradable composite carrier material for local delivery of antibiotics in bone infections. Biomaterials 2005, 26, 2677-2684.

[91] Szaraniec, B., Rosół, P., and Chłopek, J., Carbon composite material and polysulfone modified by nano-hydroxyapatite. e-Polymers 2005, no. 030.

[92] Pramanik, N., Mohapatra, S., and Pramanik, P., Processing and properties of nano-hydroxyapatite (n-HAp) / poly(ethylene-co-acrylic acid) (EAA) composite using a phosphonic acid coupling agent for orthopedic applications. J. Am. Ceram. Soc. 2007, 90, 369-375.

[93] Ren, Y. J., Sun, X. D., Cui, F. Z., Wei, Y. T., Cheng, Z. J., and Kong, X. D., Preparation and characterization of Antheraea pernyi silk fibroin based nanohydroxyapatite compo- sites. J. Bioact. Compat. Polym. 2007, 22, 465-474.

[94] Xu, H. H. K., Sun, L., Weir, M. D., Takagi, S., Chow, L. C., and Hockey, B., Effects of incorporating nanosized calcium phosphate particles on properties of whisker-reinforced dental composites. J. Biomed. Mater. Res. B (Appl. Biomater.) 2007, 81B, 116-125.

[95] Zhou, G., Li, Y., Zhang, L., Zuo, Y., and Jansen, J. A., Preparation and characterization of nano-hydroxyapatite/chitosan/konjac glucomannan composite. J. Biomed. Mater. Res. A 2007, 83A, 931-939.

[96] Liu, L., Liu, J., Wang, M., Min, S., Cai, Y., Zhu, L., and Yao, J., Preparation and characterization of nano-hydroxyapatite/silk fibroin porous scaffolds. J. Biomater. Sci. Polymer Edn. 2008, 19, 325-338.

[97] Xu, F., Li, Y. B., Deng, Y., and Xiong, J., Porous nano-hydroxyapatite/poly(vinyl alcohol) composite hydrogel as artificial cornea fringe: characterization and evaluation in vitro. J. Biomater. Sci. Polymer Edn. 2008, 19, 431-439.

[98] Huang, J., Lin, Y. W., Fu, X. W., Best, S. M., Brooks, R. A., Rushton, N., and Bonfield, W., Development of nanosized hydroxyapatite reinforced composites for tissue engineering scaffolds. J. Mater. Sci. Mater. Med. 2007, 18, 2151-2157.

[99] Yusong, P., Dangsheng, X., and Xiaolin, C., Mechanical properties of nanohydroxyapatite reinforced poly(vinyl alcohol) gel composites as biomaterial. J. Mater. Sci. 2007, 42, 5129-5134.

[100] Deng, C., Weng, J., Lu, X., Zhou, S. B., Wan, J. X., Qu, S. X., Feng, B., Li, X. H., and Cheng, Q. Y., Mechanism of ultrahigh elongation rate of poly(D,L-lactide)-matrix composite biomaterial containing nano-apatite fillers. Mater. Lett. 2008, 62, 607-610.

[101] Sundaraseelan, J., and Sastry, T. P., Fabrication of a biomimetic compound containing nano hydroxyapatite - demineralised bone matrix. J. Biomed. Nanotechnol. 2007, 3, 401-405.

[102] Teng, S., Chen, L., Guo, Y., and Shi, J., Formation of nano-hydroxyapatite in gelatin droplets and the resulting porous composite microspheres. J. Inorg. Biochem. 2007, 101, 686-691.

[103] Meng, Y. H., Tang, C. Y., Tsui, C. P., and Chen, D. Z., Fabrication and characterization of needle-like nano-HA and HA/MWNT composites. J. Mater. Sci. Mater. Med. 2008, 19, 75-81.

[104] Lin, J., Zhu, J., Gu, X., Wen, W., Li, Q., Fischer-Brandies, H., Wang, H., and Mehl, C., Effects of incorporation of nano-fluorapatite or nano-fluorohydroxyapatite on a resin-modified glass ionomer cement. Acta Biomater. 2011, 7, 1346-1353.

[105] Dorozhkin, S. V., Calcium orthophosphate-based biocomposites and hybrid biomaterials. J. Mater. Sci. 2009, 44, 2343-2387.

[106] Dorozhkin, S. V., Biocomposites and hybrid biomaterials based on calcium orthophosphates. Biomatter 2011, 1, 3-56.

[107] Williams, D. F., The relationship between biomaterials and nanotechnology. Biomaterials 2008, 29, 1737-1738.

[108] Feynman, R. P., There's plenty of room at the bottom. J. 
Microelectromechanical Systems 1992, 1, 60-66.

[109] European Commission, Scientific Committee on Emerging and Newly Identified Health Risks (SCENIHR). Opinion on "the scientific aspects of the existing and proposed definitions relating to products of nanoscience and nanotechnologies". Adopted Brussels: European Commission; 29 November 2007

[110] Moriarty, P., Nanostructured materials. Rep. Prog. Phys. 2001, 64, 297-381.

[111] Webster, T. J., and Ahn, E. S., Nanostructured biomaterials for tissue engineering bone. Adv. Biochem. Eng. Biotechnol. 2006, 103, 275-308.

[112] Streicher, R. M., Schmidt, M., and Fiorito, S., Nanosurfaces and nanostructures for artificial orthopedic implants. Nanomedicine 2007, 2, 861-874.

[113] Havancsak, K., Nanotechnology at present and its promises in the future. Mater. Sci. Forum 2003, 414-415, 85-94.

[114] Duncan, R., Nanomedicines in action. Pharm. J. 2004, 273, 485-488.

[115] Williams, D. F., On the nature of biomaterials. Biomaterials 2009, 30, 5897-5909.

[116] Liu, H., and Webster, T. J., Nanomedicine for implants: a review of studies and necessary experimental tools. Biomaterials $2007,28,354-369$.

[117] Murugan, R., and Ramakrishna, S., Bioresorbable composite bone paste using polysaccharide based nano hydroxyapatite. Biomaterials 2004, 25, 3829-3835.

[118] Murugan, R., and Ramakrishna, S., Aqueous mediated synthesis of bioresorbable nanocrystalline hydroxyapatite. J. Cryst. Growth 2005, 274, 209-213.

[119] Li, G., Huang, J., Li, Y., Zhang, R., Deng, B., Zhang, J., and Aoki, H., In vitro study on influence of a discrete nano-hydroxyapatite on leukemia P388 cell behavior. Biomed. Mater. Eng. 2007, 17, 321-327.

[120] Ganesan, K., Kovtun, A., Neumann, S., Heumann, R., and Epple, M., Calcium phosphate nanoparticles: colloidally stabilized and made fluorescent by a phosphate-functionalized porphyrin. J. Mater. Chem. 2008, 18, 3655-3661.

[121] Kim, H. W., and Kim, H. E., Nanofiber generation of hydroxyapatite and fluor-hydroxyapatite bioceramics. J. Biomed. Mater. Res. B (Appl. Biomater.) 2005, 77B, 323-328.

[122] Cihlar, J., and Castkova, K., Direct synthesis of nanocrystalline hydroxyapatite by hydrothermal hydrolysis of alkylphosphates. Monatshefte für Chemie 2002, 133, 761-771.

[123] Lak, A., Mazloumi, M., Mohajerani, M., Kajbafvala, A., Zanganeh, S., Arami, H., and Sadrnezhaad, S. K., Self-assembly of dandelion-like hydroxyapatite nanostructures via hydrothermal method. J. Am. Ceram. Soc. 2008, 91, 3292-3297.

[124] Mukesh, U., Kulkarni, V., Tushar, R., and Murthy, R. S. R., Methotrexate loaded self stabilized calcium phosphate nanoparticles: a novel inorganic carrier for intracellular drug delivery. J. Biomed. Nanotechnol. 2009, 5, 99-105.

[125] Sun, L., Chow, L. C., Frukhtbeyn, S. A., and Bonevich, J. E.,
Preparation and properties of nanoparticles of calcium phosphates with various $\mathrm{Ca} / \mathrm{P}$ ratios. J. Res. Natl. Inst. Stand. Technol. 2010, 115, 243-255.

[126] Sylvie, J., Sylvie, T. D., Pascal, P. M., Fabienne, P., Hassane, O., and Guy, C., Effect of hydroxyapatite and $\beta$-tricalcium phosphate nanoparticles on promonocytic U937 cells. J. Biomed. Nanotechnol. 2010, 6, 158-165.

[127] Sokolova, V., Knuschke, T., Kovtun, A., Buer, J., Epple, M., and Westendorf, A. M., The use of calcium phosphate nanoparticles encapsulating Toll-like receptor ligands and the antigen hemagglutinin to induce dendritic cell maturation and $\mathrm{T}$ cell activation. Biomaterials. 2010, 31, 5627-5633.

[128] Wu, H. C., Wang, T. W., Bohn, M. C., Lin. F. H., and Spector, M., Novel magnetic hydroxyapatite nanoparticles as non-viral vectors for the glial cell line-derived neurotrophic factor gene. Adv. Funct. Mater. 2010, 20, 67-77.

[129] Gergely, G., Wéber, F., Lukács, I., Illés, L., Tóth, A. L., Horváth, Z. E., Mihály, J., and Balázsi, C., Nano-hydroxyapatite preparation from biogenic raw materials. Cent. Eur. J. Chem. 2010, 8, 375-381.

[130] Ergun, C., Evis, Z., Webster, T. J., and Sahin, F. C., Synthesis and microstructural characterization of nano-size calcium phosphates with different stoichiometry. Ceram. Int. 2011, 37, 971-977.

[131] Ge, X., Leng, Y., Ren, F., and Lu, X., Integrity and zeta potential of fluoridated hydroxyapatite nanothick coatings for biomedical applications. J. Mech. Behav. Biomed. Mater. 2011, 4, 1046-1056.

[132] Wang, J., Chen, X., Yang, X., Xu, S., Zhang, X., and Gou, Z., A facile pollutant-free approach toward a series of nutritionally effective calcium phosphate nanomaterials for food and drink additives. J. Nanopart. Res. 2011, 13, 1039-1048.

[133] Sokolova, V., Knuschke, T., Buer, J., Westendorf, A. M., and Epple, M., Quantitative determination of the composition of multi-shell calcium phosphate-oligonucleotide nanoparticles and their application for the activation of dendritic cells. Acta Biomater. 2011, 7, 4029-4036.

[134] Traykova, T., Aparicio, C., Ginebra, M. P., and Planell, J. A., Bioceramics as nanomaterials. Nanomedicine 2006, 1, 91-106.

[135] Grainger, D. W., and Castner, D. G., Nanobiomaterials and nanoanalysis: opportunities for improving the science to benefit biomedical technologies. Adv. Mater. 2008, 20, 867-877.

[136] Nelson, K. G., The Kelvin equation and solubility of small particles. J. Pharmac. Sci. 1972, 61, 479-480.

[137]Fan, C., Chen, J., Chen, Y., Ji, J., and Teng, H. H., Relationship between solubility and solubility product: the roles of crystal sizes and crystallographic directions. Geochim. Cosmochim. Acta 2006, 70, 3820-3829.

[138] Sato, M., and Webster, T. J., Nanobiotechnology: implications for the future of nanotechnology in orthopedic applications. Expert Rev. Med. Dev. 2004, 1, 105-114.

[139] Hahn, H., Unique features and properties of nanostructured materials. Adv. Eng. Mater. 2003, 5, 277-284.

[140] Aronov, D., Karlov, A., and Rosenman, G., Hydroxyapatite 
nanoceramics: basic physical properties and biointerface modification. J. Eur. Ceram. Soc. 2007, 27, 4181-4186.

[141] Ramsden, J. J., and Freeman, J., The nanoscale. Nanotechnol. Percept. 2009, 5, 3-25.

[142] Rempel, A. A., Nanotechnologies. Properties and applications of nanostructured materials. Russ. Chem. Rev. 2007, $76,435-461$.

[143] Catledge, S. A., Fries, M. D., Vohra, Y. K., Lacefield, W. R., Lemons, J. E., Woodard, S., and Venugopalan, R., Nanostructured ceramics for biomedical implants. J. Nanosci. Nanotechnol. 2002, 2, 1-20.

[144] Balasundarama, G., and Webster, T. J., A perspective on nanophase materials for orthopedic implant applications. J. Mater. Chem. 2006, 16, 3737-3745.

[145] Balasundarama, G., and Webster, T. J., Nanotechnology and biomaterials for orthopedic medical applications. Nanomedicine 2006, 1, 169-176.

[146] Padilla, S., Izquierdo-Barba, I., and Vallet-Regí, M., High specific surface area in nanometric carbonated hydroxyapatite. Chem. Mater. 2008, 20, 5942-5944.

[147] Kalita, S. J., Bhardwaj, A., and Bhatt, H. A., Nanocrystalline calcium phosphate ceramics in biomedical engineering. Mater. Sci. Eng. C 2007, 27, 441-449.

[148] LeGeros, R. Z., Calcium phosphates in oral biology and medicine. Karger: Basel, Switzerland, 1991; pp. 210.

[149] Mann, S., The study of biominerals by high resolution transmission electron microscopy. Scan. Electron. Microsc. 1986, Pt. 2, 393-413.

[150] Katsura, N., Nanospace theory for biomineralization. Dent. Jpn. (Tokyo) 1990, 27, 57-63.

[151] Cuisinier, F. J. G., Voegel, J. C., Yacaman, J., and Frank, R. M., Structure of initial crystals formed during human amelogenesis. J. Cryst. Growth 1992, 116, 314-318.

[152] Cuisinier, F. J. G., Steuer, P., Senger, B., Voegel, J. C., and Frank, R. M., Human amelogenesis: high resolution electron microscopy of nanometer-sized particles. Cell Tissue Res. 1993, 273, 175-182.

[153] Brès, E. F., Moebus, G., Kleebe, H. J., Pourroy, G., Werkmann, J., and Ehret, G., High resolution electron microscopy study of amorphous calcium phosphate. J. Cryst. Growth 1993, 129, 149-162.

[154] Layrolle, P., and Lebugle, A., Characterization and reactivity of nanosized calcium phosphate prepared in anhydrous ethanol. Chem. Mater. 1994, 6, 1996-2004.

[155] Cui, F. Z., Wen, H. B., Zhang, H. B., Ma, C. L., and Li, H. D., Nanophase hydroxyapatite-like crystallites in natural ivory. J. Mater. Sci. Lett. 1994, 13, 1042-1044.

[156] Li, Y. B., de Wijn, J., Klein, C. P. A. T., de Meer, S. V., and de Groot, K., Preparation and characterization of nanograde osteoapatite-like rod crystals. J. Mater. Sci. Mater. Med. $1994,5,252-255$.

[157] Li, Y. B., de Groot, K., de Wijn, J., Klein, C. P. A. T., and de Meer, S. V., Morphology and composition of nanograde calcium phosphate needle-like crystals formed by simple hy- drothermal treatment. J. Mater. Sci. Mater. Med. 1994, 5, 326-331.

[158] Shirkhanzadeh, M., X-ray diffraction and Fourier transform infrared analysis of nanophase apatite coatings prepared by electrocrystallization. Nanostruct. Mater. 1994, 4, 677-684.

[159] Webster, T. J., Ergun, C., Doremus, R. H., Siegel, R. W., and Bizios, R., Specific proteins mediate enhanced osteoblast adhesion on nanophase ceramics. J. Biomed. Mater. Res. 2000, 51, 475-483.

[160] Chan, C. K., Kumar, T. S. S., Liao, S., Murugan, R., Ngiam, M., and Ramakrishnan, S., Biomimetic nanocomposites for bone graft applications. Nanomedicine 2006, 1, 177-188.

[161] Okada, M., Furukawa, K., Serizawa, T., Yanagisawa, Y., Tanaka, H., Kawai, T., and Furuzono, T., Interfacial interactions between calcined hydroxyapatite nanocrystals and substrates. Langmuir 2009, 25, 6300-6306.

[162] Mikołajczyk, T., Rabiej, S., and Bogun, M., Analysis of the structural parameters of polyacrylonitrile fibers containing nanohydroxyapatite. J. Appl. Polym. Sci. 2006, 101, 760-765.

[163] Wilberforce, S. I. J., Finlayson, C. E., Best, S. M., and Cameron, R. E., The influence of hydroxyapatite (HA) microparticles $(\mathrm{m})$ and nanoparticles (n) on the thermal and dynamic mechanical properties of poly-L-lactide. Polymer 2011, 52, 2883-2890.

[164] There are both nano-sized biomaterials and nanostructured biomaterials, which should be differentiated from each other. Nano-sized biomaterials refer to individual molecular level biomaterials such as single proteins (are not considered in this review), while nanostructured biomaterials refer to any biomaterials whose structure or morphology can be engineered to get features with nanometer-scale dimensions[165]. This review is limited to calcium orthophosphate-based nanostructured biomaterials only.

[165] Thomas, V., Dean, D. R., and Vohra, Y. K., Nanostructured biomaterials for regenerative medicine. Curr. Nanosci. 2006, $2,155-177$

[166] LeGeros, R. Z., Biodegradation and bioresorption of calcium phosphate ceramics. Clin. Mater. 1993, 14, 65-88.

[167] Wang, J., and Shaw, L. L., Morphology-enhanced low-temperature sintering of nanocrystalline hydroxyapatite. Adv. Mater. 2007, 19, 2364-2369.

[168] Fomin, A. S., Barinov, S. M., Ievlev, V. M., Smirnov, V. V., Mikhailov, B. P., Belonogov, E. K., and Drozdova, N. A., Nanocrystalline hydroxyapatite ceramics produced by low-temperature sintering after high-pressure treatment. Dokl. Chem. 2008, 418, 22-25.

[169] Drouet, C., Bosc, F., Banu, M., Largeot, C., Combes, C., Dechambre, G., Estournes, C., Raimbeaux, G., and Rey, C., Nanocrystalline apatites: from powders to biomaterials. Powder Technol. 2009, 190, 118-122.

[170] Ramesh, S., Tan, C. Y., Bhaduri, S. B., Teng, W. D., and Sopyan, I., Densification behaviour of nanocrystalline hydroxyapatite bioceramics. J. Mater. Process. Technol. 2008, 206, 221-230.

[171] Skorokhod, V. V., Solonin, S. M., Dubok, V. A., Kolomiets, L. L., Katashinskii, V. P., and Shinkaruk, A. V., Pressing 
and sintering of nanosized hydroxyapatite powders. Powder Metall. Metal Ceram. 2008, 47, 518-524.

[172] Sung, Y. M., Lee, J. C., and Yang, J. W., Crystallization and sintering characteristics of chemically precipitated hydroxyapatite nanopowder. J. Cryst. Growth 2004, 262, 467-472.

[173] Lin, K., Chang, J., Lu, J., Wu, W., and Zeng, Y., Properties of $\beta-\mathrm{Ca}_{3}\left(\mathrm{PO}_{4}\right)_{2}$ bioceramics prepared using nanosized powders. Ceram. Int. 2007, 33, 979-985.

[174] Tanaka, Y., Hirata, Y., and Yoshinaka, R., Synthesis and characteristics of ultra-fine hydroxyapatite particles. J. Ceram. Proc. Res. 2003, 4, 197-201.

[175] Wang, J., and Shaw, L. L., Nanocrystalline hydroxyapatite with simultaneous enhancements in hardness and toughness. Biomaterials 2009, 30, 6565-6572.

[176] Stupp, S. I., and Ciegler, G. W., Organoapatites: materials for artificial bone. I. Synthesis and microstructure. J. Biomed. Mater. Res. 1992, 26, 169-183.

[177] Webster, T. J., Ergun, C., Doremus, R. H., Siegel, R. W., and Bizios, R., Enhanced osteoclast-like cell functions on nanophase ceramics. Biomaterials 2001, 22, 1327-1333.

[178] Huang, J., Best, S. M., Bonfield, W., Brooks, R. A., Rushton, N., Jayasinghe, S. N., and Edirisinghe, M. J., In vitro assessment of the biological response to nanosized hydroxyapatite. J. Mater. Sci. Mater. Med. 2004, 15, 441-445.

[179] Kim, H. W., Kim, H. E., and Salih, V., Stimulation of osteoblast responses to biomimetic nanocomposites of gelatin-hydroxyapatite for tissue engineering scaffolds. Biomaterials $2005,26,5221-5230$.

[180] Webster, T. J., Siegel, R. W., and Bizios, R., Osteoblast adhesion on nanophase ceramics. Biomaterials 1999, 20, 1221-1227.

[181] Webster, T. J., Ergun, C., Doremus, R. H., Siegel, R. W., and Bizios, R., Enhanced functions of osteoblast on nanophase ceramics. Biomaterials 2000, 21, 1803-1810.

[182] Smith, I. O., McCabe, L. R., and Baumann, M. J., MC3T3-E1 osteoblast attachment and proliferation on porous hydroxyapatite scaffolds fabricated with nanophase powder. Int. J. Nanomed. 2006, 1, 189-194.

[183] Nelson, M., Balasundaram, G., and Webster, T. J., Increased osteoblast adhesion on nanoparticulate crystalline hydroxyapatite functionalized with KRSR. Int. J. Nanomed. 2006, 1, 339-349.

[184] Liu, H., Yazici, H., Ergun, C., Webster, T. J., and Bermek, $\mathrm{H}$., An in vitro evaluation of the $\mathrm{Ca} / \mathrm{P}$ ratio for the cytocompatibility of nano-to-micron particulate calcium phosphates for bone regeneration. Acta Biomater. 2008, 4, 1472-1479.

[185] Sato, M., Sambito, M. A., Aslani, A., Kalkhoran, N. M., Slamovich, E. B., and Webster, T. J., Increased osteoblast functions on undoped and yttrium-doped nanocrystalline hydroxyapatite coatings on titanium. Biomaterials 2006, 27, 2358-2369.

[186] Thian, E. S., Huang, J., Best, S. M. Barber, Z. H., Brooks, R. A., Rushton, N., and Bonfield, W., The response of osteoblasts to nanocrystalline silicon-substituted hydroxyapatite thin films. Biomaterials 2006, 27, 2692-2698.
[187] Palin, E., Liu, H., and Webster, T. J., Mimicking the nanofeatures of bone increases bone-forming cell adhesion and proliferation. Nanotechnology 2005, 16, 1828-1835.

[188] Sun, W., Chu, C., Wang, J., and Zhao, H., Comparison of periodontal ligament cells responses to dense and nanophase hydroxyapatite. J. Mater. Sci. Mater. Med. 2007, 18, 677-683.

[189] Ergun, C., Liu, H., Webster, T. J., Olcay, E., Yılmaz, Ş., and Sahin, F. C., Increased osteoblast adhesion on nanoparticulate calcium phosphates with higher $\mathrm{Ca} / \mathrm{P}$ ratios. J. Biomed. Mater. Res. A 2008, 85A, 236-241.

[190] Lewandrowski, K. U., Bondre, S. P., Wise, D. L., and Trantolo, D. J., Enhanced bioactivity of a poly(propylene fumarate) bone graft substitute by augmentation with nano-hydroxyapatite. Biomed. Mater. Eng. 2003, 13, 115-124.

[191] Zhou, D. S., Zhao, K. B., Li, Y., Cui, F. Z., and Lee, I. S., Repair of segmental defects with nano-hydroxyapatite / collagen / PLA composite combined with mesenchymal stem cells. J. Bioactive Compat. Polym. 2006, 21, 373-384.

[192] Khanna, R., Katti, K. S., and Katti, D. R., Bone nodules on chitosan-polygalacturonic acid-hydroxyapatite nanocomposite films mimic hierarchy of natural bone. Acta Biomater. 2011, 7, 1173-1183.

[193] Xu, Z., Sun, J., Changsheng, L., and Jie, W., Effect of hydroxyapatite nanoparticles of different concentrations on rat osteoblast. Mater. Sci. Forum 2009, 610-613, 1364-1369.

[194] Okada, S., Nagai, A., Oaki, Y., Komotori, J., and Imai, H., Control of cellular activity of fibroblasts on size-tuned fibrous hydroxyapatite nanocrystals. Acta Biomater. 2011, 7, 1290-1297.

[195] Krut'ko, V. K., Kulak, A. I., Lesnikovich, L. A., Trofimova, I. V., Musskaya, O. N., Zhavnerko, G. K., and Paribok, I. V., Influence of the dehydration procedure on the physicochemical properties of nanocrystalline hydroxylapatite xerogel. Russ. J. General Chem. 2007, 77, 336-342.

[196] Severin, A. V., Komarov, V. F., Bozhevol'nov, V. E., and Melikhov, I. V., Morphological selection in suspensions of nanocrystalline hydroxylapatite leading to spheroidal aggregates. Russ. J. Inorg. Chem. 2005, 50, 72-77.

[197] Biggemann, D., da Silva, M. H. P., Rossi, A. M., and Ramirez, A. J., High-resolution transmission electron microscopy study of nanostructured hydroxyapatite. Microsc. Microanal. 2008, 14, 433-438

[198] Hagmeyer, D., Ganesan, K., Ruesing, J., Schunk, D., Mayer, C., Dey, A., Sommerdijk, N. A. J. M., and Epple, M., Self-assembly of calcium phosphate nanoparticles into hollow spheres induced by dissolved amino acids. J. Mater. Chem. 2011, 21, 9219-9223.

[199] Kester, M., Heakal, Y., Fox, T., Sharma, A., Robertson, G. P., Morgan, T. T., Altinoğlu, E. I., Tabaković, A., Parette, M. R., Rouse, S. M., Ruiz-Velasco, V., and Adair, J. H., Calcium phosphate nanocomposite particles for in vitro imaging and encapsulated chemotherapeutic drug delivery to cancer cells. Nano Lett. 2008, 8, 4116-4121.

[200] Welzel, T., Meyer-Zaika, W., and Epple, M., Continuous preparation of functionalised calcium phosphate nanoparticles with adjustable crystallinity. Chem. Commun. 2004, 
1204-1205.

[201] Nichols, H. L., Zhang, N., Zhang, J., Shi, D., Bhaduri, S., and Wen, X., Coating nanothickness degradable films on nanocrystalline hydroxyapatite particles to improve the bonding strength between nanohydroxyapatite and degradable polymer matrix. J. Biomed. Mater. Res. A 2007, 82A, 373-382.

[202] Bouladjine, A., Al-Kattan, A., Dufour, P., and Drouet, C., New advances in nanocrystalline apatite colloids intended for cellular drug delivery. Langmuir 2009, 25, 12256-12265.

[203] Rey, C., Hina, A., Tofighi, A., and Glimcher, M. J., Maturation of poorly crystalline apatites: chemical and structural aspects in vivo and in vitro. Cell Mater. 1995, 5, 345-356.

[204] Dorozhkin, S. V., Calcium orthophosphates. J. Mater. Sci. 2007, 42, 1061-1095.

[205] Dorozhkin, S. V., Calcium orthophosphates in nature, biology and medicine. Materials 2009, 2, 399-498.

[206] Elliott, J. C., Structure and chemistry of the apatites and other calcium orthophosphates; Elsevier: Amsterdam, Holland, 1994; pp. 404.

[207] Olszta, M. J., Cheng, X., Jee, S. S., Kumar, R., Kim, Y. Y., Kaufmane, M. J., Douglas, E. P., and Gower, L. B., Bone structure and formation: a new perspective. Mater. Sci. Eng. R 2007, 58, 77-116.

[208] Cui, F. Z., Li, Y., and Ge, J., Self-assembly of mineralized collagen composites. Mater. Sci. Eng. R 2007, 57, 1-27.

[209] Meyers, M. A., Chen, P. Y., Lin, A. Y. M., and Seki, Y., Biological materials: structure and mechanical properties. Prog. Mater. Sci. 2008, 53, 1-206.

[210] Currey, J. D., Hierarchies in biomineral structures. Science $2005,309,253-254$.

[211] Rubin, M. A., Jasiuk, I., Taylor, J., Rubin, J., Ganey, T., and Apkarian, R. P., TEM analysis of the nanostructure of normal and osteoporotic human trabecular bone. Bone 2003, 33, 270-282.

[212] Hartgerink, J. D., Beniash, E., and Stupp, S. I., Self-assembly and mineralization of peptide-amphiphile nanofibers. Science 2001, 294, 1684-1688.

[213] Ji, B., and Gao, H., Elastic properties of nanocomposite structure of bone. Compos. Sci. Technol. 2006, 66, 1212-1218.

[214] Wang, L., Nancollas, G. H., Henneman, Z. J., Klein, E., and Weiner, S., Nanosized particles in bone and dissolution insensitivity of bone mineral. Biointerphases 2006, 1, 106-111.

[215] Xie, B., and Nancollas, G. H., How to control the size and morphology of apatite nanocrystals in bone. Proc. Natl. Acad. Sci. USA 2011, 107, 22369-22370.

[216] Hu, Y. Y., Rawal, A., and Schmidt-Rohr, K., Strongly bound citrate stabilizes the apatite nanocrystals in bone. Proc. Natl. Acad. Sci. USA 2011, 107, 22425-22429.

[217] Gao, H., Ji, B., Jager, I. L., Arz, E., and Fratzl, P., Materials become insensitive to flaws at nanoscale: lessons from nature. Proc. Natl. Acad. Sci. USA 2003, 100, 5597-5660.

[218] Gupta, H. S., Seto, J., Wagermaier, W., Zaslansky, P., Boe- secke, P., and Fratzl, P., Cooperative deformation of mineral and collagen in bone at the nanoscale. Proc. Natl. Acad. Sci. USA. 2006, 103, 17741-17746.

[219] Currey, J. D., Bones: structure and mechanics. Princeton University Press: Princeton, USA, 2006; pp. 456.

[220] Porter, A. E., Nalla, R. K., Minor, A., Jinschek, J. R., Kisielowski, C., Radmilovic, V., Kinney, J. H., Tomsia, A. P., and Ritchie, R. O., A transmission electron microscopy study of mineralization in age-induced transparent dentin. Biomaterials $2005,26,7650-7660$.

[221] Kirkham, J., Brookes, S. J., Shore, R. C., Wood, S. R., Smith, D. A., Zhang, J., Chen, H., and Robinson, C., Physico-chemical properties of crystal surfaces in matrix-mineral interactions during mammalian biomineralisation. Curr. Opin. Colloid Interf. Sci. 2002, 7, 124-132.

[222] Daculsi, G., Mentanteau, J., Kerebel, L. M., and Mitre, D., Length and shape of enamel crystals. Calcif. Tissue Int. 1984, $36,550-555$.

[223] Robinson, C., Connell, S., Kirkham, J., Shorea, R., and Smith, A., Dental enamel - a biological ceramic: regular substructures in enamel hydroxyapatite crystals revealed by atomic force microscopy. J. Mater. Chem. 2004, 14, 2242-2248

[224] Chen, H., Tang, Z., Liu, J., Sun, K., Chang, S. R., Peters, M. C., Mansfield, J. F., Czajka-Jakubowska, A., and Clarkson, B. H., Acellular synthesis of a human enamel-like microstructure. Adv. Mater. 2006, 18, 1846-1851.

[225] Chen, H., Clarkson, B. H., Sun, K., and Mansfield, J. F., Self-assembly of synthetic hydroxyapatite nanorods into an enamel prism-like structure. J. Colloid Interf. Sci. 2005, 288, 97-103.

[226] Robinson, C., Self-oriented assembly of nano-apatite particles: a subunit mechanism for building biological mineral crystals. J. Dental Res. 2007, 86, 677-679.

[227] Cui, F. Z., and Ge, J., New observations of the hierarchical structure of human enamel, from nanoscale to microscale. J. Tissue Eng. Regen. Med. 2007, 1, 185-191.

[228] He, L. H., and Swain, M. V., Enamel - a "metallic-like" deformable biocomposite. J. Dent. 2007, 35, 431-437.

[229] Nelson, S. J., Wheeler's dental anatomy, physiology and occlusion. $9^{\text {th }}$ Ed., W. B. Saunders: Philadelphia, USA. 2009; pp. 368 .

[230] Suvorova E. I., and Buffat P. A., Electron diffraction from micro- and nanoparticles of hydroxyapatite. J. Microscopy 1999, 196, 46-58.

[231] Panda, R. N., Hsieh, M. F., Chung, R. J., and Chin, T. S., $\mathrm{X}$-ray diffractometry and X-ray photoelectron spectroscopy investigations of nanocrytalline hydroxyapatite synthesized by a hydroxide gel technique. Jpn. J. Appl. Phys. 2001, 40, 5030-5035.

[232] Panda, R. N., Hsieh, M. F., Chung, R. J., and Chin, T. S., FTIR, XRD, SEM and solid state NMR investigations of carbonate-containing hydroxyapatite nano-particles synthesized by hydroxide-gel technique. J. Phys. Chem. Solids 2003, 64, 193-199.

[233] Eichert, D. Sfihi, H., Combes, C., and Rey, C., Specific cha- 
racteristics of wet nanocrystalline apatites. Consequences on biomaterials and bone tissue. Key Eng. Mater. 2004, 254-256, 927-930.

[234] Rey, C., Combes, C., Drouet, C., Sfihi, H., and Barroug, A., Physico-chemical properties of nanocrystalline apatites: implications for biominerals and biomaterials. Mater. Sci. Eng. C $2007,27,198-205$

[235] Eichert, D., Drouet, C., Sfihi, H., Rey, C., and Combes, C., Nanocrystalline apatite-based biomaterials: synthesis, processing and characterization. In: Biomaterials research advances. Kendall J. B. Ed., Nova Science Publishers, Inc., USA, 2007; Chapter 5, pp. 93-143.

[236] Aronov, D., and Rosenman, G., Trap state spectroscopy studies and wettability modification of hydroxyapatite nanobioceramics. J. Appl. Phys. 2007, 101, 034701 (5 pages).

[237] Jäger, C., Welzel, T., Meyer-Zaika, W., and Epple, M., A solid-state NMR investigation of the structure of nanocrystalline hydroxyapatite. Magn. Reson. Chem. 2006, 44, 573-580.

[238] Isobe, T., Nakamura, S., Nemoto, R., Senna, M., and Sfihi, H., Solid-state double nuclear magnetic resonance of calcium phosphate nanoparticules synthesized by wet-mechanochemical reaction. J. Phys. Chem. B 2002, 106, 5169-5176.

[239] Bertinetti, L., Tampieri, A., Landi, E., Ducati, C., Midgley, P. A., Coluccia, S., and Martra, G., Surface structure, hydration, and cationic sites of nanohydroxyapatite: UHR-TEM, IR, and microgravimetric studies. J. Phys. Chem. C 2007, 111, 4027-4035.

[240] Bertinetti, L., Tampieri, A., Landi, E., Bolis, V., Busco, C., and Martra, G., Surface structure, hydration and cationic sites of nanohydroxyapatite. Key Eng. Mater. 2008, 361-363, $87-90$.

[241] Bertinetti, L., Drouet, C., Combes, C., Rey, C., Tampieri, A., Coluccia, S., and Martra, G., Surface characteristics of nanocrystalline apatites: effect of $\mathrm{Mg}$ surface enrichment on morphology, surface hydration species, and cationic environments. Langmuir 2009, 25, 5647-5654.

[242] Gopi, D., Indira, J., Prakash, V. C. A., and Kavitha, L., Spectroscopic characterization of porous nanohydroxyapatite synthesized by a novel amino acid soft solution freezing method. Spectrochim. Acta A 2009, 74A, 282-284.

[243] Rossi, A. M., da Silva, M. H. P., Ramirez, A. J., Biggemann, D., Caraballo, M. M., Mascarenhas, Y. P., Eon, J. G., and Moure, G. T., Structural properties of hydroxyapatite with particle size less than 10 nanometers. Key Eng. Mater. 2007, 330-332, 255-258.

[244] Ramirez, C. A. O., Costa, A. M., Bettini, J., Ramirez, A. J., da Silva, M. H. P., and Rossi, A. M., Structural properties of nanostructured carbonate apatites. Key Eng. Mater. 2009, 396-398, 611-614.

[245] Pasteris, J. D., Wopenka, B., Freeman, J. J., Rogers, K., Valsami-Jones, E., van der Houten, J. A. M., and Silva, M. J., Lack of $\mathrm{OH}$ in nanocrystalline apatite as a function of degree of atomic order: implications for bone and biomaterials. Biomaterials 2004, 25, 229-238.

[246] Sakhno, Y., Bertinetti, L., Iafisco, M., Tampieri, A., Roveri, N., and Martra, G., Surface hydration and cationic sites of nanohydroxyapatites with amorphous or crystalline surfaces: a comparative study. J. Phys. Chem. C 2010, 114, 16640-16648.

[247] Zyman, Z. Z., Epple, M., Rokhmistrov, D., and Glushko, V., On impurities and the internal structure in precipitates occurring during the precipitation of nanocrystalline calcium phosphate. Mat. -Wiss. u. Werkstofftech. 2009, 40, 297-301.

[248] Cazalbou, S., Combes, C., Eichert, D., and Rey, C., Adaptative physico-chemistry of bio-related calcium phosphates. J. Mater. Chem. 2004, 14, 2148-2153.

[249] Eichert, D., Salomé, M., Banu, M., Susini, J., and Rey, C., Preliminary characterization of calcium chemical environment in apatitic and non-apatitic calcium phosphates of biological interest by X-ray absorption spectroscopy. Spectrochim. Acta B 2005, 60B, 850-858.

[250] Rosenman, G., Aronov, D., Oster, L., Haddad, J., Mezinskis, G., Pavlovska, I., Chaikina, M., and Karlov, A., Photoluminescence and surface photovoltage spectroscopy studies of hydroxyapatite nano-bio-ceramics. J. Luminescence 2007, 122-123, 936-938.

[251] Melikhov, I. V., Teterin, Y. A., Rudin, V. N., Teterin, A. Y., Maslakov, K. I., and Severin, A. V., An X-ray electron study of nanodisperse hydroxyapatite. Russ. J. Phys. Chem. A 2009, 83, 91-97.

[252] Aronov, D., Rosenman, G., Karlov, A., and Shashkin, A., Wettability patterning of hydroxyapatite nanobioceramics induced by surface potential modification. Appl. Phys. Lett. 2006, 88, 163902 (3 pages).

[253] Rau, J. V., Generosi, A., Ferro, D., Minozzi, F., Paci, B., Albertini, V. R., Dolci, G., and Barinov, S. M., In situ time-resolved X-ray diffraction study of evolution of nanohydroxyapatite particles in physiological solution. Mater. Sci. Eng. C 2009, 29, 1140-1143.

[254] Arora, A., Ceramics in nanotech revolution. Adv. Eng. Mater. 2004, 6, 244-247.

[255] Mao, Y., Park, T. J., Zhang, F., Zhou, H., and Wong, S. S., Environmentally friendly methodologies of nanostructure synthesis. Small 2007, 3, 1122-1139.

[256] Ioku, K., and Yoshimura, M., Stochiometric apatite fine single crystals by hydrothermal synthesis. Phosphorus Res. Bull. 1991, 1, 15-20.

[257] Chen, J. D., Wang, Y. J., Wei, K., Zhang, S. H., and Shi, X. T., Self-organization of hydroxyapatite nanorods through oriented attachment. Biomaterials 2007, 28, 2275-2280.

[258] Guo, X., Xiao, P., Liu, J., and Shen, Z., Fabrication of nanostructured hydroxyapatite via hydrothermal synthesis and spark plasma sintering. J. Am. Ceram. Soc. 2004, 88, 1026-1029.

[259] Brown, P. W., and Constantz B., Eds., Hydroxyapatite and related materials. CRC Press: Boca Raton, FL, USA, 1994; pp. 343.

[260] Amjad, Z., Ed., Calcium phosphates in biological and industrial systems. Kluwer Academic Publishers: Boston, MA, USA, 1997; pp. 529.

[261] Hughes, J. M., Kohn, M., and Rakovan, J., Eds., Phosphates: 
geochemical, geobiological and materials importance, Series: Reviews in Mineralogy and Geochemistry. Vol. 48; Mineralogical Society of America: Washington, D. C., USA, 2002; pp. 742 .

[262] Chow, L. C., and Eanes, E. D., Eds., Octacalcium phosphate. Karger: Basel, Switzerland, 2001; pp. 168.

[263] Brès, E., and Hardouin, P., Eds., Les matériaux en phosphate de calcium. Aspects fondamentaux. / Calcium phosphate materials. Fundamentals. Sauramps Medical: Montpellier, France, 1998; pp. 176

[264] Komarov, V. F., and Kibalchitz, V., Precipitation of apatite through highly saturated solutions. Moscow Univ. Bull. Chem. Dic. 1979, 2680-2685.

[265] Prakash, K. H., Kumar, R., Ooi, C. P., Cheang, P., and Khor, K. A., Conductometric study of precursor compound formation during wet-chemical synthesis of nanocrystalline hydroxyapatite. J. Phys. Chem. B 2006, 110, 24457-24462.

[266] Tao, J., Pan, H., Wang, J., Wu, J., Wang, B., Xu, X., and Tang, R., Evolution of amorphous calcium phosphate to hydroxyapatite probed by gold nanoparticles. J. Phys. Chem. C 2008, 112, 14929-14933.

[267] Chane-Ching, J. Y., Lebugle, A., Rousselot, I., Pourpoint, A., and Pelle, F., Colloidal synthesis and characterization of monocrystalline apatite nanophosphors. J. Mater. Chem. 2007, 17, 2904-2913.

[268] Zyman, Z. Z., Rokhmistrov, D. V., and Glushko, V. I., Structural and compositional features of amorphous calcium phosphate at the early stage of precipitation. J. Mater. Sci. Mater. Med. 2010, 21, 123-130.

[269] Wei, M., Ruys, A. J., Milthorpe, B. K., and Sorrell, C. C., Solution ripening of hydroxyapatite nanoparticles: effects on electrophoretic deposition. J. Biomed. Mater. Res. 1999, 45, 11-19.

[270]Zhu, X., Eibl, O., Berthold, C., Scheideler, L., and Geis-Gerstorfer, J., Structural characterization of nanocrystalline hydroxyapatite and adhesion of pre-osteoblast cells. Nanotechnology 2006, 17, 2711-2721.

[271] Rusu, V. M., Ng, C. H., Wilke, M., Tiersch, B., Fratzl, P., and Peter, M. G., Size-controlled hydroxyapatite nanoparticles as self-organized organic - inorganic composite materials. Biomaterials 2005, 26, 5414-5426.

[272] Wang, Y. J., Lai, C., Wei, K., and Tang, S. Q., Influence of temperature, ripening time and cosurfactant on solvothermal synthesis of calcium phosphate nanobelts. Mater. Lett. 2005, 59, 1098-1104.

[273] Li, Y. B., Li, D., and Weng, W., Preparation of nano carbonate-substituted hydroxyapatite from an amorphous precursor. Int. J. Appl. Ceram. Technol. 2008, 5, 442-448.

[274] Zhang, S., and Gonsalves, K. E., Preparation and characterization of thermally stable nanohydroxyapatite. J. Mater. Sci. Mater. Med. 1997, 8, 25-28.

[275] Ferraz, M. P., Monteiro, F. J., and Manuel, C. M., Hydroxyapatite nanoparticles: a review of preparation methodologies. J. Appl. Biomater. Biomech. 2004, 2, 74-80.

[276] Ahn, E. S., Gleason, N. J., Nakahira, A., and Ying, J. Y.,
Nanostructure processing of hydroxyapatite-based bioceramics. Nano Lett. 2001, 1, 149-153.

[277] Mazelsky, R., Hopkins, R. H., and Kramer, W. E., Czochralski-growth of calcium fluorophosphates. J. Cryst. Growth 1968, 3-4, 260-264.

[278] Loutts, G. B., and Chai, B. H. T., Growth of high-quality single crystals of FAP $\left(\mathrm{Ca}_{5}\left(\mathrm{PO}_{4}\right)_{3} \mathrm{~F}\right)$ and its isomorphs. Proc. SPIE - Int. Soc. Optical Eng. 1993, 1863, 31-34.

[279] Siegel, R. W., Creating nanophase materials. Sci. Am. 1996, $275,42-47$

[280] Hu, J., Odom, T. W., and Lieber, C. M., Chemistry and physics in one dimension: synthesis and properties of nanowires and nanotubes. Acc. Chem. Res. 1999, 32, 435-445.

[281] Schmidt, H. K., Nanoparticles for ceramic and nanocomposite processing. Mol. Cryst. Liq. Cryst. 2000, 353, 165-179.

[282] Cushing, B. L., Kolesnichenko, V. L., and O'Connor, C. J., Recent advances in the liquid-phase syntheses of inorganic nanoparticles. Chem. Rev. 2004, 104, 3893-3946.

[283] Wang, X., Zhuang, J., Peng, Q., and Li, Y., A general strategy for nanocrystal synthesis. Nature 2005, 437, 121-124.

[284] Yin, Y., and Alivisatos, A. P., Colloidal nanocrystal synthesis and the organic-inorganic interface. Nature 2005, 437, 664-670.

[285] Mao, Y., Park, T. J., Zhang, F., Zhou, H., and Wong, S. S., Environmentally friendly methodologies of nanostructure synthesis. Small 2007, 3, 1122-1139.

[286] Ma, M. G., and Zhu, J. F., Recent progress on fabrication of calcium-based inorganic biodegradable nanomaterials. Recent Patents on Nanotechnology 2010, 4, 164-170.

[287] Takagi, S., Chow, L. C., and Ishikawa, K., Formation of hydroxyapatite in new calcium phosphate cements. Biomaterials 1998, 19, 1593-1599.

[288] Meejoo, S., Maneeprakorn, W., and Winotai, P., Phase and thermal stability of nanocrystalline hydroxyapatite prepared via microwave heating. Thermochim. Acta 2006, 447, 115-120.

[289] Kumta, P., Sfeir, C., Lee, D. H., Olton, D., and Choi, D., Nanostructured calcium phosphates for biomedical applications: novel synthesis and characterization. Acta Biomater. $2005,1,65-83$.

[290] Liou, S. C., Chen, S. Y., Lee, H. Y., and Bow, J. S., Structural characterization of nanosized calcium deficient apatite powders. Biomaterials 2004, 25, 189-196.

[291] Mollazadeh, S., Javadpour, J., and Khavandi, A., In situ synthesis and characterization of nanosized hydroxyapatite in poly(vinyl alcohol) matrix. Ceram. Int. 2007, 33, $1579-1583$

[292] Bigi, A., Boanini, E., Gazzano, M., Rubini, K., and Torricelli, P., Nanocrystalline hydroxyapatite - polyaspartate composites. Biomed. Mater. Eng. 2004, 14, 573-579.

[293] Chen, H., Sun, K., Tang, Z., Law, R. V., Mansfield, J. F., Czajka-Jakubowska, A., and Clarkson, B. H., Synthesis of fluorapatite nanorods and nanowires by direct precipitation from solution. Cryst. Growth Des. 2006, 6, 1504-1508. 
[294] Kong, L., Gao, Y., Cao, W., Gong, Y., Zhao, N., and Zhang, $\mathrm{X}$., Preparation and characterization of nano-hydroxyapatite/chitosan composite scaffolds. J. Biomed. Mater. Res. A 2005, 75A, 275-282.

[295] Kong, L., Gao, Y., G. Lu, Gong, Y., Zhao, N., and Zhang, X., A study on the bioactivity of chitosan/nano-hydroxyapatite composite scaffolds for bone tissue engineering. Eur. Polym. J. 2006, 42, 3171-3179.

[296] Melikhov, I. V., Komarov, V. F., Severin, A. V., Bozhevol'nov, V. E., and Rudin, V. N., Two-dimensional crystalline hydroxyapatite. Dokl. Phys. Chem. 2000, 373, 355-358.

[297] Zhao, Y., Zhang, Y., Ning, F., Guo, D., and Xu, Z., Synthesis and cellular biocompatibility of two kinds of HAP with different nanocrystal morphology. J. Biomed. Mater. Res. B (Appl. Biomater.) 2007, 83B, 121-126.

[298] Ganesan, K., and Epple, M., Calcium phosphate nanoparticles as nuclei for the preparation of colloidal calcium phytate. New J. Chem. 2008, 32, 1326-1330.

[299] Zhang, Y., and Lu, J., A simple method to tailor spherical nanocrystal hydroxyapatite at low temperature. J. Nanopart. Res. 2007, 9, 589-594.

[300] Bouyer, E., Gitzhofer, F., and Boulos, M. I., Morphological study of hydroxyapatite nanocrystal suspension. J. Mater. Sci. Mater. Med. 2000, 11, 523-531.

[301] Pang, Y. X., and Bao, X., Influence of temperature, ripening time and calcination on the morphology and crystallinity of hydroxyapatite nanoparticles. J. Eur. Ceram. Soc. 2003, 23, 1697-1704.

[302] Kumar, R., Prakash, K. H., Cheang, P. and Khor, K. A., Temperature driven morphological changes of chemically precipitated hydroxyapatite nanoparticles. Langmuir 2004, 20, 5196-5200.

[303]Li-yun, C., Chuan-bo, Z., and Jian-feng, H., Influence of temperature, $\left[\mathrm{Ca}^{2+}\right], \mathrm{Ca} / \mathrm{P}$ ratio and ultrasonic power on the crystallinity and morphology of hydroxyapatite nanoparticles prepared with a novel ultrasonic precipitation method. Mater. Lett. 2005, 59, 1902-1906.

[304] Afshar, A., Ghorbani, M., Ehsani, N., Saeri, M. R., and Sorrell, C. C., Some important factors in the wet precipitation process of hydroxyapatite. Mater. Des. 2003, 24, 197-202.

[305] Wei, M., Ruys, A. J., Milthorpe, B. K., and Sorrell, C. C., Precipitation of hydroxyapatite nanoparticles: effects of precipitation method on electrophoretic deposition. J. Mater. Sci. Mater. Med. 2005, 16, 319-324.

[306] Liu, Y., Hou, D., and Wang, G., A simple wet chemical synthesis and characterization of hydroxyapatite nanorods. Mater. Chem. Phys. 2004, 86, 69-73.

[307] Saha, S. K., Banerjee, A., Banerjee, S., and Bose, S., Synthesis of nanocrystalline hydroxyapatite using surfactant template systems: role of templates in controlling morphology. Mater. Sci. Eng. C 2009, 29, 2294-2301.

[308] Shanthi, P. M. S. L., Ashok, M., Balasubramanian, T., Riyasdeen, A., and Akbarsha, M. A. Synthesis and characterization of nano-hydroxyapatite at ambient temperature using cationic surfactant. Mater. Lett. 2009, 63, 2123-2125.
[309] Mobasherpour, I., Heshajin, M. S., Kazemzadeh, A., and Zakeri, M., Synthesis of nanocrystalline hydroxyapatite by using precipitation method. J. Alloys Compd. 2007, 430, 330-333.

[310] Phillips, M. J., Darr, J. A., Luklinska, Z. B., and Rehman, I., Synthesis and characterization of nanobiomaterials with potential osteological applications. J. Mater. Sci. Mater. Med. $2003,14,875-882$

[311] Lee, S. J., Yoon, Y. S., Lee, M. H., and Oh, N. S., Nanosized hydroxyapatite powder synthesized from eggshell and phosphoric acid. J. Nanosci. Nanotechnol. 2007, 7, 4061-4064.

[312] Monmaturapoj, N., Nanosize hydroxyapatite powders preparation by wet-chemical precipitation route. J. Metals Mater. Miner. 2008, 18, 15-20.

[313] Ramesh, S., Tan, C. Y., Sopyan, I., Hamdi, M., and Teng, W. D., Consolidation of nanocrystalline hydroxyapatite powder. Sci. Technol. Adv. Mater. 2007, 8, 124-130.

[314] Zhou, W., Zhang, S. M., Hu, W., Qiu, Z. Y., and Liu, Y. H., Dialysis efficiency in rapid synthesis of nano-hydroxyapatite. Key Eng. Mater. 2007, 330-332, 211-214.

[315] Shi, H. B., Zhong, H., Liu, Y., Gu, J. Y., and Yang, C. S., Effect of precipitation method on stoichiometry and morphology of hydroxyapatite nanoparticles. Key Eng. Mater. 2007, 330-332, 271-274.

[316] Monkawa, A., Ikoma, T., Yunoki, S., Ohta, K., and Tanaka, J., Electrophoretic deposition of hydroxyapatite nanocrystal. Key Eng. Mater. 2006, 309-311, 643-646.

[317] Fujii, S., Okada, M., and Furuzono, T., Hydroxyapatite nanoparticles as stimulus-responsive particulate emulsifiers and building block for porous materials. J. Coll. Interf. Sci. 2007, 315, 287-296.

[318] Ong, H. T., Loo, J. S. C., Boey, F. Y. C., Russell, S. J., Ma, J., and Peng, K. W., Exploiting the high-affinity phosphonate - hydroxyapatite nanoparticle interaction for delivery of radiation and drugs. J. Nanopart. Res. 2008, 10, 141-150.

[319] Silva, G. W. C., Ma, L., Hemmers, O., and Lindle, D., Micro-structural characterization of precipitation-synthesized fluorapatite nano-material by transmission electron microscopy using different sample preparation techniques. Micron 2008, 39, 269-274.

[320] Poinern, G. E., Brundavanam, R. K., Mondinos, N., and Jiang, Z. T., Synthesis and characterisation of nanohydroxyapatite using an ultrasound assisted method. Ultrason. Sonochem. 2009, 16, 469-474.

[321] Doğan, Ö., and Öner, M., The influence of polymer architecture on nanosized hydroxyapatite precipitation. J. Nanosci. Nanotechnol. 2008, 8, 667-674.

[322] Loo, S. C. J., Siew, Y. E., Ho, S., Boey, F. Y. C., and Ma, J., Synthesis and hydrothermal treatment of nanostructured hydroxyapatite of controllable sizes. J. Mater. Sci. Mater. Med. 2008, 19, 1389-1397.

[323] Guo, X., Gough, J. E., Xiao, P., Liu, J., and Shen, Z., Fabrication of nanostructured hydroxyapatite and analysis of human osteoblastic cellular response. J. Biomed. Mater. Res. A 2007, 82A, 1022-1032.

[324] Safronova, T. V., Putlyaev, V. I., Sergeeva, A. I., Kunenkov, 
E. V., and Tret'yakov, Y. D., Synthesis of nanocrystalline calcium hydroxyapatite from calcium saccharates and ammonium hydrogen phosphate. Dokl. Chem. 2009, 426, 118-123.

[325] Iafisco, M., Palazzo, B., Marchetti, M., Margiotta, N., Ostuni, R., Natile, G., Morpurgo, M., Gandin, V., Marzano, C., and Roveri, N., Smart delivery of antitumoral platinum complexes from biomimetic hydroxyapatite nanocrystals. J. Mater. Chem. 2009, 19, 8385-8392.

[326] Wang, P., Li, C., Gong, H., Jiang, X., Wang, H., and Li, K., Effects of synthesis conditions on the morphology of hydroxyapatite nanoparticles produced by wet chemical process. Powder Technol. 2010, 203, 315-321.

[327] Leskiv, M., Lagoa, A. L. C., Urch, H., Schwiertz, J., da Piedade, M. E. M., and Epple, M., Energetics of calcium phosphate nanoparticle formation by the reaction of $\mathrm{Ca}\left(\mathrm{NO}_{3}\right)_{2}$ with $\left(\mathrm{NH}_{4}\right)_{2} \mathrm{HPO}_{4}$. J. Phys. Chem. C 2009, 113, 5478-5484.

[328] Rodrigues, L. R., Motisuke, M., and Zavaglia, C. A. C., Synthesis of nanostructured hydroxyapatite: a comparative study between sol-gel and aqueous solution precipitation. Key Eng. Mater. 2009, 396-398, 623-626.

[329] Medvecky, L., Sopcak, T., Durisin, J., and Briancin, J., Nanohydroxyapatite prepared from non-toxic organic $\mathrm{Ca}^{2+}$ compounds by precipitation in aqueous solution. Mater. Lett. 2011, 65, 3566-3569.

[330] Okada, M., and Furuzono, T., Low-temperature synthesis of nanoparticle-assembled, transparent, and low-crystallized hydroxyapatite blocks. J. Coll. Interf. Sci. 2011, 360, 457-462.

[331] Sheykhan, M., Heydari, A., Ma'mani, L., and Badiei, A., The synthesis and spectroscopic characterization of nano calcium fluorapatite using tetra-butylammonium fluoride. Spectrochim. Acta A 2011, 83, 379-783.

[332] Kazemzadeh, R., Behnamghader, A., and Hesaraki, S., Effect of synthesis temperature on phase and morphological characteristics of hydroxyapatite nanoparticles. Adv. Mater. Res. 2011, 264-265, 1329-1333.

[333] López-Macipe, A., Gómez-Morales, J., and Rodríguez-Clemente, R., Nanosized hydroxyapatite precipitation from homogeneous calcium/citrate/phosphate solutions using microwave and conventional heating. Adv. Mater. 1998, 10, 49-53.

[334] Siddharthan, A., Seshadri, S. K., and Kumar, T. S. S., Rapid synthesis of calcium deficient hydroxyapatite nanoparticles by microwave irradiation. Trends Biomater. Artif. Organs 2005, 18, 110-113.

[335] Ioku, K., Yamauchi, S., Fujimori, H., Goto, S., and Yoshimura, M., Hydrothermal preparation of fibrous apatite and apatite sheet. Solid State Ionics 2002, 151, 147-150.

[336] Kasahara, H., Ogata, N., and Ogihara, T., Effect of starting solution on the formation of calcium phosphate nano particles by hydrothermal process. J. Ceram. Soc. Jpn. 2004, $112,650-654$.

[337] Lemos, A. F., Rocha, J. H. G., Quaresma, S. S. F., Kannana, S., Oktar, F. N., Agathopoulos, S., and Ferreira, J. M. F., Hydroxyapatite nano-powders produced hydrothermally from nacreous material. J. Eur. Ceram. Soc. 2006, 26,
$3639-3646$

[338] Chaudhry, A. A., Haque, S., Kellici, S., Boldrin, P., Rehman, I., Khalid, F. A., and Darr, J. A., Instant nano-hydroxyapatite: a continuous and rapid hydrothermal synthesis. Chem. Commun. 2006, 2286-2288.

[339] Cao, M., Wang, Y., Guo, C., Qi, Y., and Hu, C., Preparation of ultrahigh-aspect-ratio hydroxyapatite nanofibers in reverse micelles under hydrothermal conditions. Langmuir 2004, 20, 4784-4786.

[340] Jinlong, N., Hydrothermal synthesis of nano-crystalline hydroxyapatite. Key Eng. Mater. 2007, 330-332, 247-250.

[341] Ryu, I. Y., Kim, D. J., Han, J. S., and Lee, M. H., Influence of two-step sintering variables on phase stability of hydrothermally prepared HAp nano powders. Key Eng. Mater. 2008, 361-363, 91-94.

[342] Han, J. K., Song, H. Y., Saito, F., and Lee, B. T., Synthesis of high purity nanosized hydroxyapatite powder by microwave-hydrothermal method. Mater. Chem. Phys. 2006, 99, 235-239.

[343] Suchanek, W. L., Shuk, P., Byrappa, K., Riman, R. E., TenHuisen, K. S., and Janas, V. F., Mechanochemical-hydrothermal synthesis of carbonated apatite powders at room temperature. Biomaterials 2002, 23, 699-710.

[344] Guo, X., and Xiao, P., Effects of solvents on properties of nanocrystalline hydroxyapatite produced from hydrothermal process. J. Eur. Ceram. Soc. 2006, 26, 3383-3391.

[345] Xin, R., and Yu, K., Ultrastructure characterization of hydroxyapatite nanoparticles synthesized by EDTA-assisted hydrothermal method. J. Mater. Sci. 2009, 44, 4205-4209.

[346] Zhang, C., Yang, J., Quan, Z., Yang, P., Li, C., Hou, Z., Lin, J. Hydroxyapatite nano- and microcrystals with multiform morphologies: controllable synthesis and luminescence properties. Cryst. Growth Des. 2009, 9, 2725-2733.

[347] Zhang, H. B., Zhou, K. C., Li, Z. Y., and Huang, S. P., Plate-like hydroxyapatite nanoparticles synthesized by the hydrothermal method. J. Phys. Chem. Solids 2009, 70, 243-248.

[348] Abdel-Aal, E. A., El-Midany, A. A., and El-Shall, H., Mechanochemical-hydrothermal preparation of nano-crystallite hydroxyapatite using statistical design. Mater. Chem. Phys. 2008, 112, 202-207.

[349] Sun, Y., Guo, G., Tao, D., and Wang, Z., Reverse microemulsion-directed synthesis of hydroxyapatite nanoparticles under hydrothermal conditions. J. Phys. Chem. Solids 2007, 68, 373-377.

[350] Du, X., Chu, Y., Xing, S., and Dong, L., Hydrothermal synthesis of calcium hydroxyapatite nanorods in the presence of PVP. J. Mater. Sci. 2009, 44, 6273-6279.

[351] Xin, R., Ren, F., and Leng, Y., Synthesis and characterization of nano-crystalline calcium phosphates with EDTA-assisted hydrothermal method. Mater. Des. 2010, 31, 1691-1694.

[352] Yan, L., Li, Y., Deng, Z., Zhuang, J., Sun, X. Surfactant-assisted hydrothermal synthesis of hydroxyapatite nanorods. Int. J. Inorg. Mater. 2001, 3, 633-637. 
[353] Zhang, F., Zhou, Z., Yang, S., Mao, L., Chen, H., and Yu, X., Hydrothermal synthesis of hydroxyapatite nanorods in the presence of anionic starburst dendrimer. Mater. Lett. 2005, $59,1422-1425$.

[354] Pathi, S. P., Lin, D. D., Dorvee, J. R., Estroff, L. A., and Fischbach, C., Hydroxyapatite nanoparticle-containing scaffolds for the study of breast cancer bone metastasis. Biomaterials $2011,32,5112-5122$.

[355] Zhu, A., Lu, Y., Si, Y., and Dai, S., Frabicating hydroxyapatite nanorods using a biomacromolecule template. Appl. Surf. Sci. 2011, 257, 3174-3179.

[356] Wang, Y. Z., and Fu, Y., Microwave-hydrothermal synthesis and characterization of hydroxyapatite nanocrystallites. Mater. Lett. 2011, 65, 3388-3390.

[357] Manafi, S., and Rahimipour, M. R., Synthesis of nanocrystalline hydroxyapatite nanorods via hydrothermal conditions. Chem. Engin. Technol. 2011, 34, 972-976.

[358] Byrappa, K., and Haber, M., Handbook of hydrothermal technology: a technology for crystal growth and materials processing. Noyes Publications: New Jersey, USA, 2002, 893 pp.

[359] Yu-Song, P., Surface modification of nanocrystalline hydroxyapatite. Micro and Nano Lett. 2011, 6, 129-132.

[360] Chai, C. S., and Ben-Nissan, B., Bioactive nanocrystalline sol-gel hydroxyapatite coatings. J. Mater. Sci. Mater. Med. 1999, 10, 465-469.

[361] Ben-Nissan, B., Green, D. D., Kannangara, G. S. K., Chai, C. S., and Milev, A., ${ }^{31} \mathrm{P}$ NMR studies of diethyl phosphite derived nanocrystalline hydroxyapatite. J. Sol-Gel Sci. Technol. 2001, 21, 27-37.

[362] Gopi, D., Govindaraju, K. M., Victor, C. A. P., Kavitha, L., and Rajendiran, N., Spectroscopic investigations of nanohydroxyapatite powders synthesized by conventional and ultrasonic coupled sol-gel routes. Spectrochim. Acta A: Mol. Biomol. Spectrosc. 2008, 70, 1243-1245.

[363] Natarajan, V. U., and Rajeswari, S., Influence of calcium precursors on the morphology and crystallinity of sol-gel-derived hydroxyapatite nanoparticles. J. Cryst. Growth 2008, 310, 4601-4611.

[364] Ben-Nissan, B., and Choi, A. H., Sol-gel production of bioactive nanocoatings for medical applications. Part 1: an introduction. Nanomedicine 2006, 1, 311-319.

[365] Choi, A. H., and Ben-Nissan, B., Sol-gel production of bioactive nanocoatings for medical applications. Part 2: current research and development. Nanomedicine 2007, 2, 51-61.

[366] Kim, T. S., and Kumta, P. N., Sol-gel synthesis and characterization of nanostructured hydroxyapatite powder. Mater. Sci. Eng. B 2004, 111, 232-236.

[367] Rajabi-Zamani, A. H., Behnamghader, A., and Kazemzadeh, A., Synthesis of nanocrystalline carbonated hydroxyapatite powder via nonalkoxide sol-gel method. Mater. Sci. Eng. C 2008, 28, 1326-1329.

[368] Sopyan, I., Toibah, A. R., and Natasha, A. N., Nanosized bioceramic hydroxyapatite powders via sol-gel method. Int. J. Mech. Mater. Eng. 2008, 3, 133-138.
[369] Padmanabhan, S. K., Balakrishnan, A., Chu, M. C., Lee, Y. J., Kim, T. N., and Cho, S. J., Sol-gel synthesis and characterization of hydroxyapatite nanorods. Particuology 2009, 7, 466-470.

[370] Yuan, Y., Liu, C., Zhang, Y., and Shan, X., Sol-gel auto-combustion synthesis of hydroxyapatite nanotubes array in porous alumina template. Mater. Chem. Phys. 2008, 112, 275-280.

[371] Kuriakose, T. A., Kalkura, S. N., Palanichamy, M., Arivuoli, D., Dierks, K., Bocelli, G., and Betzel, C., Synthesis of stoichiometric nano crystalline hydroxyapatite by ethanol-based sol-gel technique at low temperature. J. Cryst. Growth 2004, $263,517-523$.

[372] Jahandideh, R., Behnamghader, A., Rangie, M., Youzbashi, A., Joughehdoust, S., and Tolouei, R., Sol-gel synthesis of FHA nanoparticles and CDHA agglomerates from a mixture with a nonstochiometric $\mathrm{Ca} / \mathrm{P}$ ratio. Key Eng. Mater. 2009, 396-398, 607-610

[373] Pang, X., Zeng, H., Liu, J., Wei, S., and Zheng, Y., The properties of nanohydroxyapatite materials and its biological effects. Mater. Sci. Applications 2010, 1, 81-90.

[374] Sanosh, K. P., Chu, M. C., Balakrishnan, A., Lee, Y. J., Kim, T. N., and Cho, S. J., Synthesis of nano hydroxyapatite powder that simulate teeth particle morphology and composition. Curr. Appl. Phys. 2009, 9, 1459-1462.

[375] Darroudi, M., Eshtiagh-Hosseini, H., Housaindokht, M. R., and Youssefi, A., Preparation and characterization of fluorohydroxyapatite nanopowders by nonalkoxide sol-gel method. Digest J. Nanomater. Biostruct. 2010, 5, 29-33.

[376] Montazeri, N., Jahandideh, R., and Biazar, E., Synthesis of fluorapatite-hydroxyapatite nanoparticles and toxicity investigations. Int. J. Nanomedicine 2011, 6, 197-201.

[377] Li, B., Wang, X. L., Guo, B., Xiao, Y. M., Fan, H. S., and Zhang, X. D., Preparation and characterization of nano hydroxyapatite. Key Eng. Mater. 2007, 330-332, 235-238.

[378] Tas, A. C., Synthesis of biomimetic Ca-hydroxyapatite powders at $37^{\circ} \mathrm{C}$ in synthetic body fluids. Biomaterials 2000, 21, 1429-1438.

[379] Wu, Y. S., Lee, Y. H., and Chang, H. C., Preparation and characteristics of nanosized carbonated apatite by urea addition with coprecipitation method. Mater. Sci. Eng. C 2009, 29, 237-241.

[380] Swain, S. K., and Sarkar, D., A comparative study: hydroxyapatite spherical nanopowders and elongated nanorods. Ceram. Int. 2011, 37, 2927-2930.

[381] Rameshbabu, N., Kumar, T. S. S., Murugan, R., and Rao, K. P., Mechanochemical synthesis of nanocrystalline fluorinated hydroxyapatite. Int. J. Nanosci. 2005, 4, 643-649.

[382] Yeong, K. C. B., Wang, J., and Ng, S. C., Mechanochemical synthesis of nanocrystalline hydroxyapatite from $\mathrm{CaO}$ and $\mathrm{CaHPO}_{4}$. Biomaterials 2001, 22, 2705-2712.

[383] Coreno, J. A., Coreno, O. A., Cruz, R. J. J., and Rodriguez, C. C., Mechanochemical synthesis of nanocrystalline carbonate-substituted hydroxyapatite. Optical Mater. 2005, 27, $1281-1285$

[384] el Briak-Ben Abdeslam, H., Mochales, C., Ginebra, M. P., 
Nurit, J., Planell J. A., and Boudeville, P., Dry mechanochemical synthesis of hydroxyapatites from dicalcium phosphate dihydrate and calcium oxide: a kinetic study. J. Biomed. Mater. Res, A 2003, 67A, 927-937.

[385] Nakamura, S., Isobe, T., and Senna, M., Hydroxyapatite nano sol prepared via a mechanochemical route. J. Nanopart. Res. 2001, 3, 57-61.

[386] Nasiri-Tabrizi, B., Honarmandi, P., Ebrahimi-Kahrizsangi, R., and Honarmandi, P., Synthesis of nanosize single-crystal hydroxyapatite via mechanochemical method. Mater. Lett. 2009, 63, 543-546.

[387] Sharifah, A., Iis, S., Mohd, H., and Singh, R., Mechanochemical synthesis of nanosized hydroxyapatite powder and its conversion to dense bodies. Mater. Sci. Forum 2011, 694, 118-122.

[388] Fathi, M. H., and Zahrani, E. M., Fabrication and characterization of fluoridated hydroxyapatite nanopowders via mechanical alloying. J. Alloys Compd. 2009, 475, 408-414.

[389] Fathi, M. H., and Zahrani, E. M., Mechanical alloying synthesis and bioactivity evaluation of nanocrystalline fluoridated hydroxyapatite. J. Cryst. Growth 2009, 311, 1392-1403.

[390] Silva, C. C., Graça, M. P. F., Valente, M. A., and Sombra, A. S. B., Crystallite size study of nanocrystalline hydroxyapatite and ceramic system with titanium oxide obtained by dry ball milling. J. Mater. Sci. 2007, 42, 3851-3855.

[391] Zahrani, E. M., and Fathi, M. H., The effect of high-energy ball milling parameters on the preparation and characterization of fluorapatite nanocrystalline powder. Ceram. Int. 2009, $35,2311-2323$

[392] Mochales, C., Wilson, R. M., Dowker, S. E. P., and Ginebra, M. P., Dry mechanosynthesis of nanocrystalline calcium deficient hydroxyapatite: structural characterization. J. Alloys Compounds 2011, 509, 7389-7394.

[393] Xu, J. L., Khor, K. A., Dong, Z. L., Gu, Y. W., Kumar, R., and Cheang, P., Preparation and characterization of nanosized hydroxyapatite powders produced in a radio frequency (rf) thermal plasma. Mater. Sci. Eng. A 2004, 374, 101-108.

[394] Xu, J. L., Khor, K. A., Kumar, R., and Cheang, P., RF induction plasma synthesized calcium phosphate nanoparticles. Key Eng. Mater. 2006, 309-311, 511-514.

[395] Ruksudjarit, A., Pengpat, K., Rujijanagul, G., and Tunkasiri, T., Synthesis and characterization of nanocrystalline hydroxyapatite from natural bovine bone. Curr. Appl. Phys. 2008, 8, 270-272.

[396] Cho, J. S., and Kang, Y. C., Nano-sized hydroxyapatite powders prepared by flame spray pyrolysis. J. Alloys Compd. 2008, 464, 282-287.

[397] Wang, X., Zhuang, J., Peng, Q., and Li, Y., Liquid-solid-solution synthesis of biomedical hydroxyapatite nanorods. Adv. Mater. 2006, 18, 2031-2034.

[398] Shirkhanzadeh, M., Direct formation of nanophase hydroxyapatite on cathodically polarized electrodes. J. Mater. Sci. Mater. Med. 1998, 9, 67-72.

[399] Montalbert-Smith, R., Palma, C. A., Arias, J. D., and Montero, M. L., Formation of hydroxyapatite nanosized and oth- er apatites by electrolysis process. Key Eng. Mater. 2009, 396-398, 579-582.

[400] Gao, J. H., Guan, S. K., Chen, J., Wang, L. G., Zhu, S. J., Hu, J. H., and Ren, Z. W., Fabrication and characterization of rod-like nano-hydroxyapatite on MAO coating supported on Mg-Zn-Ca alloy. Appl. Surf. Sci. 2011, 257, 2231-2237.

[401] Liu, J., Li, K., Wang, H., Zhu, M., Xu, H., and Yan, H., Self-assembly of hydroxyapatite nanostructures by microwave irradiation. Nanotechnology 2005, 16, 82-87.

[402] Rameshbabu, N., Rao, K. P., and Kumar, T. S. S., Accelerated microwave processing of nanocrystalline hydroxyapatite. J. Mater. Sci. 2005, 40, 6319-6323.

[403] Ran, X., Chen, J., Ran, J., Gou, L., and Zhang, X., Synthesis of nanosized carbonated hydroxyapatite under microwave irradiation. Key Eng. Mater. 2007, 330-332, 303-306.

[404] Siddharthan, A., Seshadri, S. K., and Kumar, T. S. S., Microwave accelerated synthesis of nanosized calcium deficient hydroxyapatite. J. Mater. Sci. Mater. Med. 2004, 15, 1279-1284.

[405] Liu, J., Li, K., Wang, H., Zhu, M., and Yan, H., Rapid formation of hydroxyapatite nanostructures by microwave irradiation. Chem. Phys. Lett. 2004, 396, 429-432.

[406] Krishna, D. S. R., Siddharthan, A., Seshadri, S. K., and Kumar, T. S. S., A novel route for synthesis of nanocrystalline hydroxyapatite from eggshell waste. J. Mater. Sci. Mater. Med. 2007, 18, 1735-1743.

[407] Seo, D. S., Hwang, K. H., and Lee, J. K., Nanostructured hydroxyapatite by microwave sintering. J. Nanosci. Nanotechnol. 2008, 8, 944-948.

[408] Arami, H., Mohajerani, M., Mazloumi, M., Khalifehzadeh, R., Lak, A., and Sadrnezhaad, S. K., Rapid formation of hydroxyapatite nanostrips via microwave irradiation. J. Alloys Compd. 2009, 469, 391-394.

[409] Lak, A., Mazloumi, M., Mohajerani, M. S., Zanganeh, S., Shayegh, M. R., Kajbafvala, A., Arami, H., and Sadrnezhaad, S. K., Rapid formation of mono-dispersed hydroxyapatite nanorods with narrow-size distribution via microwave irradiation. J. Am. Ceram. Soc. 2008, 91, 3580-3584.

[410] Rameshbabu, N., Kumar, T. S. S., and Rao, K. P., Synthesis of nanocrystalline fluorinated hydroxyapatite by microwave processing and its in vitro dissolution study. Bull. Mater. Sci. 2006, 29, 611-615.

[411] Kumar, A. R., Kalainathan, S., and Saral, A. M., Microwave assisted synthesis of hydroxyapatite nano strips. Cryst. Res. Technol. 2010, 45, 776-778.

[412] Kalita, S. J., and Verma, S., Nanocrystalline hydroxyapatite bioceramic using microwave radiation: synthesis and characterization. Mater. Sci. Eng. C 2010, 30, 295-303.

[413] Vani, R., Raja, S. B., Sridevi, T. S., Savithri, K., Devaraj, S. N., Girija, E. K., Thamizhavel, A., and Kalkura, S. N., Surfactant free rapid synthesis of hydroxyapatite nanorods by a microwave irradiation method for the treatment of bone infection. Nanotechnology 2011, 22, 285701.

[414] Cabrera, J. L., Velázquez-Castillo, R., and Rivera-Muñoz, E. M., Synthesis of hydroxyapatite nanostructures using microwave heating. J. Nanosci. Nanotechnol. 2011, 11, $5555-5561$. 
[415] Zyman, Z., Goncharenko, A., Rokhmistrov, D., and Epple, M., Nanocrystalline calcium-deficient hydroxyapatite prepared by a microwave-assisted solvent-free reaction. Mat. -Wiss. u. Werkstofftech. 2011, 42, 154-157.

[416] Shih, W. J., Chen, Y. F., Wang, M. C., and Hon, M. H., Crystal growth and morphology of the nanosized hydroxyapatite powders synthesized from $\mathrm{CaHPO}_{4} \cdot 2 \mathrm{H}_{2} \mathrm{O}$ and $\mathrm{CaCO}_{3}$ by hydrolysis method. J. Cryst. Growth 2004, 270, 211-218.

[417] Zhang, Y., and Lu, J., The transformation of single-crystal calcium phosphate ribbon-like fibres to hydroxyapatite spheres assembled from nanorods. Nanotechnology 2008, 19, 155608 (10 pages).

[418] Furuichi, K., Oaki, Y., and Imai, H., Preparation of nanotextured and nanofibrous hydroxyapatite through dicalcium phosphate with gelatin. Chem. Mater. 2006, 18, 229-234.

[419] Yoruç, A. B. H., and Koca, Y., Double step stirring: a novel method for precipitation of nano-sized hydroxyapatite powder. Digest J. Nanomater. Biostructures 2009, 4, 73-81.

[420] Jarudilokkul, S., Tanthapanichakoon, W., and Boonamnuayvittaya, V., Synthesis of hydroxyapatite nanoparticles using an emulsion liquid membrane system. Colloids Surf. A 2007, 296, 149-153

[421] Lim, G. K., Wang, J., Ng, S. C., and Gan, L. M., Nanosized hydroxyapatite powders from microemulsions and emulsions stabilized by a biodegradable surfactant. J. Mater. Chem. $1999,9,1635-1639$.

[422] Guo, G., Sun, Y., Wang, Z., and Guo, H., Preparation of hydroxyapatite nanoparticles by reverse microemulsion. Ceram. Int. 2005, 31, 869-872.

[423] Lim, G. K., Wang, J., Ng, S. C., and Gan, L. M., Formation of nanocrystalline hydroxyapatite in nonionic surfactant emulsions. Langmuir 1999, 15, 7472-7477.

[424] Sun, Y., Guo, G., Wang, Z., and Guo, H., Synthesis of single-crystal HAP nanorods. Ceram. Int. 2006, 32, 951-954.

[425] Bose, S., and Saha, S. K., Synthesis and characterization of hydroxyapatite nanopowders by emulsion technique. Chem. Mater. 2003, 15, 4464-4469.

[426] Lai, C., Tang, S. Q., Wang, Y. J., and Wei, K., Formation of calcium phosphate nanoparticles in reverse microemulsions. Mater. Lett. 2005, 59, 210-214.

[427] Jiang, F. X., Lu, X. Y., Zhang, M. L., and Weng, J., Regulating size, morphology and dispersion of nano-crystallites of hydroxyapatite by $\mathrm{pH}$ value and temperature in microemulsion system. Key Eng. Mater. 2008, 361-363, 195-198.

[428] Sato, K., Hotta, Y., Nagaoka, T., Yasuoka, M., and Watari, K., Agglomeration control of hydroxyapatite nano-crystals grown in phase-separated microenvironments. J. Mater. Sci. 2006, 41, 5424-5428.

[429] Li, H., Zhu, M. Y., Li, L. H., and Zhou, C. R., Processing of nanocrystalline hydroxyapatite particles via reverse microemulsions. J. Mater. Sci. 2008, 43, 384-389.

[430] Koetz, J., Baier, J., and Kosmella, S., Formation of zinc sulfide and hydroxylapatite nanoparticles in polyelectrolyte-modified microemulsions. Colloid Polym. Sci. 2007, $285,1719-1726$.
[431] Lim, H. N., Kassim, A., and Huang, N. M., Preparation and characterization of calcium phosphate nanorods using reverse microemulsion and hydrothermal processing routes. Sains Malaysiana 2010, 39, 267-273.

[432] Furuzono, T., Walsh, D., Sato, K., Sonoda, K., and Tanaka, J., Effect of reaction temperature on the morphology and size of hydroxyapatite nanoparticles in an emulsion system. J. Mater. Sci. Lett. 2001, 2, 111-114.

[433] Sadjadi, M. A. S., Akhavan, K., and Zare, K., Preparation of hydroxyapatite nanoparticles by reverse microemulsions and polyelectrolyte-modified microemulsions. Res. J. Chem. Environment 2011, 15, 959-962.

[434] Shen, S. C., Chia, L., Ng, W. K., Dong, Y. C., and Tan, R. B. H., Solid-phase steam-assisted synthesis of hydroxyapatite nanorods and nanoparticles. J. Mater. Sci. 2010, 45, 6059-6067.

[435] Jevtić, M., Mitrić, M., Škapin, S., Jančar, B., Ignjatović, N., and Uskoković, D., Crystal structure of hydroxyapatite nano-rods synthesized by sonochemical homogenous precipitation. Cryst. Growth Des. 2008, 8, 2217-2222.

[436] Wang, Y. J., Lai, C., Wei, K., Chen, X., Ding, Y., and Wang, Z. L., Investigations on the formation mechanism of hydroxyapatite synthesized by the solvothermal method. Nanotechnology 2006, 17, 4405-4412.

[437] Cao, L. Y., Zhang, C. B., and Huang, J. F., Synthesis of hydroxyapatite nanoparticles in ultrasonic precipitation. Ceram. Int. 2005, 31, 1041-1044.

[438] Liu, J., Wu, Q., and Ding, Y., Self-assembly and fluorescent modification of hydroxyapatite nanoribbon spherulites. Eur. J. Inorg. Chem. 2005, 20, 4145-4149.

[439] Huang, J., Jayasinghe, S. N., Su, X., Ahmad, Z., Best, S. M., Edirisinghe, M. J., Brooks, R. A., Rushton, N., and Bonfield, W., Electrostatic atomisation spraying: a novel deposition method for nano-sized hydroxyapatite. Key Eng. Mater. 2006, 309-311, 635-638.

[440] Hwang, K. S., and Kim, B. H., Preparation of calcium phosphate nano-powders prepared by sol-gel assisted-electrostatic spraying method. J. Mater. Sci. 2005, 40, 4665-4666.

[441] Uota, M., Arakawa, H., Kitamura, N., Yoshimura, T., Tanaka, J., and Kijima, T., Synthesis of high surface area hydroxyapatite nanoparticles by mixed surfactant-mediated approach. Langmuir 2005, 21, 4724-4728.

[442] Chu, M., and Liu, G., Preparation and characterization of hydroxyapatite/liposome core - shell nanocomposites. Nanotechnology 2005, 16, 1208-1212.

[443] Huang, F., Shen, Y., Xie, A., Zhu, J., Zhang, C., Li, S., and Zhu, J., Study on synthesis and properties of hydroxyapatite nanorods and its complex containing biopolymer. J. Mater. Sci. 2007, 42, 8599-8605.

[444] Wang, A., Liu, D., Yin, H., Wu, H., Wada, Y., Ren, M., Jiang, T., Cheng, X., and Xu, Y., Size-controlled synthesis of hydroxyapatite nanorods by chemical precipitation in the presence of organic modifiers. Mater. Sci. Eng. C 2007, 27, 865-869.

[445] Ye, F., Guo, H., and Zhang, H., Biomimetic synthesis of 
oriented hydroxyapatite mediated by nonionic surfactants. Nanotechnology 2008, 19, 245605 (7 pages).

[446] Han, Y., Wang, X., and Li, S., A simple route to prepare stable hydroxyapatite nanoparticles suspension. J. Nanoparticle Res. 2009, 11, 1235-1240.

[447] Tseng, Y. H., Kuo, C. S., Li, Y. Y., and Huang, C. P., Polymer-assisted synthesis of hydroxyapatite nanoparticle. Mater. Sci. Eng. C 2009, 29, 819-822.

[448] Klinkaewnarong, J., Swatsitang, E., and Maensiri, S., Nanocrystalline hydroxyapatite powders by a chitosan-polymer complex solution route: synthesis and characterization. Solid State Sci. 2009, 11, 1023-1027.

[449] Li, Y., Li, D., and Xu, Z., Synthesis of hydroxyapatite nanorods assisted by Pluronics. J. Mater. Sci. 2009, 44, 1258-1263.

[450] Nayar, S., Sinha, M. K., Basu, D., and Sinha, A., Synthesis and sintering of biomimetic hydroxyapatite nanoparticles for biomedical applications. J. Mater. Sci. Mater. Med. 2006, 17, 1063-1068.

[451] Yao, X., Yao, H., Li, G., and Li, Y., Biomimetic synthesis of needle-like nano-hydroxyapatite templated by double-hydrophilic block copolymer. J. Mater. Sci. 2010, 45, 1930-1936.

[452] Hong, Y., Fan, H., Li, B., Guo, B., Liu, M., and Zhang, X., Fabrication, biological effects, and medical applications of calcium phosphate nanoceramics. Mater. Sci. Eng. R 2010, $70,225-242$.

[453] Mostaghaci, B., Fathi, M. H., Sheikh-Zeinoddin, M., and Soleimanian-Zad, S., Bacterial synthesis of nanostructured hydroxyapatite using Serratia marcescens PTCC 1187. Int. J. Nanotechnol. 2009, 6, 1015-1030.

[454] Nathanael, A. J., Hong, S. I., Mangalaraj, D., and Chen, P. C., Large scale synthesis of hydroxyapatite nanospheres by high gravity method. Chem. Eng. J. 2011, 173, 846-854.

[455] Parisi, M., Stoller, M., and Chianese, A., Production of nanoparticles of hydroxy apatite by using a rotating disk reactor. Chem. Eng. Trans. 2011, 24, 211-216.

[456] Yuan, J., Wu, Y., Zheng, Q., and Xie, X., Synthesis and characterization of nano hydroxylapatite by reaction precipitation in impinging streams. Adv. Mater. Res. 2011, 160-162, 1301-1308.

[457] Mohn, D., Doebelin, N., Tadier, S., Bernabei, R. E., Luechinger, N. A., Stark, W. J., and Bohner, M., Reactivity of calcium phosphate nanoparticles prepared by flame spray synthesis as precursors for calcium phosphate cements. J. Mater. Chem. 2011, 21, 13963-13972.

[458] Tadic, D., Veresov, A., Putlayev, V. I., and Epple, M., In-vitro preparation of nanocrystalline calcium phosphates as bone substitution materials in surgery. Mat. -Wiss. u. Werkstofftech. 2003, 34, 1048-1051.

[459] Qiu, Y., Xia, H., and Jiang, H., Fabrication of nano-hydroxyapatite using a novel ultrasonic atomization precipitation method. J. Nanosci. Nanotechnol. 2010, 10 , 2213-2218.

[460] Rouhani, P., Taghavinia, N., and Rouhani, S., Rapid growth of hydroxyapatite nanoparticles using ultrasonic irradiation. Ultrasonics Sonochemistry 2010, 17, 853-856.
[461] Giardina, M. A., and Fanovich, M. A., Synthesis of nanocrystalline hydroxyapatite from $\mathrm{Ca}(\mathrm{OH})_{2}$ and $\mathrm{H}_{3} \mathrm{PO}_{4}$ assisted by ultrasonic irradiation. Ceram. Int. 2010, 36, 1961-1969.

[462] Sadjadi, M. S., Meskinfam, M., Sadeghi, B., Jazdarreh, H., and Zare, K., In situ biomimetic synthesis, characterization and in vitro investigation of bone-like nanohydroxyapatite in starch matrix. Mater. Chem. Phys. 2010, 124, 217-222.

[463] Mhin, S. W., Ryu, J. H., Kim, K. M., Park, G. S., Ryu, H. W., Shim, K. B., Sasaki, T., and Koshizaki, N., Simple synthetic route for hydroxyapatite colloidal nanoparticles via a $\mathrm{Nd}$ :YAG laser ablation in liquid medium. Appl. Phys. A 2009, 96A, 435-440.

[464] Musaev, O. R., Dusevich, V., Wieliczka, D. M., Wrobel, J. M., and Kruger, M. B., Nanoparticle fabrication of hydroxyapatite by laser ablation in water. J. Appl. Phys. 2008, 104, 084316 (5 pages).

[465] Boutinguiza, M., Lusquiños, F., Riveiro, A., Comesaña, R., and Pou, J., Hydroxylapatite nanoparticles obtained by fiber laser-induced fracture. Appl. Surf. Sci. 2009, 255, $5382-5385$

[466] Boutinguiza, M., Pou, J., Lusquiños, F., Comesaña, R., and Riveiro, A., Production of calcium phosphate nanoparticles by laser ablation in liquid. Physics Procedia 2011, 12, 54-59.

[467] Boutinguiza, M., Comesaña, R., Lusquiños, F., Riveiro, A., and Pou, J., Production of nanoparticles from natural hydroxylapatite by laser ablation. Nanoscale Res. Lett. 2011, 6, $1-5$.

[468]Zuo, Y., Li, Y. B., Wei, J., and Yan, Y., Influence of ethylene glycol on the formation of calcium phosphate nanocrystals. J. Mater. Sci. Technol. 2003, 19, 628-630.

[469] Barinov, S. M., Belonogov, E. K., Ievlev, V. M., Kostyuchenko, A. V., Putlyaev, V. I., Tret'yakov, Y. D., Smirnov, V. V., and Fadeeva, I. V., Synthesis of dense nanocrystalline hydroxyapatite films. Dokl. Phys. Chem. 2007, 412, 15-18.

[470] Mello, A., Mavropoulos, E., Hong, Z., Ketterson, J. B., and Rossi, A. M., Nanometer coatings of hydroxyapatite characterized by glancing-incidence X-ray diffraction. Key Eng. Mater. 2009, 396-398, 369-372.

[471] Iafisco, M., Morales, J. G., Hernández-Hernández, M. A., García-Ruiz, J. M., and Roveri, N., Biomimetic carbonate-hydroxyapatite nanocrystals prepared by vapor diffusion. Adv. Eng. Mater. 2010, 12, B218-B223.

[472] Luo, P., and Nieh, T. G., Synthesis of ultrafine hydroxyapatite particles by a spray dry method. Mater. Sci. Eng. C 1995, 3, 75-78.

[473] Chen, F., Wang, Z. C., and Chang, J. L., Preparation and characterization of nanosized hydroxyapatite particles and hydroxyapatite / chitosan nano-composite for use in biomedical materials. Mater. Lett. 2002, 57, 858-861.

[474] Sarig, S., and Kahana, F., Rapid formation of nanocrystalline apatite. J. Cryst. Growth 2002, 237-239, 55-59.

[475] Bose, S., and Saha, S. K., Synthesis of hydroxyapatite nanopowders via sucrose-templated sol-gel method. J. Am. Ceram. Soc. 2003, 86, 1055-1057.

[476] Han, Y., Li, S., Wang, X., and Chen, X., Synthesis and sintering of nanocrystalline hydroxyapatite powders by citric acid sol-gel combustion method. Mater. Res. Bull. 2004, 39, 
25-32.

[477] Liu, D. M., Yang, Q., Troczynski, T., and Tseng, W. J., Structural evolution of sol-gel-derived hydroxyapatite. Biomaterials 2002, 23, 1679-1687.

[478] Liu, D. M., Troczynski, T., and Tseng, W. J., Water-based sol-gel synthesis of hydroxyapatite: process development. Biomaterials 2001, 22, 1721-1730.

[479] Wang, F., Li, M. S., Lu, Y. P., and Ge, S. S., Synthesis of nanocrystalline hydroxyapatite powders in stimulated body fluid. J. Mater. Sci. 2005, 40, 2073-2076.

[480] Wang, J., and Shaw, L. L., Synthesis of high purity hydroxyapatite nanopowder via sol-gel combustion process. J. Mater. Sci. Mater. Med. 2009, 20, 1223-1227.

[481] Varma, H. K., Kalkura, S. N., and Sivakumar, R., Polymeric precursor route for the preparation of calcium phosphate compounds. Ceram. Int. 1998, 24, 467-470.

[482] Ghosh, S. K., Roy, S. K., Kundu, B., Datta, S., and Basu, D., Synthesis of nano-sized hydroxyapatite powders through solution combustion route under different reaction conditions. Mater. Sci. Eng. B 2011, 176, 14-21.

[483] Loher, S., Stark, W. J., Maciejewski, M., Baiker, A., Pratsinis, S. E., Reichardt, D., Maspero, F., Krumeich, F., and Günther, D., Fluoro-apatite and calcium phosphate nanoparticles by flame synthesis. Chem. Mater. 2005, 17, 36-42.

[484] Trommer, R. M., Santos, L. A., and Bergmann, C. P., Nanostructured hydroxyapatite powders produced by a flame-based technique. Mater. Sci. Eng. C 2009, 29, 1770-1775.

[485] Chow, L. C., Sun, L., and Hockey, B., Properties of nanostructured hydroxyapatite prepared by a spray drying technique. J. Res. Natl. Inst. Stand. Technol. 2004, 109, 543-551.

[486] Li, J., Chen, Y. P., Yin, Y., Yao, F., and Yao, K., Modulation of nano-hydroxyapatite size via formation on chitosan-gelatin network film in situ. Biomaterials 2007, 28, 781-790.

[487] Zhai, Y., Cui, F. Z., and Wang, Y., Formation of nano hydroxyapatite on recombinant human like collagen fibrils. Curr. Appl. Phys. 2005, 5, 429-432.

[488] Liou, S. C., Chen, S. Y., and Liu, D. M., Synthesis and characterization of needlelike apatitic nanocomposite with controlled aspect ratios. Biomaterials 2003, 24, 3981-3988.

[489] Liou, S. C., Chen, S. Y., and Liu, D. M., Manipulation of nanoneedle and nanosphere apatite/poly(acrylic acid) nanocomposites. J. Biomed. Mater. Res. B (Appl. Biomater.) 2005, 73B, 117-122.

[490] Amjad, Z., Performance of polymeric additives as HA crystal growth inhibitors. Phosphorus Res. Bull. 1995, 5, 1-12.

[491] Kamitahara, M., Kawashita, M., Kokubo, T., and Nakamura, $\mathrm{T}$., Effect of polyacrylic acid on the apatite formation of a bioactive ceramic in a simulated body fluid: fundamental examination of the possibility of obtaining bioactive glass-ionomer cements for orthopedic use. Biomaterials 2001, 22, 3191-3196.

[492] Wang, X., Li, Y., Wei, J., and de Groot, K., Development of biomimetic nano-hydroxyapatite/poly(hexamethylene adi- pamide) composites. Biomaterials 2002, 23, 4787-4791.

[493] Sinha, A., Nayar, S., and Agrawak, A. C., Synthesis of nanosized and microporous precipitated hydroxyapatite in synthetic polymers and biopolymers. J. Am. Ceram. Soc. 2003, 86, 357-359.

[494] Liao, S., Watari, F., Zhu, Y., Uo, M., Akasaka, T., Wang, W., $\mathrm{Xu}$, G., and Cui, F., The degradation of the three layered nano-carbonated hydroxyapatite/collagen/PLGA composite membrane in vitro. Dental Mater. 2007, 23, 1120-1128.

[495] Gonzalez-McQuire, R., Chane-Ching, J. Y., Vignaud, E., Lebugle, A., and Mann, S., Synthesis and characterization of amino acid-functionalized hydroxyapatite nanorods. J. Mater. Chem. 2004, 14, 2277-2281.

[496] Rosseeva, E. V., Golovanova, O. A., and Frank-Kamenetskaya, O. V., The influence of amino acids on the formation of nanocrystalline hydroxyapatite. Glass Phys. Chem. 2007, 33, 283-286.

[497] Zhan, J., Tseng, Y. H., Chan, J. C. C., and Mou, C. Y., Biomimetic formation of hydroxyapatite nanorods by a single-crystal-to-single-crystal transformation. Adv. Funct. Mater. 2005, 15, 2005-2010.

[498] Xu, A. W., Ma, Y., and Cölfen, H., Biomimetic mineralization. J. Mater. Chem. 2007, 17, 415-449.

[499] Pileni, M., The role of soft colloidal templates in controlling the size and shape of inorganic nanocrystals. Nature Mater. $2003,12,145-150$.

[500] Wu, Y., and Bose, S., Nanocrystalline hydroxyapatite: micelle templated synthesis and characterization. Langmuir $2005,21,3232-3234$

[501] Wei, K., Lai, C., and Wang, Y., Solvothermal synthesis of calcium phosphate nanowires under different $\mathrm{pH}$ conditions. J. Macromolec. Sci. A 2006, 43A, 1531-1540.

[502] Lai, C., Tang, S. Q., Wang, Y. J., Wei, K., and Zhang, S. Y., Insight into shape control mechanism of calcium phosphate nanopartiles in reverse micelles solution. Synth. React. Inorg. Met. Met. Org. Nano-Metal Chem. 2005, 35, 717-725.

[503] Banerjee, A., Bandyopadhyay, A., and Bose, S., Hydroxyapatite nanopowders: synthesis, densification and cell-materials interaction. Mater. Sci. Eng. C 2007, 27, 729-735.

[504] Han, J. Y., Tan, T. T. Y., and Loo, J. S. C., Utilizing inverse micelles to synthesize calcium phosphate nanoparticles as nano-carriers. J. Nanoparticle Res. 2011, 13, 3441-3454.

[505] Shchukin, D. G., Sukhorukov, G. B., and Möhwald, H., Biomimetic fabrication of nanoengineered hydroxyapatite/polyelectrolyte composite shell. Chem. Mater. 2003, 15, $3947-3950$

[506] Mateus, A. Y. P., Ferraz, M. P., and Monteiro, F. J., Microspheres based on hydroxyapatite nanoparticles aggregates for bone regeneration. Key Eng. Mater. 2007, 330-332, 243-246.

[507] Cai, Y., Liu, Y., Yan, W., Hu, Q., Tao, J., Zhang, M., Shi, Z., and Tang, R., Role of hydroxyapatite nanoparticle size in bone cell proliferation. J. Mater. Chem. 2007, 17, 3780-3787. 
[508] Mossaad, C., Tan, M. C., Starr, M., Payzant, E. A., Howe, J. Y., and Riman, R. E., Size-dependent crystalline to amorphous uphill phase transformation of hydroxyapatite nanoparticles. Cryst. Growth Des. 2011, 11, 45-52.

[509] Quantum dots, first developed in the early 1980's, are crystalline semi-conducting nanodimensional particles comprised of a metalloid crystalline core and a "cap" or "shell" that shields the core and renders the dots biologically compatible. They are used or being developed for use in electronics, biomedical imaging and surveillance.

[510] Guo, Y., Shi, D., Lian, J., Dong, Z., Wang, W., Cho, H., Liu, G., Wang, L., and Ewing, R. C., Quantum dot conjugated hydroxylapatite nanoparticles for in vivo imaging. Nanotechnology 2008, 19, 175102 (6 pages).

[511] Liu, Q., de Wijn, J. R., de Groot, K., and van Blitterswijk, C. A., Surface modification of nano-apatite by grafting organic polymer. Biomaterials 1998, 19, 1067-1072.

[512] Palazzo, B., Iafisco, M., Laforgia, M., Margiotta, N., Natile, G., Bianchi, C. L., Walsh, D., Mann, S., and Roveri, N., Biomimetic hydroxyapatite-drug nanocrystals as potential bone substitutes with antitumor drug delivery properties. Adv. Funct. Mater. 2007, 17, 2180-2188.

[513] Lee, H. J., Choi, H. W., Kim, K. J., and Lee, S. C., Modification of hydroxyapatite nanosurfaces for enhanced colloidal stability and improved interfacial adhesion in nanocomposites. Chem. Mater. 2006, 18, 5111-5118.

[514] Lee, S. C., Choi, H. W., Lee, H. J., Kim, K. J., Chang, J. H., Kim, S. Y., Choi, J., Oh, K. S., and Jeong, Y. K., In-situ synthesis of reactive hydroxyapatite nanocrystals for a novel approach of surface grafting polymerization. J. Mater. Chem. 2007, 17, 174-180.

[515] Li, L., Liu, Y. K., Tao, J. H., Zhang, M., Pan, H. H., Xu, X. R., and Tang, R. K., Surface modification of hydroxyapatite nanocrystallite by a small amount of terbium provides a biocompatible fluorescent probe. J. Phys. Chem. C 2008, $112,12219-12224$

[516] Neumeier, M., Hails, L. A., Davis, S. A., Mann, S., and Epple, M., Synthesis of fluorescent core-shell hydroxyapatite nanoparticles. J. Mater. Chem. 2011, 21, 1250-1254.

[517] Wang, W., Shi, D., Lian, J., Guo, Y., Liu, G., Wang, L., and Ewing, R. C., Luminescent hydroxylapatite nanoparticles by surface functionalization. Appl. Phys. Lett. 2006, 89, 183106 (3 pages)

[518] Liu, H., Xi, P., Xie, G., Chen, F., Li, Z., Bai, D., and Zeng, $\mathrm{Z}$., Biocompatible hydroxyapatite nanoparticles as a redox luminescence switch. J. Biol. Inorg. Chem. 2011;16, $1135-1140$.

[519] Bow, J. S., Liou, S. C., and Chen, S. Y., Structural characterization of room-temperature synthesized nanosized $\beta$-tricalcium phosphate. Biomaterials 2004, 25, 3155-3161.

[520] Brunner, T. J., Bohner, M., Dora, C., Gerber, C., and Stark, W. J., Comparison of amorphous TCP nanoparticles to micron-sized $\alpha$-TCP as starting materials for calcium phosphate cements. J. Biomed. Mater. Res. B (Appl. Biomater.) 2007, 83B, 400-407.

[521] Brunner, T. J., Grass, R. N., Bohner, M., and Stark, W. J., Effect of particle size, crystal phase and crystallinity on the reactivity of tricalcium phosphate cements for bone reconstruction. J. Mater. Chem. 2007, 17, 4072-4078.

[522] Döbelin, N., Brunner, T. J., Stark, W. J., Eggimann, M., Fisch, M., and Bohner, M., Phase evolution of thermally treated amorphous tricalcium phosphate nanoparticles. Key Eng. Mater. 2009, 396-398, 595-598.

[523] Bohner, M., Brunner, T. J., Döbelin, N., Tang, R., and Stark, W. J., Effect of thermal treatments on the reactivity of nanosized tricalcium phosphate powders. J. Mater. Chem. 2008, $18,4460-4467$.

[524] Liu, Y. H., Zhang, S. M., Liu, L., Zhou, W., Hu, W., Li, J., and Qiu, Z. Y., Rapid wet synthesis of nano-sized $\beta$-TCP by using dialysis. Key Eng. Mater. 2007, 330-332, 199-202.

[525] Abdel-Fattah, W. I., Reicha, F. M., and Elkhooly, T. A., Nano-beta-tricalcium phosphates synthesis and biodegradation: 1. Effect of microwave and $\mathrm{SO}_{4}{ }^{2-}$ ions on $\beta$-TCP synthesis and its characterization. Biomed. Mater. 2008, 3, 034121 (13 pages).

[526] Sanosh, K. P., Chu, M. C., Balakrishnan, A., Kim, T. N., and Cho, S. J., Sol-gel synthesis of pure nano sized $\beta$-tricalcium phosphate crystalline powders. Curr. Appl. Phys. 2010, 10, 68-71.

[527] Dasgupta, S., Bandyopadhyay, A., and Bose, S., Reverse micelle-mediated synthesis of calcium phosphate nanocarriers for controlled release of bovine serum albumin. Acta Biomater. 2009, 5, 3112-3121.

[528] Xia, C., Deng, X., Lin, Y. H., and Nan, C. W., Preparation and characterisation of nano-sized beta-tricalcium phosphate with a ps template method. Int. J. Mater. Product Technol. $2010,37,257-262$

[529] Choi, D., and Kumta, P. N., Mechano-chemical synthesis and characterization of nanostructured $\beta$-TCP powder. Mater. Sci. Eng. C 2007, 27, 377-381.

[530] Nikcević, I., Maravić, D., Ignjatović, N., Mitrić, M., Makoveć, D., and Uskoković, D., The formation and characterization of nanocrystalline phases by mechanical milling of biphasic calcium phosphate/poly-L-lactide biocomposite. Mater. Transact. 2006, 47, 2980-2986.

[531] Cho, J. S., Jung, D. S., Han, J. M., and Kang, Y. C., Nano-sized $\alpha$ and $\beta$-TCP powders prepared by high temperature flame spray pyrolysis. Mater. Sci. Eng. C 2009, 29, 1288-1292.

[532] Boutinguiza, M., Pou, J., Lusquiños, F., Comesaña, R., and Riveiro, A., Laser-assisted production of tricalcium phosphate nanoparticles from biological and synthetic hydroxyapatite in aqueous medium. Appl. Surf. Sci. 2011, 257, 5195-5199.

[533] Jalota, S., Tas, A. C., and Bhaduri, S. B., Microwave-assisted synthesis of calcium phosphate nanowhiskers. J. Mater. Res. 2004, 19, 1876-1881.

[534] Rameshbabu, N., and Rao, K. P., Microwave synthesis, characterization and in-vitro evaluation of nanostructured biphasic calcium phosphates. Curr. Appl. Phys. 2009, 9, S29-S31.

[535] Li, B., Chen, X., Guo, B., Wang, X., Fan, H., and Zhang, X., Fabrication and cellular biocompatibility of porous carbonated biphasic calcium phosphate ceramics with a nano- 
structure. Acta Biomater. 2009, 5, 134-143.

[536] Guha, A. K., Singh, S., Kumaresan, R., Nayar, S., and Sinha, A., Mesenchymal cell response to nanosized biphasic calcium phosphate composites. Colloids Surf. B 2009, 73, 146-151.

[537] Layrolle, P., and Lebugle, A., Synthesis in pure ethanol and characterization of nanosized calcium phosphate fluoroapatite. Chem. Mater. 1996, 8, 134-144.

[538] Andres, C., Sinani, V., Lee, D., Gun'ko, Y., and Kotov, N., Anisotropic calcium phosphate nanoparticles coated with 2-carboxyethylphosphonic acid. J. Mater. Chem. 2006, 16, 3964-3968.

[539] Lim, H., Kassim, A., Huang, N., Hashim, R., Radiman, S., Khiew, P., and Chiu, W., Fabrication and characterization of 1D brushite nanomaterials via sucrose ester reverse microemulsion. Ceram. Int. 2009, 35, 2891-2897.

[540] Shirkhanzadeh, M., and Sims, S., Immobilization of calcium phosphate nano-clusters into alkoxy-derived porous $\mathrm{TiO}_{2}$ coatings. J. Mater. Sci. Mater. Med. 1997, 8, 595-601.

[541] Schmidt, H. T., and Ostafin, A. E., Liposome directed growth of calcium phosphate nanoshells. Adv. Mater. 2002, $14,532-535$.

[542] Schmidt, H. T., Gray, B. L., Wingert, P. A., and Ostafin, A. E., Assembly of aqueous-cored calcium phosphate nanoparticles for drug delivery. Chem. Mater. 2004, 16, 4942-4947.

[543] Yeo, C. H., Zein, S. H. S., Ahmad, A. L., and McPhail, D. S., Comparison of DOPA and DPPA liposome templates for the synthesis of calcium phosphate nanoshells. Ceram. Int. 2012, $38,561-570$.

[544] Xu, H. H. K., Sun, L., Weir, M. D., Antonucci, J. M., Takagi, S., Chow, L. C., and Peltz, M., Nano DCPA - whisker composites with high strength and $\mathrm{Ca}$ and $\mathrm{PO}_{4}$ release. J. Dent. Res. 2006, 85, 722-727.

[545] Xu, H. H. K., Weir, M. D., Sun, L., Takagi, S., and Chow, L. C., Effects of calcium phosphate nanoparticles on $\mathrm{Ca}-\mathrm{PO}_{4}$ composite. J. Dent. Res. 2007, 86, 378-383.

[546] Xu, H. H. K., Weir, M. D., and Sun, L., Nanocomposites with $\mathrm{Ca}$ and $\mathrm{PO}_{4}$ release: effects of reinforcement, dicalcium phosphate particle size and silanization. Dental Mater. 2007, $23,1482-1491$.

[547] Singh, S., Bhardwaj, P., Singh, V., Aggarwal, S., and Mandal, U. K., Synthesis of nanocrystalline calcium phosphate in microemulsion - effect of nature of surfactants. J. Colloid Interf. Sci. 2008, 319, 322-329.

[548] Wals, D., and Mann, S., Chemical synthesis of microskeletal calcium phosphate in bicontinuous microemulsions. Chem. Mater. 1996, 8, 1944-1953.

[549] Ma, Z., Chen, F., Zhu, Y. J., Cui, T., and Liu, X. Y., Amorphous calcium phosphate/poly(D,L-lactic acid) composite nanofibers: electrospinning preparation and biomineralization. J. Coll. Interf. Sci. 2011, 15, 371-379.

[550] Urch, H., Vallet-Regí, M., Ruiz, L., Gonzalez-Calbet, J. M., and Epple, M., Calcium phosphate nanoparticles with adjustable dispersability and crystallinity. J. Mater. Chem. 2009, 19, 2166-2171.
[551] Holt, C., Wahlgren, N. M., and Drakenberg, T., Ability of a $\beta$-casein phosphopeptide to modulate the precipitation of calcium phosphate by forming amorphous dicalcium phosphate nanoclusters. Biochem. J. 1996, 314, 1035-1039.

[552] Holt, C., Timmins, P. A., Errington, N., and Leaver, J., A core-shell model of calcium phosphate nanoclusters stabilized by $\beta$-casein phosphopeptides, derived from sedimentation equilibrium and small-angle $\mathrm{X}$-ray and neutron-scattering measurements. Eur. J. Biochem. 1998, 252, 73-78.

[553] Duan, B., Wang, M., Zhou, W. Y., and Cheung, W. L., Synthesis of Ca-P nanoparticles and fabrication of $\mathrm{Ca}-\mathrm{P} / \mathrm{PHBV}$ nanocomposite microspheres for bone tissue engineering applications. Appl. Surf. Sci. 2008, 255, 529-533.

[554] Hwang, K. S., Jeon, K. O., Jeon, Y. S., and Kim, B. H., Hydroxyapatite forming ability of electrostatic spray pyrolysis derived calcium phosphate nano powder. J. Mater. Sci. 2006, $41,4159-4162$

[555] Hwang, K. S., Jeon, K. O., Jeon, Y. S., and Kim, B. H., Hydroxyapatite forming ability of electrostatic spray pyrolysis derived calcium phosphate nano powder. J. Mater. Sci. Mater. Med. 2007, 18, 619-622.

[556] Perkin, K. K., Turner, J. L., Wooley, K. L., and Mann, S., Fabrication of hybrid nanocapsules by calcium phosphate mineralization of shell cross-linked polymer micelles and nanocages. Nano Lett. 2005, 5, 1457-1461.

[557] Tjandra, W., Ravi, P., Yao, J., and Tam, K. C., Synthesis of hollow spherical calcium phosphate nanoparticles using polymeric nanotemplates. Nanotechnology 2006, 17, 5988-5994.

[558] Sadasivan, S., Khushalani, D., and Mann, S., Synthesis of calcium phosphate nanofilaments in reverse micelles. Chem. Mater. 2005, 17, 2765-2770.

[559] Morgan, T. T., Muddana, H. S., Altinoglu, E. I., Rouse, S. M., Tabakovic, A., Tabouillot, T., Russin, T. J., Butler, P. J., Eklund, P., Yun, J. K., Kester, M., and Adair, J. H., Encapsulation of organic molecules in calcium phosphate nanocomposite particles for intracellular imaging and drug delivery. Nano Lett. 2008, 8, 4108-4115.

[560] Lai, C., Wang, Y. J., and Wei, K., Nucleation kinetics of calcium phosphate nanoparticles in reverse micelle solution. Colloids Surf. A 2008, 315, 268-274.

[561] Yang, X., Gao, X., Gan, Y., Gao, C., Zhang, X., Ting, K., $\mathrm{Wu}, \mathrm{B}$. M., and Gou, Z., Facile synthesis of octacalcium phosphate nanobelts: growth mechanism and surface adsorption properties. J. Phys. Chem. C 2010, 114, 6265-6271.

[562] Socol, G., Torricelli, P., Bracci, B., Iliescu, M., Miroiu, F., Bigi, A., Werckmann, J., and Mihailescu, I. N., Biocompatible nanocrystalline octacalcium phosphate thin films obtained by pulsed laser deposition. Biomaterials 2004, 25, 2539-2545.

[563] Cho, J. S., Ko, Y. N., Koo, H. Y., and Kang, Y. C., Synthesis of nano-sized biphasic calcium phosphate ceramics with spherical shape by flame spray pyrolysis. J. Mater. Sci. Mater. Med. 2010, 21, 1143-1149.

[564] Farzadi, A., Solati-Hashjin, M., Tahmasebi-Birgani, Z., and Aminian, A., Microwave-assisted synthesis and characterization of biphasic calcium phosphate nanopowders. Ceram. 
Transact. 2010, 218, 59-65.

[565] Farzadi, A., Solati-Hashjin, M., Bakhshi, F., and Aminian, A., Synthesis and characterization of hydroxyapatite/ $\beta$-tricalcium phosphate nanocomposites using microwave irradiation. Ceram. Int. 2011, 37, 65-71.

[566] Pan, L., Li, Y., Zou, C., Weng, W., Cheng, K., Song, C., Du, P., Zhao, G., Shen, G., Wang, J., and Han, G., Surface modification of nanosized biphasic $\alpha-\mathrm{TCP} / \mathrm{HA}$ powders. Key Eng. Mater. 2007, 330-332, 223-226.

[567] Urch, H., Franzka, S., Dahlhaus, D., Hartmann, N., Hasselbrink, E., and Epple, M., Preparation of two-dimensionally patterned layers of functionalised calcium phosphate nanoparticles by laser direct writing. J. Mater. Chem. 2006, 16, 1798-1802.

[568] Sokolova, V., Prymak, O., Meyer-Zaika, W., Cölfen, H., Rehage, H., Shukla, A., and Epple, M., Synthesis and characterization of DNA functionalized calcium phosphate nanoparticles. Mat. -Wiss. u. Werkstofftech. 2006, 37, 441-445.

[569] Muddana, H. S., Morgan, T. T., Adair, J. H., and Butler, P. J., Photophysics of Cy3-encapsulated calcium phosphate nanoparticles. Nano Lett. 2009, 9, 1559-1566.

[570] Altinoğlu, E. I., Russin, T. J., Kaiser, J. M., Barth, B. M., Eklund, P. C., Kester, M., and Adair, J. H., Near-infrared emitting fluorophore-doped calcium phosphate nanoparticles for in vivo imaging of human breast cancer. ACS Nano 2008, 2, 2075-2084.

[571] Schwiertz, J., Wiehe, A., Gräfe, S., Gitter, B., and Epple, M., Calcium phosphate nanoparticles as efficient carriers for photodynamic therapy against cells and bacteria. Biomaterials 2009, 30, 3324-3331.

[572] Chen, F., Zhu, Y. J., Zhang, K. H., Wu, J., Wang, K. W., Tang, Q. L., and Mo, X. M., Europium-doped amorphous calcium phosphate porous nanospheres: preparation and application as luminescent drug carriers. Nanoscale Res. Lett. 2011, 6, 1-9.

[573] Schwiertz, J., Meyer-Zaika, W., Ruiz-Gonzalez, L., González-Calbet, J. M., Vallet-Regí, M., and Epple, M., Calcium phosphate nanoparticles as templates for nanocapsules prepared by the layer-by-layer technique. J. Mater. Chem. 2008, 18, 3831-3834.

[574] Hayakawa, S., Li, Y., Tsuru, K., Osaka, A., Fujii, E., and Kawabata, K., Preparation of nanometer-scale rod array of hydroxyapatite crystal. Acta Biomater. 2009, 5, 2152-2160.

[575] Liao, S. S., Cui, F. Z., Zhang, W., and Feng, Q. L., Hierarchically biomimetic bone scaffold materials: nano-HA/collagen/PLA composite. J. Biomed. Mater. Res. B (Appl. Biomater.) 2004, 69B, 158-165.

[576] Thomas, V., Dean, D. R., Jose, M. V., Mathew, B., Chowdhury, S., and Vohra, Y. K., Nanostructured biocomposite scaffolds based on collagen co-electrospun with nanohydroxyapatite. Biomacromolecules 2007, 8, 631-637.

[577] de Yoreo, J. J., and Vekilov, P. G., Principles of crystal nucleation and growth. Rev. Mineral. Geochem. 2003, 54, 57-93.

[578] Liao, S., Xu, G., Wang, W., Watari, F., Cui, F., Ramakrishna, S., and Chan, C. K., Self-assembly of nano-hydroxyapatite on multi-walled carbon nanotubes. Acta Biomater. 2007, 3,
669-675.

[579] Penn, R. L., and Banfield, J. F., Imperfect oriented attachment: dislocation generation in defect-free nanocrystals. Science 1998, 281, 969-971.

[580] Tao, J., Pan, H., Zeng, Y., Xu, X., and Tang, R., Roles of amorphous calcium phosphate and biological additives in the assembly of hydroxyapatite nanoparticles. J. Phys. Chem. B 2007, 111, 13410-13418.

[581] Hing, K. A., Bone repair in the twenty-first century: biology, chemistry or engineering? Philos. Trans. R. Soc. Lond. A 2004, 362, 2821-2850.

[582] Kokubo, T., Kim, H. M., and Kawashita, M., Novel bioactive materials with different mechanical properties. Biomaterials 2003, 24, 2161-2175.

[583] Fu, J. M., Miao, B., Jia, L. H., and Lü, K. L., Nano-hydroxyapatite for repair of rabbit jaw bone defect: bone mineral density analysis. J. Clin. Rehabil. Tissue Eng. Res. 2009, 13, 2387-2390.

[584] Zhou, H., and Lee, J., Nanoscale hydroxyapatite particles for bone tissue engineering. Acta Biomater. 2011, 7, 2769-2781.

[585] Barralet, J. E., Lilley, K. J., Grover, L. M., Farrar, D. F., Ansell, C., and Gbureck, U., Cements from nanocrystalline hydroxyapatite. J. Mater. Sci. Mater. Med. 2004, 15, 407-411.

[586] Lilley, K. J., Gbureck, U., Wright, A. J., Farrar, D. F., and Barralet, J. E., Cement from nanocrystalline hydroxyapatite: effect of calcium phosphate ratio. J. Mater. Sci. Mater. Med. 2005, 16, 1185-1190.

[587] Neira, I. S., Kolen'ko, Y. V., Lebedev, O. I., van Tendeloo, G., Gupta, H. S., Matsushita, N., Yoshimura, M., and Guitián, F., Rational synthesis of a nanocrystalline calcium phosphate cement exhibiting rapid conversion to hydroxyapatite. Mater. Sci. Eng. C 2009, 29, 2124-2132.

[588] Dorozhkin, S. V., Calcium orthophosphate cements for biomedical application. J. Mater. Sci. 2008, 43, 3028-3057.

[589] Dorozhkin, S. V., Calcium orthophosphate cements and concretes. Materials 2009, 2, 221-291.

[590] Fu, Q., Zhou, N., Huang, W., Wang, D., Zhang, L., and Li, H., Effects of nano HAP on biological and structural properties of glass bone cement. J. Biomed. Mater. Res. A 2005, 74A, 156-163.

[591] Strnadova, M., Protivinsky, J., Strnad, J., and Vejsicka, Z., Preparation of porous synthetic nanostructured HA scaffold. Key Eng. Mater. 2008, 361-363, 211-214.

[592] Kim, J. Y., Lee, J. W., Lee, S. J., Park, E. K., S. Y. Kim, and Cho, D. W., Development of a bone scaffold using HA nanopowder and micro-stereolithography technology. Microelectronic Engineering 2007, 84, 1762-1765.

[593] Severin, A. V., Komarov, V. F., Bozhevol'nov, V. E., and Melikhov, I. V., Morphological selection in suspensions of nanocrystalline hydroxylapatite leading to spheroidal aggregates. Russ. J. Inorg. Chem. 2005, 50, 72-77.

[594] Krylova, I. V., Ivanov, L. N., Bozhevol'nov, V. E., and Severin, A. V., Self-organization processes and phase transitions in nanocrystalline hydroxyapatite according to exoe- 
mission data. Russ. J. Phys. Chem. A 2007, 81, 241-245.

[595] Veljovic, D., Jokic, B., Jankovic-Castvan, I., Smiciklas, I., Petrovic, R., and Janackovic, D., Sintering behaviour of nanosized HAP powder. Key Eng. Mater. 2007, 330-332, 259-262.

[596] Zhang, F., Lin, K., Chang, J., Lu, J., and Ning, C., Spark plasma sintering of macroporous calcium phosphate scaffolds from nanocrystalline powders. J. Eur. Ceram. Soc. 2008, 28, 539-545.

[597] Grossin, D., Banu, M., Sarda, S., Martinet-Rollin, S., Drouet, C., Estournès, C., Champion, E., Rossignol, F., Combes, C., and Rey, C., Low temperature consolidation of nanocrystalline apatites toward a new generation of calcium phosphate ceramics. Ceram. Eng. Sci. Proc. 2010, 30, 113-126.

[598] Chaudhry, A. A., Yan, H., Gong, K., Inam, F., Viola, G., Reece, M. J., Goodall, J. B. M., ur Rehman, I., McNeil-Watson, F. K., Corbett, J. C. W., Knowles, J. C, and Darr, J. A., High-strength nanograined and translucent hydroxyapatite monoliths via continuous hydrothermal synthesis and optimized spark plasma sintering. Acta Biomater. 2011, 7, 791-799.

[599] Eriksson, M., Liu, Y., Hu, J., Gao, L., Nygren, M., and Shen, Z., Transparent hydroxyapatite ceramics with nanograin structure prepared by high pressure spark plasma sintering at the minimized sintering temperature. J. Eur. Ceram. Soc. 2011, 31, 1533-1540.

[600] Kutty, M. G., Loertscher, J., Bhaduri, S., Bhaduri, S. B., and Tinga, W. R., Microwave sintering of nanocrystalline hydroxyapatite. Ceram. Eng. Sci. Proc. 2001, 22, 3-10.

[601] Vijayan, S., and Varma, H., Microwave sintering of nanosized hydroxyapatite powder compacts. Mater. Lett. 2002, $56,827-831$.

[602] Ramesh, S., Tan, C. Y., Bhaduri, S. B., and Teng, W. D., Rapid densification of nanocrystalline hydroxyapatite for biomedical applications. Ceram. Int. 2007, 33, 1363-1367.

[603] Okada, M., and Furuzono, T., Fabrication of high-dispersibility nanocrystals of calcined hydroxyapatite. J. Mater. Sci. 2006, 41, 6134-6137.

[604] Okada, M., and Furuzono, T., Nanosized ceramic particles of hydroxyapatite calcined with an anti-sintering agent. J. Nanosci. Nanotechnol. 2007, 7, 848-851.

[605] Okada, M., and Furuzono, T., Calcination of rod-like hydroxyapatite nanocrystals with an anti-sintering agent surrounding the crystals. J. Nanopart. Res. 2007, 9, 807-815.

[606] Müller-Mai, C. M., Stupp, S. I., Voigt, C., and Gross, U., Nanoapatite and organoapatite implants in bone: histology and ultrastructure of the interface. J. Biomed. Mater. Res. 1995, 29, 9-18.

[607] Du, C., Cui, F. Z., Feng, Q. L., Zhu, X. D., and de Groot, K., Tissue response to nano-hydroxyapatite/collagen composite implants in marrow cavity. J. Biomed. Mater. Res. 1998, 42, 540-548.

[608] Du, C., Cui, F. Z., Zhu, X. D., and de Groot, K., Three-dimensional nano-HAp/collagen matrix loading with osteogenic cells in organ culture. J. Biomed. Mater. Res. 1999, 44, 407-415.
[609] Paul, W., and Sharma, C. P., Nanoceramic matrices: biomedical applications. Am. J. Biochem. Biotechnol. 2006, 2, 41-48.

[610] Huber, F. X., McArthur, N., Hillmeier, J., Kock, H. J., Baier, M., Diwo, M., Berger, I., and Meeder, P. J., Void filling of tibia compression fracture zones using a novel resorbable nanocrystalline hydroxyapatite paste in combination with a hydroxyapatite ceramic core: first clinical results. Arch. Orthop. Trauma Surg. 2006, 126, 533-540.

[611] Smeets, R., Jelitte, G., Heiland, M., Kasaj, A., Grosjean, M., Riediger, D., Yildirim, M., Spiekermann, H., and Maciejewski, O., Hydroxylapatit-Knochenersatzmaterial $\left(\right.$ Ostim $\left.^{\circledR}\right)$ bei der Sinusbodenelevation. Schweiz Monatsschr. Zahnmed. 2008, 118, 203-208.

[612] Gerlach, K. L., and Niehues, D., Die Behandlung der Kieferzysten mit einem neuartigen nanopartikulären Hydroxylapatit. Mund Kiefer GesichtsChir. 2007, 11, 131-137.

[613] Schwarz, F., Bieling, K., Latz, T., Nuesry, E., and Becker, J., Healing of intrabony periimplantitis defects following application of a nanocristalline hydroxyapatite $\left(\mathrm{Ostim}^{\mathrm{TM}}\right)$ or a bovine-derived xenograft (Bio-Oss ${ }^{\mathrm{TM}}$ ) in combination with a collagen membrane (Bio-Gide ${ }^{\mathrm{TM}}$ ). A case series. J. Clin. Periodontol. 2006, 33, 491-499.

[614] Strietzel, F. P., Reichart, P. A., and Graf, H. L., Lateral alveolar ridge augmentation using a synthetic nano-crystalline hydroxyapatite bone substitution material $\left(\mathrm{Ostim}^{\mathbb{B}}\right)$. Preliminary clinical and histological results. Clin. Oral Implants Res. 2007, 18, 743-751.

[615] Spies, C., Schnürer, S., Gotterbarm, T., and Breusch, S., Tierexperimentelle Untersuchung des Knochenersatzstoffs Ostim $^{T M}$ im knöchernen Lager des Göttinger Miniaturschweins. Z. Orthop. Unfall. 2008, 146, 64-69.

[616] Thorwarth, M., Schultze-Mosgau, S., Kessler, P., Wiltfang, J., and Schlegel, K. A., Bone regeneration in osseous defects using a resorbable nanoparticular hydroxyapatite. J. Oral Maxillofac. Surg. 2005, 63, 1626-1633.

[617] Brandt, J., Henning, S., Michler, G., Schulz, M., and Bernstein, A., Nanocrystalline hydroxyapatite for bone repair. Key Eng. Mater. 2008, 361-363, 35-38.

[618] Huber, F. X., Hillmeier, J., Herzog, L., McArthur, N., Kock, H. J., and Meeder, P. J., Open reduction and palmar plate-osteosynthesis in combination with a nanocrystalline hydroxyapatite spacer in the treatment of comminuted fractures of the distal radius. J. Hand Surg. (Brit.) 2006, 31B, 298-303.

[619] Huber, F. X., Hillmeier, J., McArthur, N., Kock, H. J., and Meeder, P. J., The use of nanocrystalline hydroxyapatite for the reconstruction of calcaneal fractures: preliminary results. J. Foot Ankle Surg. 2006, 45, 322-328.

[620] Laschke, M. W., Witt, K., Pohlemann, T., and Menger, M. D., Injectable nanocrystalline hydroxyapatite paste for bone substitution: in vivo analysis of biocompatibility and vascularization. J. Biomed. Mater. Res. B (Appl. Biomater.) 2007, 82B, 494-505.

[621] Spies, C. K. G., Schnürer, S., Gotterbarm, T., and Breusch, S., The efficacy of Biobon ${ }^{\mathrm{TM}}$ and Ostim ${ }^{\mathrm{TM}}$ within metaphyseal defects using the Göttinger Minipig. Arch. Orthop. Trauma Surg. 2009, 129, 979-988. 
[622] Chitsazi, M. T., Shirmohammadi, A., Faramarzie, M., Pourabbas, R., and Rostamzadeh, A. N., A clinical comparison of nano-crystalline hydroxyapatite (Ostim) and autogenous bone graft in the treatment of periodontal intrabony defects. Medicina Oral, Patologia Oral y Cirugia Bucal 2011, 16, 448-453.

[623] Huber, F. X., Belyaev, O., Hillmeier, J., Kock, H. J., Huber, C., Meeder, P. J., and Berger, I., First histological observations on the incorporation of a novel nanocrystalline hydroxyapatite paste OSTIM $^{\circledR}$ in human cancellous bone. BMC Musculoskelett. Disord. 2006, 7, 50 (14 pages).

[624] Huber, F. X., Berger, I., McArthur, N., Huber, C., Kock, H. P., Hillmeier, J., and Meeder, P. J., Evaluation of a novel nanocrystalline hydroxyapatite paste and a solid hydroxyapatite ceramic for the treatment of critical size bone defects (CSD) in rabbits. J. Mater. Sci. Mater. Med. 2008, 19, 33-38.

[625] Arts, J. J. C., Verdonschot, N., Schreurs, B. W., and Buma, P., The use of a bioresorbable nano-crystalline hydroxyapatite paste in acetabular bone impaction grafting. Biomaterials 2006, 27, 1110-1118.

[626] Zhang, W., Liao, S. S., and Cui, F. Z., Hierarchical self-assembly of nano-fibrils in mineralized collagen. Chem. Mater. 2003, 15, 3221-3226.

[627] Li, X., Huang, J., and Edirisinghe, M. J., Development of nano-hydroxyapatite coating by electrohydrodynamic atomization spraying. J. Mater. Sci. Mater. Med. 2008, 19, $1545-1551$.

[628] Guo, L., and Li, H., Fabrication and characterization of thin nano-hydroxyapatite coatings on titanium. Surf. Coat. Technol. 2004, 185, 268-274.

[629] Thian, E. S., Ahmad, Z., Huang, J., Edirisinghe, M. J., Jayasinghe, S. N., Ireland, D. C., Brooks, R. A., Rushton, N., Bonfield, W., and Best, S. M., Electrosprayed nanoapatite: a new generation of bioactive material. Key Eng. Mater. 2008, 361-363, 597-600.

[630] Han, Y., Xu, K., Montay, G., Fu, T., and Lu, J., Evaluation of nanostructured carbonated hydroxyapatite coatings formed by a hybrid process of plasma spraying and hydrothermal synthesis. J. Biomed. Mater. Res. 2002, 60, 511-516.

[631] Li, P., Biomimetic nano-apatite coating capable of promoting bone ingrowth. J. Biomed. Mater. Res. A 2003, 66A, 79-85.

[632] Mendes, V. C., Moineddin, R., and Davies, J. E., The effect of discrete calcium phosphate nanocrystals on bone-bonding to titanium surfaces. Biomaterials 2007, 28, 4748-4755.

[633] Oh, S. H., Finõnes, R. R., Daraio, C., Chen, L. H., and Jin, S., Growth of nano-scale hydroxyapatite using chemically treated titanium oxide nanotubes. Biomaterials 2005, 26, 4938-4943.

[634] Ma, J., Wong, H., Kong, L. B., and Peng, K. W., Biomimetic processing of nanocrystallite bioactive apatite coating on titanium. Nanotechnology 2003, 14, 619-623.

[635] Gu, Y. W., Tay, B. Y., Lim, C. S., and Yong, M. S., Nanocrystallite apatite formation and its growth kinetics on chemically treated porous NiTi. Nanotechnology 2006, 17, 2212-2218.

[636] Hu, R., Lin, C. J., and Shi, H. Y., A novel ordered nano hy- droxyapatite coating electrochemically deposited on titanium substrate. J. Biomed. Mater. Res. A 2007, 80A, 687-692.

[637] Bigi, A., Boanini, E., Bracci, B., Facchini, A., Panzavolta, S., Segatti, F., and Sturba, L., Nanocrystalline hydroxyapatite coatings on titanium: a new fast biomimetic method. Biomaterials 2005, 26, 4085-4089.

[638] Narayanan, R., Seshadri, S. K., Kwon, T. Y., and Kim, K. H., Electrochemical nano-grained calcium phosphate coatings on Ti-6Al-4V for biomaterial applications. Scripta Mater. 2007, 56, 229-232.

[639] Thian, E. S., Huang, J., Best, S. M., Barber, Z. H., and Bonfield, W., Nanostructured apatite coatings for rapid bone repair. Key Eng. Mater. 2006, 309-311, 519-522.

[640] Cai, X., Gong, P., Man, Y., Chen, Z., and He, G., The construction and characterization of nano-FHA bioceramic coating on titanium surface. Key Eng. Mater. 2007, 330-332, 333-336.

[641] Citterio, H., Jakani, S., Benmarouane, A., Millet, P., and Lodini, A., Nano-hydroxyapatite coatings on titanium substrates. Finite element analysis of process and experimental plasma thermal sprayed coatings. Key Eng. Mater. 2008, 361-363, 745-748.

[642] Lee, S. H., Kim, H. E., and Kim, H. W., Nanosized hydroxyapatite coatings on $\mathrm{Ti}$ substrate with $\mathrm{TiO}_{2}$ buffer layer by e-beam deposition. J. Am. Ceram. Soc. 2007, 90, 50-56.

[643] Nishimura, I., Huang, Y., Butz, F., Ogawa, T., Lin, A., and Wang, C. J., Discrete deposition of hydroxyapatite nanoparticles on a titanium implant with predisposing substrate microtopography accelerated osseointegration. Nanotechnology 2007, 18, 245101 ( 9 pages).

[644] Narayanan, R., Kwon, T. Y., and Kim, K. H., Preparation and characteristics of nano-grained calcium phosphate coatings on titanium from ultrasonated bath at acidic $\mathrm{pH}$. J. Biomed. Mater. Res. B (Appl. Biomater.) 2008, 85B, 231-239.

[645] Hahn, B. D., Park, D. S., Choi, J. J., Ryu, J., Yoon, W. H., Kim, K. H., Park, C., and Kim, H. E., Dense nanostructured hydroxyapatite coating on titanium by aerosol deposition. J. Am. Ceram. Soc. 2009, 92, 683-687.

[646] Narayanan, R., Kwon, T. Y., and Kim, K. H., Direct nanocrystalline hydroxyapatite formation on titanium from ultrasonated electrochemical bath at physiological $\mathrm{pH}$. Mater. Sci. Eng. C 2008, 28, 1265-1270.

[647] Yousefpour, M., Afshar, A., Yang, X., Li, X., Yang, B., Wu, Y., Chen, J., and Zhang, X., Nano-crystalline growth of electrochemically deposited apatite coating on pure titanium. J. Electroanal. Chem. 2006, 589, 96-105.

[648] Mendes, V. C., Moineddin, R., and Davies, J. E., Discrete calcium phosphate nanocrystalline deposition enhances osteoconduction on titanium-based implant surfaces. J. Biomed. Mater. Res. A 2009, 90A, 577-585.

[649] Yang, Y., Kim, K. H., and Ong, J. L., A review on calcium phosphate coatings produced using a sputtering process - an alternative to plasma spraying. Biomaterials 2005, 26, 327-337.

[650] Nies, B., Rößler, S., and Reinstorf, A., Formation of nano hydroxyapatite - a straightforward way to bioactivate bone 
implant surfaces. Int. J. Mat. Res. (formerly Z. Metallkd.) 2007, 98, 630-636.

[651] Jalota, S., Bhaduri, S. B., and Tas, A. C., Effect of carbonate content and buffer type on calcium phosphate formation in SBF solutions. J. Mater. Sci. Mater. Med. 2006, 17, 697-707.

[652] Chen, F., Lam, W. M., Lin, C. J., Qiu, G. X., Wu, Z. H., Luk, K. D. K., and Lu, W. W., Biocompatibility of electrophoretical deposition of nanostructured hydroxyapatite coating on roughen titanium surface: in vitro evaluation using mesenchymal stem cells. J. Biomed. Mater. Res. B (Appl. Biomater.) 2007, 82B, 183-191.

[653] Thian, E. S., Ahmad, Z., Huang, J., Edirisinghe, M. J., Jayasinghe, S. N., Ireland, D. C., Brooks, R. A., Rushton, N., Bonfield, W., and Best, S. M., The role of electrosprayed nanoapatites in guiding osteoblast behaviour. Biomaterials 2008, 29, 1833-1843.

[654] Bigi, A., Nicoli-Aldini, N., Bracci, B., Zavan, B., Boanini, E., Sbaiz, F., Panzavolta, S., Zorzato, G., Giardino, R., Facchini, A., Abatangelo, G., and Cortivo, R., In vitro culture of mesenchymal cells onto nanocrystalline hydroxyapatite coated Ti13Nb13Zr alloy. J. Biomed. Mater. Res. A 2007, 82A, 213-221.

[655] Bigi, A., Fini, M., Bracci, B., Boanini, E., Torricelli, P., Giavaresi, G., Aldini, N. N., Facchini, A., Sbaiz, F., and Giardino, R., The response of bone to nanocrystalline hydroxyapatite-coated $\mathrm{Ti} 13 \mathrm{Nb} 11 \mathrm{Zr}$ alloy in an animal model. Biomaterials 2008, 29, 1730-1736.

[656] Thian, E. S., Huang, J., Ahmad, Z., Edirisinghe, M. J., Jayasinghe, S. N., Ireland, D. C., Brooks, R. A., Rushton, N., Best, S. M., and Bonfield, W., Influence of nanohydroxyapatite patterns deposited by electrohydrodynamic spraying on osteoblast response. J. Biomed. Mater. Res. A 2008, 85A, 188-194.

[657] Furuzono, T., Masuda, M., Okada, M., Yasuda, S., Kadono, H., Tanaka, R., and Miyatake, K., Increase in cell adhesiveness on a poly(ethylene terephthalate) fabric by sintered hydroxyapatite nanocrystal coating in the development of an artificial blood vessel. ASAIO J. 2006, 52, 315-320.

[658] Yanagida, H., Okada, M., Masuda, M., Ueki, M., Narama, I., Kitao, S., Koyama, Y., Furuzono, T., and Takakuda, K., Cell adhesion and tissue response to hydroxyapatite nanocrystal-coated poly(L-lactic acid) fabric. J. Biosci. Bioeng. 2009, $108,235-243$.

[659] Li, X., Huang, J., and Edirisinghe, M. J., Development of template-assisted electrohydrodynamic atomization spraying for nanoHA patterning. Key Eng. Mater. 2008, 361-363, 585-588.

[660] Shi, Z. L., Huang, X., Cai, Y. R., Tang, R. K., and Yang, D. S., Size effect of hydroxyapatite nanoparticles on proliferation and apoptosis of osteoblast-like cells. Acta Biomater. 2009, 5, 338-345.

[661] Liu, Y., Wang, G., Cai, Y., Ji, H., Zhou, G., Zhao, X., Tang, R., and Zhang, M., In vitro effects of nanophase hydroxyapatite particles on proliferation and osteogenic differentiation of bone marrow-derived mesenchymal stem cells. J. Biomed. Mater. Res. A 2009, 15, 1083-1091.

[662]Zhu, X., Eibl, O., Scheideler, L., and Geis-Gerstorfer, J., Characterization of nano hydroxyapatite/collagen surfaces and cellular behaviors. J. Biomed. Mater. Res. A 2006, 79A, 114-127.

[663] Zhu, W., Zhang, X., Wang, D., Lu, W., Ou, Y., Han, Y., Zhou, K., Liu, H., Fen, W., Peng, L., He, C., and Zeng, Y., Experimental study on the conduction function of nano-hydroxyapatite artificial bone. Micro Nano Lett. 2010, 5, 19-27.

[664] Wang, H., Li, Y., Zuo, Y., Li, J., Ma, S., and Cheng, L., Biocompatibility and osteogenesis of biomimetic nano-hydroxyapatite/polyamide composite scaffolds for bone tissue engineering. Biomaterials 2007, 28, 3338-3348.

[665] Zhang, Y. F., Cheng, X. R., Chen, Y., Shi, B., Chen, X. H., $\mathrm{Xu}, \mathrm{D} . \mathrm{X}$., and Ke, J., Three-dimensional nanohydroxyapatite / chitosan scaffolds as potential tissue engineered periodontal tissue. J. Biomater. Appl. 2007, 21, 333-349.

[666] Huang, Y. X., Ren, J., Chen, C., Ren, T. B., and Zhou, X. Y., Preparation and properties of poly(lactide-co-glycolide) (PLGA) / nano-hydroxyapatite (NHA) scaffolds by thermally induced phase separation and rabbit mscs culture on scaffolds. J. Biomater. Appl. 2008, 22, 409-432.

[667] Thian, E. S., Ahmad, Z., Huang, J., Edirisinghe, M. J., Jayasinghe, S. N., Ireland, D. C., Brooks, R. A., Rushton, N., Bonfield, W., and Best, S. M., Bioactivity of nanoapatite produced by electrohydrodynamic atomization. J. Bionanosci. $2007,1,60-63$.

[668] Pezzatini, S., Solito, R., Morbidelli, L., Lamponi, S., Boanini, E., Bigi, A., and Ziche, M., The effect of hydroxyapatite nanocrystals on microvascular endothelial cell viability and functions. J. Biomed. Mater. Res. A 2006, 76A, 656-663.

[669] Pezzatini, S., Morbidelli, L., Solito, R., Paccagnini, E., Boanini, E., Bigi, A., and Ziche, M., Nanostructured HA crystals up-regulate FGF-2 expression and activity in microvascular endothelium promoting angiogenesis. Bone 2007, 41, 523-534.

[670] Hu, Q., Tan, Z., Liu, Y., Tao, J., Cai, Y., Zhang, M., Pan, H., $\mathrm{Xu}, \mathrm{X}$., and Tang, R., Effect of crystallinity of calcium phosphate nanoparticles on adhesion, proliferation, and differentiation of bone marrow mesenchymal stem cells. J. Mater. Chem. 2007, 17, 4690-4698.

[671] Kim, K., Dean, D., Lu, A., Mikos, A. G., and Fisher, J. P., Early osteogenic signal expression of rat bone marrow stromal cells is influenced by both hydroxyapatite nanoparticle content and initial cell seeding density in biodegradable nanocomposite scaffolds. Acta Biomater. 2011, 7, 1249-1264.

[672] Svanborg, L. M., Hoffman, M., Andersson, M., Currie, F., Kjellin, P., and Wennerberg, A., The effect of hydroxyapatite nanocrystals on early bone formation surrounding dental implants. Int. J. Oral Maxillofac. Surg. 2011, 40, 308-315.

[673] Balasundaram, G., Sato, M., and Webster, T. J., Using hydroxyapatite nanoparticles and decreased crystallinity to promote osteoblast adhesion similar to functionalizing with RGD. Biomaterials 2006, 27, 2798-2805.

[674] Detsch, R., Hagmeyer, D., Neumann, M., Schaefer, S., Vortkamp, A., Wuelling, M., Ziegler, G., and Epple, M., The resorption of nanocrystalline calcium phosphates by osteoclast-like cells. Acta Biomater. 2010, 6, 3223-3233. 
[675] Stevens, M. M., and George, J. H., Exploring and engineering the cell surface interface. Science 2005, 310, 1135-1138.

[676] Martínez, E., Engel, E., Planell, J. A., and Samitier, J., Effects of artificial micro- and nano-structured surfaces on cell behaviour. Annals Anat. 2009, 191, 126-135.

[677] Lee, D. H., Han, J. S., Yang, J. H., and Lee, J. B., MC3T3-E1 cell response to pure titanium, zirconia and nano-hydroxyapatite. Int. J. Modern Phys. B 2009, 23, 1535-1540.

[678] Onuma, K., Yamagishi, K., and Oyane, A., Nucleation and growth of hydroxyapatite nanocrystals for nondestructive repair of early caries lesions. J. Cryst. Growth 2005, 282, 199-207.

[679] Huang, S., Gao, S., Cheng, L., and Yu, H., Remineralization potential of nano-hydroxyapatite on initial enamel lesions: an in vitro study. Caries Res. 2011, 45, 460-468.

[680] Roveri, N., Battistella, E., Bianchi, C. L., Foltran, I., Foresti, E., Iafisco, M., Lelli, M., Naldoni, A., Palazzo, B., and Rimondini, L., Surface enamel remineralization: biomimetic apatite nanocrystals and fluoride ions different effects. J. Nanomater. 2009, 746383 (9 pages).

[681] Lv, K., Zhang, J., Meng, X., and Li, X., Remineralization effect of the nano-HA toothpaste on artificial caries. Key Eng. Mater. 2007, 330-332, 267-270.

[682] Jeong, S. H., Jang, S. O., Kim, K. N., Kwon, H. K., Park, Y. D., and Kim, B. I., Remineralization potential of new toothpaste containing nano-hydroxyapatite. Key Eng. Mater. 2006, 309-311, 537-540.

[683] Tschoppe, P., Zandim, D. L., Martus, P., and Kielbassa, A. M., Enamel and dentine remineralization by nano-hydroxyapatite toothpastes. J. Dent. 2011, 39, 430-437.

[684] Wang, C. J., Zhang, Y. F., Wei, J., and Wei, S. C., Repair of artificial enamel lesions by nano fluorapatite paste containing fluorin. J. Clin. Rehabil. Tiss. Eng. Res. 2011, 15, 6346-6350.

[685] Kim, B. I., Jeong, S. H., Jang, S. O., Kim, K. N., Kwon, H. K., and Park, Y. D., Tooth whitening effect of toothpastes containing nano-hydroxyapatite. Key Eng. Mater. 2006, 309-311, 541-544.

[686] Collares, F. M., Leitune, V. C. B., Rostirolla, F. V., Trommer, R. M., Bergmann, C. P., and Samuel, S. M. W., Nanostructured hydroxyapatite as filler for methacrylate-based root canal sealers. Int. Endodontic 2012, 45, 63-67.

[687] Kim, M. Y., Kwon, H. K., Choi, C. H., and Kim, B. I., Combined effects of nano-hydroxyapatite and $\mathrm{NaF}$ on remineralization of early caries lesion. Key Eng. Mater. 2007, $330-332,1347-1350$.

[688] Lee, H. J., Min, J. H., Choi, C. H., Kwon, H. G., and Kim, B. I., Remineralization potential of sports drink containing nano-sized hydroxyapatite. Key Eng. Mater. 2007, 330-332, $275-278$

[689] Min, J. H., Kwon, H. K., and Kim, B. I., The addition of nano-sized hydroxyapatite to a sports drink to inhibit dental erosion - in vitro study using bovine enamel. J. Dent. 2011, $39,629-635$.

[690] Hong, Y. W., Kim, J. H., Lee, B. H., Lee, Y. K., Choi, B. J.,
Lee, J. H., and Choi, H. J., The effect of nano-sized $\beta$-tricalcium phosphate on remineralization in glass ionomer dental luting cement. Key Eng. Mater. 2008, 361-363, 861-864.

[691] Li, L., Pan, H. H., Tao, J. H., Xu, X. R., Mao, C. Y., Gu, X. H., and Tang, R. K., Repair of enamel by using hydroxyapatite nanoparticles as the building blocks. J. Mater. Chem. 2008, 18, 4079-4084.

[692] Meng, X., Lv, K., Zhang, J., and Qu, D., Caries inhibitory activity of the nano-HA in vitro. Key Eng. Mater. 2007, $330-332,251-254$

[693] Li, B. G., Wang, J. P., Zhao, Z. Y., Sui, Y. F., and Zhang, Y. $\mathrm{X}$., Mineralizing of nano-hydroxyapatite powders on artificial caries. Rare Metal. Mat. Eng. 2007, 36, 128-130.

[694] Ashokan, A., Menon, D., Nair, S., and Koyakutty, M., A molecular receptor targeted, hydroxyapatite nanocrystal based multi-modal contrast agent. Biomaterials 2010, 31, 2606-2616

[695] Bauer, I. W., Li, S. P., Han, Y. C., Yuan, L., and Yin, M. Z., Internalization of hydroxyapatite nanoparticles in liver cancer cells. J. Mater. Sci. Mater. Med. 2008, 19, 1091-1095.

[696] Liu, T., Tang, A., Zhang, G. Y., Chen, Y. X., Zhang, J. Y., Peng, S. S., and Cai, Z. M., Calcium phosphate nanoparticles as a novel nonviral vector for efficient transfection of DNA in cancer gene therapy. Cancer Biother. Radiopharm. 2005, 20, 141-149.

[697] Czupryna, J., and Tsourkas, A., Suicide gene delivery by calcium phosphate nanoparticles. A novel method of targeted therapy for gastric cancer. Cancer Biol. Ther. 2006, 5, 1691-1692.

[698] Li, B., Guo, B., Fan, H., and Zhang, X., Preparation of nano-hydroxyapatite particles with different morphology and their response to highly malignant melanoma cells in vitro. Appl. Surf. Sci. 2008, 255, 357-360.

[699] Dai, H., Pei, C., Han, Y., Xinyu, W., and Li, S., Inhibitory effect of hydroxyapatite nanoparticles on K562 cells. Mater. Sci. Forum 2011, 685, 352-356.

[700] Borum, L., and Wilson, O. C., Surface modification of hydroxyapatite. Part II. Silica. Biomaterials 2003, 24, $3681-3688$

[701] Lee, H. J., Kim, S. E., Choi, H. W., Kim, C. W., Kim, K. J., and Lee, S. C., The effect of surface-modified nano-hydroxyapatite on biocompatibility of poly( $\varepsilon$-caprolactone)/hydroxyapatite nanocomposites. Eur. Polym. J. 2007, 43, 1602-1608.

[702] Wilson, O. C., and Hull, J. R., Surface modification of nanophase hydroxyapatite with chitosan. Mater. Sci. Eng. C 2008, 28, 434-437.

[703] Liao, J. G., Wang, X. J., Zuo, Y., Zhang, L., Wen, J. Q., and Li, Y. B., Surface modification of nano-hydroxyapatite with silane agent. J. Inorg. Mater. 2008, 23, 145-149.

[704] Wang, Y., Xiao, Y., Huang, X., and Lang, M., Preparation of poly(methyl methacrylate) grafted hydroxyapatite nanoparticles via reverse ATRP. J. Coll. Interf. Sci. 2011, 15, 415-421.

[705] Deng, C., Xiao, X., Yao, N., Yang, X. B., and Weng, J., 
Effect of surface modification of nano-hydroxyapatite particles on in vitro biocompatibility of poly ( $\varepsilon$-caprolactone)-matrix composite biomaterials. Int. J. Polym. Mater. 2011, 60, 969-978.

[706] Jensen, T., Baas, J., Dolathshahi-Pirouz, A., Jacobsen, T., Singh, G., Nygaard, J. V., Foss, M., Bechtold, J., Bünger, C., Besenbacher, F., and Søballe, K., Osteopontin functionalization of hydroxyapatite nanoparticles in a PDLLA matrix promotes bone formation. J. Biomed. Mater. Res. A 2011, 99A, 94-101.

[707] Ramachandran, R., Paul, W., and Sharma, C. P., Synthesis and characterization of PEGylated calcium phosphate nanoparticles for oral insulin delivery. J. Biomed. Mater. Res. B (Appl. Biomater.) 2009, 88B, 41-48.

[708] Uskoković, V., and Uskoković, D. P., Nanosized hydroxyapatite and other calcium phosphates: chemistry of formation and application as drug and gene delivery agents. J. Biomed. Mater. Res. B (Appl. Biomater.) 2010, 96B, 152-191.

[709] Loo, S. C., Moore, T., Banik, B., and Alexis, F., Biomedical applications of hydroxyapatite nanoparticles. Curr. Pharm. Biotechnol. 2010, 11, 333-342.

[710] Fu, H., Hu, Y., McNelis, T., and Hollinger, J. O., A calcium phosphate-based gene delivery system. J. Biomed. Mater. Res. A 2005, 74A, 40-48.

[711] Liu, T. Y., Chen, S. Y., Liu, D. M., and Liou, S. C., On the study of BSA-loaded calcium-deficient hydroxyapatite nano-carriers for controlled drug delivery. J. Control. Release $2005,107,112-121$.

[712] Barroug, A., Kuhn, L. T., Gerstenfeld, L. C., and Glimcher, M. J., Interactions of cisplatin with calcium phosphate nanoparticles: in vitro controlled adsorption and release. J. Orthop. Res. 2004, 22, 703-708.

[713] Cheng, X. G., and Kuhn, L. T., Chemotherapy drug delivery from calcium phosphate nanoparticles. Int. J. Nanomed. 2007, 2, 667-674.

[714] Maitra, A., Calcium phosphate nanoparticles: second-generation nonviral vectors in gene therapy. Expert Rev. Mol. Diagn. 2005, 5, 893-905.

[715] Yang, X. C., Walboomers, X. F., van den Dolder, J., Yang, F., Bian, Z., Fan, M. W., and Jansen, J. A., Non-viral bone morphogenetic protein 2 transfection of rat dental pulp stem cells using calcium phosphate nanoparticles as carriers. Tissue Eng. A 2008, 14, 71-81.

[716] Altinoğlu, E. I., and Adair, J. H., Calcium phosphate nanocomposite particles: a safer and more effective alternative to conventional chemotherapy? Future Oncology 2009, 5, 279-281.

[717] Joyappa, D. H., Kumar, C. A., Banumathi, N., Reddy, G. R., and Suryanarayana, V. V. S., Calcium phosphate nanoparticle prepared with foot and mouth disease virus P1-3CD gene construct protects mice and guinea pigs against the challenge virus. Veter. Microbiol. 2009, 139, 58-66.

[718] Dreesen, I. A. J., Lüchinger, N. A., Stark, W. J., and Fussenegger, M., Tricalcium phosphate nanoparticles enable rapid purification, increase transduction kinetics, and modify the tropism of mammalian viruses. Biotechnol. Bioeng. 2009, 102, 1197-1208.
[719] Tang, Q. L., Zhu, Y. J., Wu, J., Chen, F., and Cao, S. W., Calcium phosphate drug nanocarriers with ultrahigh and adjustable drug-loading capacity: one-step synthesis, in situ drug loading and prolonged drug release. Nanomedicine 2011, 7, 428-434.

[720] Pittella, F., Zhang, M., Lee, Y., Kim, H. J., Tockary, T., Osada, K., Ishii, T., Miyata, K., Nishiyama, N., and Kataoka, K., Enhanced endosomal escape of siRNA-incorporating hybrid nanoparticles from calcium phosphate and PEG-block charge-conversional polymer for efficient gene knockdown with negligible cytotoxicity. Biomaterials 2011, 32, 3106-3114.

[721] Behera, T., and Swain, P., Antigen adsorbed calcium phosphate nanoparticles stimulate both innate and adaptive immune response in fish, Labeo rohita H. Cell. Immunol. 2011, 271, 350-359.

[722] Chu, T. C., He, Q., and Potter, D. E., Biodegradable calcium phosphate nanoparticlesas a new vehicle for delivery of a potential ocular hypotensive agent. J. Ocular Pharmacol. Therapeutics 2002, 18, 507-514.

[723] Paul, W., and Sharma, C. P., Porous hydroxyapatite nanoparticles for intestinal delivery of insulin. Trends Biomater. Artif. Organs 2001, 14, 37-38.

[724] Victor, S. P., and Kumar, T. S. S., Tailoring calcium-deficient hydroxyapatite nanocarriers for enhanced release of antibiotics. J. Biomed. Nanotechnol. 2008, 4, 203-209.

[725] Kilian, O., Alt, V., Heiss, C., Jonuleit, T., Dingeldein, E., Flesch, I., Fidorra, U., Wenisch, S., and Schnettler, R., New blood vessel formation and expression of VEGF receptors after implantation of platelet growth factor-enriched biodegradable nanocrystalline hydroxyapatite. Growth Factors $2005,23,125-133$

[726] Klesing, J., Wiehe, A., Gitter, B., Grafe, S., and Epple, M., Positively charged calcium phosphate/polymer nanoparticles fro photodynamic therapy. J. Mater. Sci. Mater. Med. 2010, 21, 887-892.

[727] Ling, J. Y., Loo, S. C., Phung, N. T., Boey, F., and Ma, J., Controlled size and morphology of EDTMP-doped hydroxyapatite nanoparticles as model for ${ }^{153}$ Samarium-EDTMP doping. J. Mater. Sci. Mater. Med. 2008, 19, 2993-3003.

[728] Jordan, M., Schallhorn, A., and Wurm, F. M., Transfecting mammalian cells: optimization of critical parameters affecting calcium-phosphate precipitate formation. Nucleic Acids Res. 1996, 24, 596-601.

[729] Sokolova, V. V., and Epple, M., Inorganic nanoparticles as carriers of nucleic acids into cells. Angew. Chem. Int. Ed. 2008, 47, 1382-1395.

[730] Olton, D., Li, J., Wilson, M. E., Rogers, T., Close, J., Huang, L., Kumta, P. N., and Sfeir, C., Nanostructured calcium phosphates (NanoCaPs) for non-viral gene delivery: influence of the synthesis parameters on transfection efficiency. Biomaterials 2007, 28, 1267-1279.

[731] Bisht, S., Bhakta, G., Mitra, S., and Maitra, A., pDNA loaded calcium phosphate nanoparticles: highly efficient non-viral vector for gene delivery. Int. J. Pharm. 2005, 288, 157-168. 
[732] Chowdhury, E. H., and Akaike, T., A bio-recognition device developed onto nano-crystals of carbonate apatite for cell-targeted gene delivery. Biotechnol. Bioeng. 2005, 90, 414-421.

[733] Bisht, S., Chattopadhyay, D., and Maitra, A., Intraperitoneal administration of calcium phosphate nanoparticles encapsulating pSV $\beta$ gal elicits immune response to encoded protein. J. Biomed. Nanotechnol. 2006, 2, 229-238.

[734] Zhu, S. H., Huang, B. Y., Zhou, K. C., Huang, S. P., Liu, F., Li, Y. M., Xue, Z. G., and Long, Z. G., Hydroxyapatite nanoparticles as a novel gene carrier. J. Nanopart. Res. 2004, 6, 307-311.

[735] Chowdhury, E. H., Kutsuzawa, K., and Akaike, T., Designing smart nano-apatite composites: the emerging era of non-viral gene delivery. Gene Ther. Mol. Biol. 2005, 9, 301-316.

[736] Chowdhury, E. H., Maruyama, A., Kano, A., Nagaoka, M., Kotaka, M., Hirose, S., Kunou, M., and Akaike, T., $\mathrm{pH}$-sensing nano-crystals of carbonate apatite: effects on intracellular delivery and release of DNA for efficient expression into mammalian cells. Gene 2006, 376, 87-94.

[737] Chowdhury, E. H., pH-sensitive nano-crystals of carbonate apatite for smart and cell-specific transgene delivery. Expert Opin. Drug Deliv. 2007, 4, 193-196.

[738] Chowdhury, E. H., and Akaike, T., High performance DNA nano-carriers of carbonate apatite: multiple factors in regulation of particle synthesis and transfection efficiency. Int. J. Nanomed. 2007, 2, 101-106.

[739] Pedraza, C. E., Bassett, D. C., McKee, M. D., Nelea, V., Gbureck, U., and Barralet, J. E., The importance of particle size and DNA condensation salt for calcium phosphate nanoparticle transfection. Biomaterials 2008, 29, 3384-3392.

[740] Zhou, C., Yu, B., Yang, X., Huo, T., Lee, L. J., Barth, R. F., and Lee, R. J., Lipid-coated nano-calcium-phosphate (LNCP) for gene delivery. Int. J. Pharm. 2010, 392, 201-208.

[741] Giger, E. V., Puigmartí-Luis, J., Schlatter, R., Castagner, B., Dittrich, P. S., and Leroux, J. C., Gene delivery with bisphosphonate-stabilized calcium phosphate nanoparticles. J. Control. Release 2011, 28, 87-93.

[742] Olton, D. Y., Close, J. M., Sfeir, C. S., and Kumta, P. N., Intracellular trafficking pathways involved in the gene transfer of nano-structured calcium phosphate-DNA particles. Biomaterials. 2011, 32, 7662-7670.

[743] Welzel, T., Radtke, I., Meyer-Zaika, W., Heumann, R., and Epple, M., Transfection of cells with custom-made calcium phosphate nanoparticles coated with DNA. J. Mater. Chem. 2004, 14, 2213-2217.

[744] Sokolova, V. V., Radtke, I., Heumann, R., and Epple, M., Effective transfection of cells with multi-shell calcium phosphate-DNA nanoparticles. Biomaterials 2006, 27, 3147-3153.

[745] Sokolova, V. V., Kovtun, A., Heumann, R., and Epple, M., Tracking the pathway of calcium phosphate/DNA nanoparticles during cell transfection by incorporation of red-fluorescing tetramethylrhodamine isothiocyanate-bovine serum albumin into these nanoparticles. J. Biol. Inorg. Chem. 2007, 12, 174-179.
[746] Sokolova, V. V., Kovtun, A., Prymak, O., Meyer-Zaika, W., Kubareva, E. A., Romanova, E. A., Oretskaya, T. S., Heumann, R., and Epple, M., Functionalisation of calcium phosphate nanoparticles by oligonucleotides and their application for gene silencing. J. Mater. Chem. 2007, 17, 721-727.

[747] Neumann, S., Kovtun, A., Dietzel, I. D., Epple, M., and Heumann, R., The use of size-defined DNA-functionalized calcium phosphate nanoparticles to minimise intracellular calcium disturbance during transfection. Biomaterials 2009, 30, 6794-6802.

[748] Graham, F. L., and van der Eb, A. J., A new technique for the assay of infectivity of human adenovirus 5 DNA. Virology $1973,52,456-467$.

[749] Kovtun, A., Heumann, R., and Epple, M., Calcium phosphate nanoparticles for the transfection of cells. Bio-Med. Mater. Eng. 2009, 19, 241-247.

[750] Roy, I., Mitra, S., Maitra, A., and Mozumdar, S., Calcium phosphate nanoparticles as novel non-viral vectors for targeted gene delivery. Int. J. Pharm. 2003, 250, 25-33.

[751] Li, J., Chen, Y. C., Tseng, Y. C., Mozumdar, S., and Huang, L., Biodegradable calcium phosphate nanoparticle with lipid coating for systemic siRNA delivery. J. Controlled Release 2010, 142, 416-421.

[752] Kakizawa, Y., and Kataoka, K., Block copolymer self-assembly into monodispersive nanoparticles with hybrid core of antisense DNA and calcium phosphate. Langmuir 2002, 18, 4539-4543.

[753] Wang, K. W., Zhou, L. Z., Sun, Y., Wu, G. J., Gu, H. C., Duan, Y. R., Chen, F., and Zhu, Y. J., Calcium phosphate/PLGA-mPEG hybrid porous nanospheres: a promising vector with ultrahigh gene loading and transfection efficiency. J. Mater. Chem. 2010, 20, 1161-1166.

[754] Epple, M., and Kovtun, A., Functionalized calcium phosphate nanoparticles for biomedical application. Key Eng. Mater. 2010, 441, 299-305.

[755] Sokolova, V., Neumann, S., Kovtun, A., Chernousova, S., Heumann, R., and Epple, M., An outer shell of positively charged poly(ethyleneimine) strongly increases the transfection efficiency of calcium phosphate/DNA nanoparticles. J. Mater. Sci. 2010, 45, 4952-4957.

[756] Epple, M., Ganesan, K., Heumann, R., Klesing, J., Kovtun, A., Neumann, S., and Sokolova, V., Application of calcium phosphate nanoparticles in biomedicine. J. Mater. Chem. 2010, 20, 18-23.

[757] He, Q., Mitchell, A. R., Johnson, S. L., Wagner-Bartak, C., Morcol, T., and Bell, S. J. D., Calcium phosphate nanoparticle adjuvant. Clin. Diagn. Lab. Immunol. 2000, 7, 899-903.

[758] He, Q., Mitchell, A. R., Morcol, T., and Bell, S. J. D., Calcium phosphate nanoparticles induce mucosal immunity and protection against herpes simplex virus type 2. Clin. Diagn. Lab. Immunol. 2002, 9, 1021-1024.

[759] Liu, Z. S., Tang, S. L., and Ai, Z. L., Effects of hydroxyapatite nanoparticles on proliferation and apoptosis of human hepatoma BEL-7402 cells. World J. Gastroenterol. 2003, 9, 1968-1971.

[760] Sun, J., and Ding, T., P53 reaction to apoptosis induced by 
hydroxyapatite nanoparticles in rat macrophages. J. Biomed. Mater. Res. A 2009, 88A, 673-679.

[761] Yuan, Y., Liu, C., Qian, J., Wang, J., and Zhang, Y., Size-mediated cytotoxicity and apoptosis of hydroxyapatite nanoparticles in human hepatoma HepG2 cells. Biomaterials 2010, 31, 730-740.

[762] Allen, T. M., and Cullis, P. R., Drug delivery systems: entering the mainstream. Science 2004, 303, 1818-1822.

[763] Schmidt, H. T., Kroczynski, M., Maddox, J., Chen, Y., Josephs, R., and Ostafin, A. E. J., Antibody-conjugated soybean oil-filled calcium phosphate nanoshells for targeted delivery of hydrophobic molecules. Microencapsulation 2006, 23, 769-781.

[764] Ferraz, M. P., Mateus, A. Y., Sousa, J. C., and Monteiro, F. J., Nanohydroxyapatite microspheres as delivery system for antibiotics: release kinetics, antimicrobial activity, and interaction with osteoblasts. J. Biomed. Mater. Res. A 2007, 81A, 994-1004.

[765] Cai, Y., Pan, H., Xu, X., Hu, Q., Li, L., and Tang, R., Ultrasonic controlled morphology transformation of hollow calcium phosphate nanospheres: a smart and biocompatible drug release system. Chem. Mater. 2007, 19, 3081-3083.

[766] Zhou, W. Y., Wang, M., Cheung, W. L., Guo, B. C., and Jia, D. M., Synthesis of carbonated hydroxyapatite nanospheres through nanoemulsion. J. Mater. Sci. Mater. Med. 2008, 19, 103-110.

[767] Wingert, P. A., Mizukami, H., and Ostafin, A. E., Enhanced chemiluminescent resonance energy transfer in hollow calcium phosphate nanoreactors and the detection of hydrogen peroxide. Nanotechnology 2007, 18, 295707 (7 pages).

[768] Kottegoda, N., Munaweera, I., Madusanka, N., and Karunaratne, V., A green slow-release fertilizer composition based on urea-modified hydroxyapatite nanoparticles encapsulated wood. Curr. Sci. 2011, 101, 73-78.

[769] Chen, J. H., Wang, Y. J., Zhou, D. M., Cui, Y. X., Wang, S. Q., and Chen, Y. C., Adsorption and desorption of $\mathrm{Cu}(\mathrm{II})$, $\mathrm{Zn}(\mathrm{II}), \mathrm{Pb}(\mathrm{II})$, and $\mathrm{Cd}(\mathrm{II})$ on the soils amended with nanoscale hydroxyapatite. Environ. Prog. Sustain. Energy 2010, 29, 233-241.

[770] Wang, D., Chu, L., Paradelo, M., Peijnenburg, W. J., Wang, Y., and Zhou, D., Transport behavior of humic acid-modified nano-hydroxyapatite in saturated packed column: effects of $\mathrm{Cu}$, ionic strength, and ionic composition. J. Coll. Interf. Sci. 2011, 15, 398-407.

[771] Mobasherpour, I., Salahi, E., and Pazouki, M., Comparative of the removal of $\mathrm{Pb}^{2+}, \mathrm{Cd}^{2+}$ and $\mathrm{Ni}^{2+}$ by nano crystallite hydroxyapatite from aqueous solutions: adsorption isotherm study. Arab. J. Chem. 2012, (early view).

[772] Handley-Sidhu, S., Renshaw, J. C., Yong, P., Kerley, R., and Macaskie, L. E., Nano-crystalline hydroxyapatite bio-mineral for the treatment of strontium from aqueous solutions. Biotechnol. Lett. 2011, 33, 79-87.

[773] Gandhi, R. M., Kousalya, G. N., and Meenakshi, S., Removal of copper(II) using chitin/chitosan nano-hydroxyapatite composite. Int. J. Biol. Macromolecules 2011, 48, 119-124.

[774] Manocha, L. M., Disher, I. A., and Manocha, S., Sorption of cadmium ions on (AB-type) carbonated hydroxyapatite nanoparticles. Adv. Sci. Lett. 2011, 4, 44-50.

[775] Ma'mani, L., Heydari, A., and Shiroodi, R. K., Nanohydroxyapatite microspheres as a biocompatible and recoverable catalyst for synthesis of carbon -phosphorous bond formation. Curr. Org. Chem. 2009, 13, 758-762.

[776] Liu, Y., Zhong, H., Li, L., and Zhang, C., Temperature dependence of magnetic property and photocatalytic activity of $\mathrm{Fe}_{3} \mathrm{O}_{4}$ /hydroxyapatite nanoparticles. Mater. Res. Bull. 2010, 45, 2036-2039.

[777] Yih, T. C., and Al-Fandi, M., Engineered nanoparticles as precise drug delivery systems. J. Cell. Biochem. 2006, 97, $1184-1190$

[778] Celotti, G., Tampieri, A., Sprio, S., Landi, E., Bertinetti, L., Martra, G., and Ducati, C., Crystallinity in apatites: how can a truly disordered fraction be distinguished from nanosize crystalline domains? J. Mater. Sci. Mater. Med. 2006, 17, 1079-1087.

[779] Christenson, E. M., Anseth, K. S., van den Beucken, J. J. J. P., Chan, C. K., Ercan, B., Jansen, J. A., Laurencin, C. T., Li, W. J., Murugan, R., Nair, L. S., Ramakrishna, S., Tuan, R. S., Webster, T. J., and Mikos, A. G., Nanobiomaterial applications in orthopedics. J. Orthop. Res. 2007, 25, 11-22.

[780] Schmidt, S. M., Moran, K. A., Kent, A. M. T., Slosar, J. L., Webber, M. J., McCready, M. J., Deering, C., Veranth, J. M., and Ostafin, A., Uptake of calcium phosphate nanoshells by osteoblasts and their effect on growth and differentiation. J. Biomed. Mater. Res. A 2008, 87A, 418-428.

[781] Motskin, M., Müller, K. H., Genoud, C., Monteith, A. G., and Skepper, J. N., The sequestration of hydroxyapatite nanoparticles by human monocyte-macrophages in a compartment that allows free diffusion with the extracellular environment. Biomaterials 2011, 32, 9470-9482.

[782] Powell, M. C., and Kanarek, M. S., Nanomaterials health effects - Part 1: background and current knowledge. Wisconsin Med. J. 2006, 105, 16-20.

[783] Powell, M. C., and Kanarek, M. S., Nanomaterials health effects - Part 2: uncertainties and recommendations for the future. Wisconsin Med. J. 2006, 105, 18-23.

[784] Motskin, M., Wright, D. M., Muller, K., Kyle, N., Gard, T. G., Porter, A. E., and Skepper, J. N., Hydroxyapatite nano and microparticles: correlation of particle properties with cytotoxicity and biostability. Biomaterials 2009, 30, 3307-3317.

[785] Liu, X., Qin, D., Cui, Y., Chen, L., Li, H., Chen, Z., Gao, L., Li, Y., and Liu, J., The effect of calcium phosphate nanoparticles on hormone production and apoptosis in human granulosa cells. Reproductive Biology and Endocrinology 2010, 8,32 (8 pages).

[786] Li, S., and Huang, L., Pharmacokinetics and biodistribution of nanoparticles. Mol. Pharm. 2008, 5, 496-504.

[787] Bionanotechnologies are modeled after biological substances and structures, or combine nanomaterials with biological substances. They include materials such as biochips, drug release systems, nanofibers, hybrid nanobiodevices, molecular electronics and biomimetics (synthetic genes, proteins and viruses)[788]. 
[788] Moghimi, S. J., Hunter, A. C., and Murray, J. C., Nanomedicine: current status and future prospects. FASEB J. 2005, 19, 311-330.

[789] Xu, H. H. K., Weir, M. D., and Simon, C. G., Jr., Injectable and strong nano-apatite scaffolds for cell/growth factor delivery and bone regeneration. Dental Mater. 2008, 24, 1212-1222.

[790] Watari, F., Abe, S., Tamura, K., Uo, M., Yokoyama, A., and Totsuka, Y., Internal diffusion of micro/nanoparticles inside body. Key Eng. Mater. 2008, 361-363, 95-98.

[791] Oberdorster, G., Oberdorster, E., and Oberdorster, J., Nanotoxicology: an emerging discipline evolving from studies of ultrafine particles. Environ. Health Perspect. 2005, 113, 823-839.

[792] Nel, A., Xia, T., Mädler, L., and Li, N., Toxic potential of materials at the nanolevel. Science 2006, 311, 622-627.
[793] Jahnen-Dechent, W., and Simon, U., Function follows form: shape complementarity and nanoparticle toxicity. Nanomedicine 2008, 3, 601-603.

[794] Singh, N., Manshian, B., Jenkins, G. J. S., Griffiths, S. M., Williams, P. M., Maffeis, T. G. G., Wright, C. J., and Doak, S. H., NanoGenotoxicology: the DNA damaging potential of engineered nanomaterials. Biomaterials 2009, 30, 3891-3914.

[795] Dhawan, A., Sharma, V., and Parmar, D., Nanomaterials: a challenge for toxicologists. Nanotoxicology 2009, 3, 1-9.

[796] Dwivedi, P. D., Misra, A., Shanker, R., and Das, M., Are nanomaterials a threat to the immune system? Nanotoxicology 2009, 3, 19-26. 